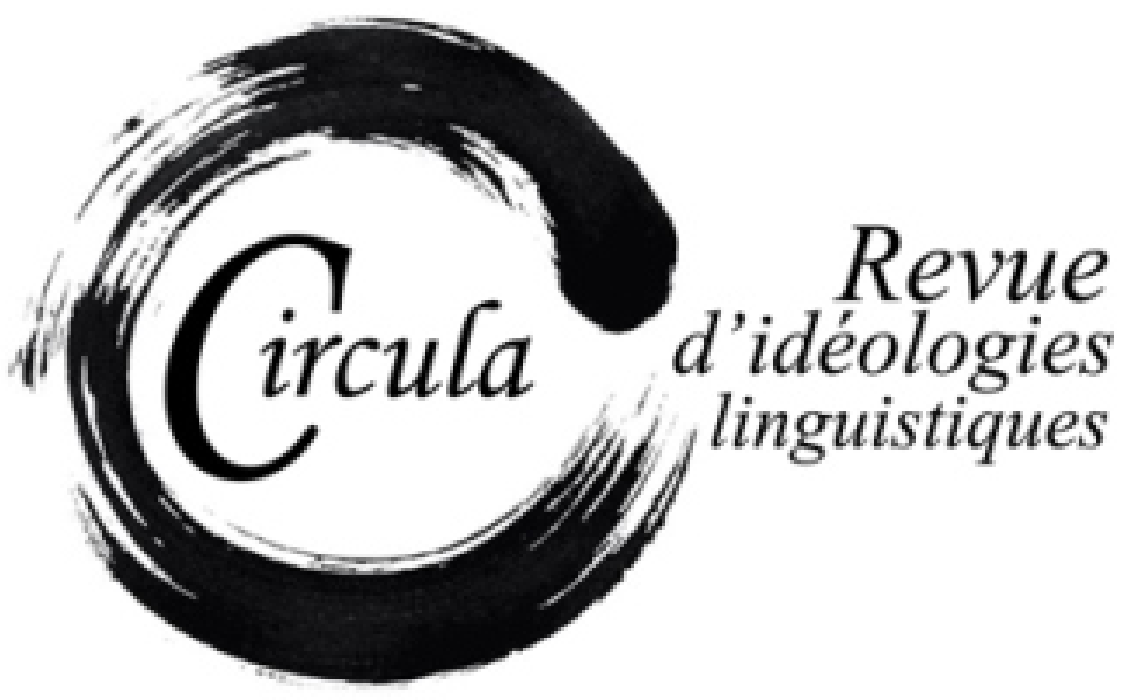

CONTENU: NUMÉRO LIBRE

Publication: NumÉRO 10 (Automne 2019)

PAgES: $1-97$

ISSN: 2369-6761

Directeurs: Wim Remysen, Sabine Schwarze et Juan Antonio Ennis ÉdiTEUR: LES ÉdITIONS DE L'UNIVERSITÉ DE SHERBROOKE (ÉDUS)

URI: HTTP://HDL.HANDLE.NET/11143/16776

DOI: HTTPS://DOI.ORG/10.17118/11143/16776 


\section{Table des matières}

Ideologías lingüísticas en la prensa de la Transición:

análisis de las cartas al director publicadas en El País. 2

Narcís Iglésias

Primi spunti per un'analisi del discorso sulla questione meridionale:

materiali, metodi, prospettive.

Paolo Orrù

Nuove ideologie, nuove autorità in contesto europeo:

i discorsi polemici di Grillo e Dieudonné.....

Sara Amadori et Cristiana De Santis

La littératie, une notion chargée idéologiquement:

le traitement de l'alphabétisation dans la presse acadienne 65

Laurence Arrighi

Narvaja de Arnoux, Elvira y Bein, Roberto (eds.) (2019).

Ideologías lingüísticas. Legislación, universidad, medios,

Buenos Aires, Editorial Biblos, col. Ciencias del Lenguje, 246 p. [ISBN: 978-987-691-719-3]

Victoria Scotto 


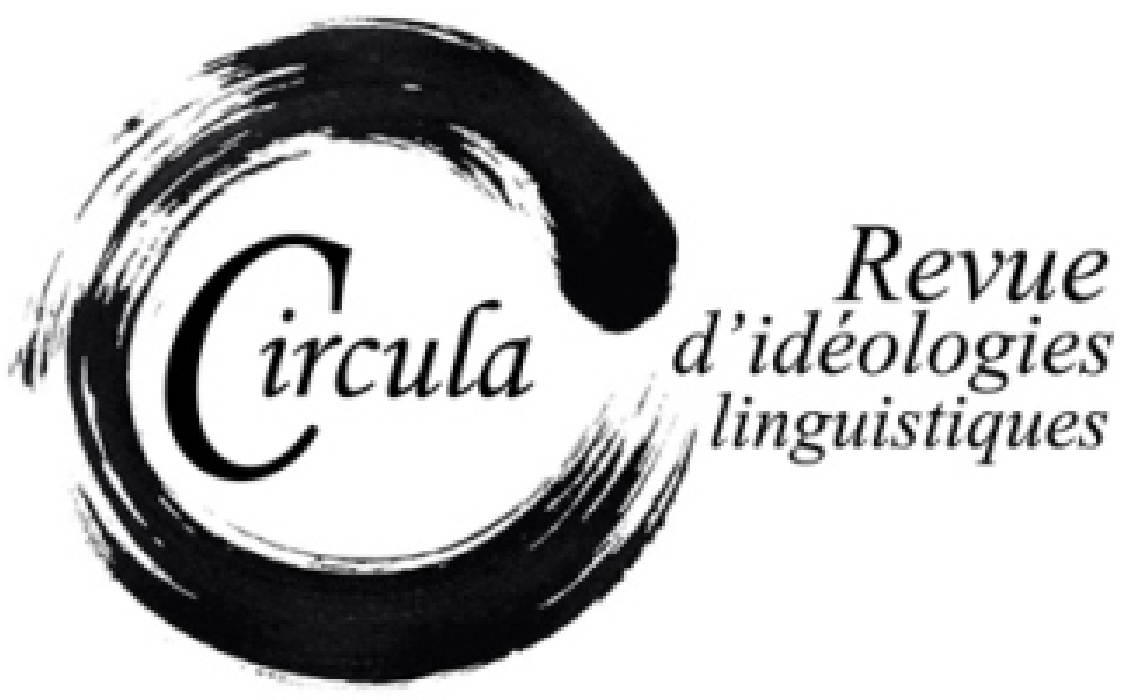

TITRE: IDEOLOGÍAS LINGÜÍSTICAS EN LA PRENSA DE LA TRANSICIÓN: ANÁLISIS DE LAS CARTAS AL DIRECTOR PUBLICADAS EN EL PAÍS

AUTEUR: NARCíS IGLÉSIAS, UNIVERSIDAD DE GIRONA

Revue: CIRCULA, NUMÉRO 10

PAGES: $1-21$

ISSN: 2369-6761

URI: HTTP://HDL.HANDLE.NET/11143/16771

DOI: HTTPS://DOI.ORG/10.17118/11143/16771 


\section{Ideologías lingüísticas en la prensa de la Transición: análisis de las cartas al director publicadas en El País}

Narcís Iglésias, Universidad de Girona narcis.iglesias@udg.edu

Resumen: La Transición supuso poner fin al monolingüismo instaurado por el franquismo y abrir una etapa de reconocimiento a la diversidad lingüística. A pesar de ser un período de gran transcendencia, son más bien escasos los estudios dedicados al tema. En este artículo me he limitado a estudiar las ideologías lingüísticas de los lectores del periódico El País durante la Transición, expresadas a través de su sección de cartas al director. Las opiniones de los lectores no presentan un tono uniforme, sino que abarcan todo tipo de planteamientos, a menudo antagónicos, desde aspectos generales y teóricos (lengua nacional, dialectos, oficialidad...), hasta temas más concretos, tales como la enseñanza o los derechos lingüísticos, más habituales durante los primeros años de democracia. En términos generales, en las cartas al director publicadas en El País dominan las opiniones de los lectores que expresan sus objeciones hacia la diversidad lingüística.

Palabras clave: ideologías lingüísticas; diversidad lingüística; Transición; El País; cartas al director

Abstract: The Spanish transition meant the end of the monolingualism established by the Francoist regime and the beginning of a period of recognition of language diversity. Despite the importance of the issue, during what was a crucial period, there is relatively little work dedicated to it. This article focuses on the language ideologies of the readers of El País, as expressed in the newspaper's letters section, during the Spanish transition. The readers' opinions do not have a uniform tone, but they cover, in a quite often agonistic way, a wide range of issues, from general and theoretical ones (national language, dialects and officialdom...), to more concrete ones, such as education and linguistic rights, which was more usual during the first years of democracy. In general terms, a vast majority of opinions defended in the letters to the editor of El País raise objections to language diversity.

Key words: language ideologies; language diversity; Spanish transition; El País; letters to the editor 


\section{Introducción: objeto de estudio y planteamiento de la investiga- ción}

Los grandes cambios sociopolíticos son momentos privilegiados para el análisis de la evolución de las lenguas. La España contemporánea, marcada por el régimen de Franco y por la democracia nacida con la Constitución de 1978, ha pasado en pocas décadas de diferencia por dos modos bien distintos de tratar la diversidad lingüística dentro del Estado. El franquismo se fundamentó desde sus inicios en una ideología uniformista, basada en la exaltación de una única lengua nacional' ${ }^{1}$ y no fue hasta la Transición cuando se fraguó el fin del monolingüismo que caracterizó la dictadura para dar paso a una democracia que se plantearía la diversidad lingüística. En la historiografia española se ha subrayado que la Constitución de 1978, un momento crucial de la Transición, representa la primera vez en la historia de España en que se reconoce la diversidad lingüística (González Ollé 1978 ; Brumme 2006). En el plano legal e institucional, varias lenguas de España consiguieron cambiar su estatus al adquirir la condición de cooficialidad en sus respectivos territorios, lo que ha permitido que en democracia se hayan promovido las lenguas no castellanas a todos los niveles públicos e institucionales, aunque en grados diferentes según cada comunidad².

La etapa de la Transición que se abrió despúes de la muerte del general Franco (1975) fue un momento de cambio (o de ruptura según se interprete) a todos los niveles, no solo para la obtención de derechos fundamentales en toda democracia (derecho a voto, libertad de expresión, separación entre Estado e Iglesia, etc.), sino también para el fomento y creación de nueva cultura política ciudadana, pilar fundamental de las democracias individuales, en la que los medios de comunicación de la época, y especialmente la prensa, tuvo una influencia determinante 3 . En un momento de profundas transformaciones de la sociedad española a muchos niveles, la prensa jugó un papel determinante a la hora de crear un estado de opinión que contribuyera a superar la dictadura franquista y a poner los cimientos de la naciente democracia española. A menudo se habla de la importancia

1. Tal y como ha escrito Brumme (2004: 948) en la Historia de la lengua española dirigida por Rafael Cano: "Durante la dictadura (1939-1975) se derogó toda la legislación relativa a la emancipación de las 'lenguas regionales', se prohibió su uso público y se coaccionó a los hablantes con la ayuda de repetidas invectivas y eslóganes como "Si eres español habla en español" o "Si eres español habla la lengua del Imperio". En la historiografía vasca y catalana se ha estudiado con profundidad la persecución contra las .lenguas no castellanas: véase, por ejemplo, Benet (1995), Sánchez Erauskin (1994) o Gallofré (1991). Para una panorámica crítica sobre el franquismo y las lenguas, así como las políticas lingüísticas contemporáneas llevadas a cabo en Cataluña, véase Iglésias (2018).

2. Obviamente, sobre las políticas lingüísticas desarrolladas desde la Transición, no hay unanimidad entre los especialistas. Véase, por ejemplo, Castillo Lluch y Kabatek (2006). Por otra parte, algunos de los principales sociolingüistas catalanes han considerado que la España democrática no ha dejado de ser un Estado monolingüe, que también ha legislado a favor del castellano; véase, por ejemplo, Bastardas y Boix (1994) o Joan Marcet (2013). Desde hace unos años, han ido apareciendo autores partidarios de limitar las políticas lingüísticas de las comunidades autónomas bilingües y de reclamar para el estado una política unitarista; véase, por ejemplo, Pericay (2007)

3. Se suele considerar que la Transición empieza en 1975 con la muerte de Franco y acaba en 1982, con la mayoría absoluta del PSOE (Tusell, 1997). Sin embargo, no todos los especialistas comparten esta periodización; sobre la variedad de aproximaciones históricas al período en cuestión, véase la revisión de Martín (2014). 
del "Parlamento de Papel" (términino ya acuñado en la época), es decir, de la influencia de la prensa española a la hora de preparar la sociedad para la democracia. Durante la Transición, la mayoría de periódicos, incluidos los que fueron próximos o fieles al régimen franquista, defendieron una democracia de corte liberal y representativa, respetuosa con algunas instituciones, normas legales y élites de la dictadura. La prensa, pues, se convirtió en un medio fundamental para encauzar las reformas políticas democratizadoras que se llevarían a cabo durante la Transición.

El interés académico por este período sigue permanentemente abierto, con frecuentes aportaciones desde ángulos muy varios en lo que se refiere a la historia política, social o cultural (Ysàs, 2013). En cuanto a las lenguas se refiere, en cambio, todavía no ha habido estudios monográficos de lo que representó la Transición. Así por ejemplo, en obras de referencia que se ocupan de la historia de la lengua española hasta el periodo contemporáneo, o bien no se llega a tratar el período, o bien el tratamiento es bastante tangencial ${ }^{4}$. Algo semejante ocurre en estudios que se han propuesto relatar a partir de los periódicos los vaivenes de la Transición 5 . En términos generales, pues, la literatura académica no ha integrado en su narrativa los cambios que se abrieron durante la Transición en cuanto a las lenguas se refiere, más allá de subrayar los cambios legales, como el estatus de cooficialidad que consiguen varias lenguas en sus respectivos territorios.

La poca atención que hasta el momento el mundo académico le ha dedicado contrasta con la abundante presencia de información y opinión sobre las lenguas en la prensa española. En los más variados periódicos españoles de diferentes ciudades, se publicaron numerosas informaciones y opiniones sobre la cuestión de las lenguas. No hay duda de que en el plano político e institucional, la Transición fue el inicio del final del estado monolingüe concebido y ejecutado durante el franquismo, y se abrió la puerta a la diversidad lingüística, especialmente a lenguas como el catalán, el euskera y el gallego. En el plano macropolítico, el alcance del cambio era de gran calado: pasar de un estado ferozmente monolingüe, a un estado democrático abierto a promover todas las lenguas en sus respectivos territorios.

4. En la historia de la lengua dirigida por Cano, el excelente capítulo escrito por Brumme (2006), que entre otros temas trata el franquismo y la España salida de la Constitución de 1978, se centra en aspectos legislativos. Por su parte, la obra de Moreno Fernández (2005) dedica un capítulo a "Planes lingúísticos", en el que sitúa el tratamiento de las lenguas en la Constitución de 1931 y la de 1978, sin entrar a analizar a fondo lo que representó para las lenguas el franquismo y la Transición. La reciente historia del español dirigida por del Valle (2013), una de las aportaciones más recientes y novedosas que se han propuesto la renovación del relato historiográfico hispánico, no abarca por razones de corte temporal de la obra la etapa del franquismo y de la Transición. La historiografia lingüística catalana tampoco ha entrado a fondo en la cuestión, más allá de informaciones contextuales contenidas en obras generales como las de Ferrando y Nicolás (2011).

5. Véase, por ejemplo, el estudio La prensa en la transición española (1966-1978) de Castro Torres (2010), que resigue de un modo muy meticuloso las principales noticias y editoriales de muchas de las principales publicaciones periódicas (El País, Diario 16, Triunfo, Cuadernos para el Diálogo, Arriba, Ya, etc.). La referencia más importante de este estudio a las minorías se refiere a la organización territorial del Estado y a las negociaciones sobre el capítulo VIII de la Constitución (Castro, 2010: 305-308). No hay, sin embargo, ninguna referencia a lo que representan las lenguas durante la transición y al reflejo de este debate político y académico en la prensa. 
Sin embargo, una cosa fue el plano legal e institucional de las lenguas, y otra de muy diferente el debate público en los medios o las actitudes lingüísticas de los ciudadanos. Si durante la Transición varias lenguas encauzaron su condición de oficialidad y, en este sentido, se pondría fin al monolingüismo que había caracterizado el franquismo, esta ruptura a nivel legal no se convirtió en el foco principal del debate público. La mayoría de lectores que participaron en la opinión pública se centraron en otro tipo de temas, con más relevancia de uno u otro en función del contexto concreto de cada momento: cuestiones conceptuales relacionadas con las lenguas y los territorios (nación, región...), el uso de las lenguas en determinados acontecimientos culturales o las lenguas de la educación en las comunidades con lengua propia.

Todas estas cuestiones se van a analizar en los apartados sucesivos de este artículo, a partir de una aproximación que persigue relacionar los distintos niveles de intervención sobre las lenguas. Desde una concepción holística en el devenir de las lenguas, son varios los niveles a tener en cuenta: el nivel macrosocial (el plano legal y el institucional), el mesosocial (el que abarca desde las instituciones a la implementación de una política sectorial) y el microsocial (el que corresponde a los hablantes individuales y que puede abarcar desde el discurso público hasta las representaciones lingüísticas más variadas de los hablantes) 6 .

En una perspectiva histórica, estos tres niveles sociolingüísticos (micro, meso, macro) no actúan como compartimentos estancos y es todo un reto para el investigador entrelazar los varios niveles. El presente estudio parte del análisis del nivel microsocial o individual, lo que permite observar cómo se superponen los varios estratos y captar las distintas temporalidades, le temps long y le temps

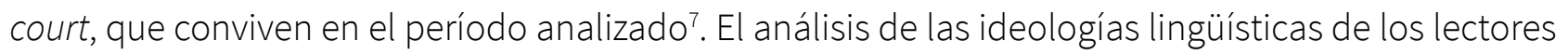
que se propone este estudio pone luz sobre los ritmos distintos del cambio: si en el plano legal la Transición supuso romper con el monolingüismo que caracterizó el franquismo, en el terreno de las actitudes individuales hacia las lenguas expresadas en el debate público hay no pocas continuidades, cuando no inercias que persisten. Esta aproximación ofrece una perspectiva sobre las lenguas durante la Transición que va más allá de lo que la literatura académica ha establecido hasta el momento, aunque haya cuestiones de carácter más general que desbordan los límites de este artículo. La riqueza y complejidad del tema va a necesitar de muchos estudios y aproximaciones. En el presente artículo me voy a centrar en una perspectiva microsocial, concretamente en el análisis de las ideologías lingüísticas expresadas por los lectores en las cartas al director publicadas en El País. Para ello, en primer lugar, voy a presentar brevemente el enfoque de las ideologías lingüísticas en

6. Para una concepción holística de la lengua, de acuerdo con las tendencias actuales en sociolingüística, véase, por ejemplo, Curdt-Christiansen (2016).

7. Para una enfoque teórico sobre las distintas concepciones del tiempo en los trabajos de sociolingüística histórica, véase el trabajo de Sara Cotelli (2009). Esta especialista defiende una aproximación histórica a las lenguas "plurielle, dynamique et multi-stratique", en la que se combinen por lo menos dos visiones sobre la temporalidad, "le temps long" y "le temps court". Este enfoque teórico se inscribe en un marco más amplio, el de la interpretación del tiempo en la historiografia y el de la visión de la historia como "continuidad" o como "ruptura". Sobre esta cuestión, véase, por ejemplo, Leduc (1999). 
el ámbito hispano. En segundo lugar, me voy a ocupar de la categorización y características de este texto periodístico para el análisis de la opinión. En tercer lugar, de lo que representó El País en sus inicios. En último lugar, voy a desarrollar mi análisis sobre las cartas al director (véanse apartados 2 y 3$)^{8}$. Este enfoque micro conduce, a su vez, a relacionar los varios niveles de análisis: a menudo, los lectores de los periódicos se sitúan en relación a los cambios macrosociales expresando su posicionamiento crítico o su actitud favorable. El punto de vista de los lectores es, pues, una excelente perspectiva que aúna el plano microsocial, individual en este caso, con los cambios propuestos, de corte más reformista o rupturista según los casos, por parte de los intelectuales, los movimientos sociales o las instituciones, tal y como se mostrará en el apartado 2.

Dentro de los estudios sobre las ideologías lingüísticas, existen corrientes muy diferentes, unas más próximas a la socio lingüística y a la antropología y otras más próximas a los estudios sobre el discurso o la comunicación (véanse las diferentes contribuciones teóricas de autores como Schieffelin et al. (1998); Wodak (1989); Kroskrity (2000) o Woolard (2008)). En el ámbito hispánico son de referencia las aportaciones de José del Valle (2007) y (2016), quien no solo ha emprendido obras analíticas dentro de este campo, sino que ha hecho un esfuerzo muy clarificador sobre los límites teóricos de esta corriente. Según la definición de del Valle (2016: 628) las ideologías lingüísticas son

sistemas de ideas que articulan nociones del lenguaje, las lenguas, el habla y/o la comunicación con formaciones culturales, políticas y/o sociales específicas. Aunque pertenecen al ámbito de las ideas y se pueden concebir como marcos cognitivos que ligan coherentemente el lenguaje con un orden extralingüístico, naturalizándolo y normalizándolo, también hay que señalar que se producen y reproducen en el ámbito material de las prácticas lingüísticas y metalingüísticas. ${ }^{9}$

Las piezas periodísticas de tema lingüístico y, en particular, las cartas al director representan una excelente muestra de la opinión de los ciudadanos en relación a las lenguas, tal y como se ha puesto de relieve en los estudios sobre "lingüística popular" o "lingüística de los legos"10. En lo que se referiere a su consideración dentro de la teoría de los géneros periodísticos, las cartas al director merecen valoraciones muy varias, a pesar de que son piezas fundamentales para el estudio de la opinión. Por una parte, son unos textos valorados por los profesionales del periodismo (son seleccionadas y editadas por el director o el editor, de aquí la noción de coautoría atribuida a dicho género) y, por

8. Dejo para otros estudios el análisis crítico de las informaciones y las opiniones acerca de las lenguas que los más varios periódicos españoles publicaron durante la Transición.

9. Definición ya propuesta anteriormente por el mismo autor en del Valle (2007: 20).

10. En el ámbito hispánico, destacan los trabajos de Lebsanft (1990, 1997 o 2017) dedicados a la cuestión, especialmente en relación a las actitudes de los hablantes respecto a la norma y al lenguaje periodístico. 
otra parte, son textos dirigidos implícitamente a la comunidad de lectores, aunque el director sea el lector explícito (Gomis, 2008 y Córdoba Jiménez, 2011)¹1.

Las funciones comunicativas de las cartas al director pueden ser muy varias (informativas, argumentativas, explicativas...), pero a menudo forman parte de un complejo universo discursivo configurado por artículos o columnas (para combatirlos, apoyarlos, matizarlos...) publicados por periodistas o intelectuales que colaboran regularmente en un periódico. No son pocas las cartas al director que comentan piezas informativas o de opinión (como respuesta a otras cartas al director o a columnas de opinadores regulares) publicadas en el mismo periódico o por otro. En este sentido, cabe destacar que dentro de nuestro corpus de cartas, un artículo de opinión de Federico Jiménez Losantos desencandenó varias reacciones, favorables o contrarias, e incluso se abrió un debate entre los lectores que participaron en la polémica, como se va a analizar en el apartado 3.1. Así pues, las cartas al director participan de una intertextualidad que configura, en su conjunto, la opinión pública.

En cuanto a la prensa española en el contexto de la Transición, cabe tener en cuenta los cambios que conllevó dicho perío do: el mapa comunicativo se reorganizó con la creación de nuevos rotativos. De aquellos años son, por ejemplo, los periódicos Diario 16, El Periódico de Catalunya, Avui o El País. Este último nace el 4 de mayo de 1976 bajo el impulso empresarial de PRISA, constituida 4 años antes. El núcleo fundacional lo constituyeron José Ortega Spottorno, Carlos Mendo, antiguo periodista de ABC, Darío Valcárcel, un aristócrata vinculado a la causa de Estoril, y Jesús de Polanco. Concebido como diario liberal conservador, se materializó como periódico liberal progresista o social-liberal, línea marcada por su director Juan Luis Cebrián, antiguo subdirector del periódico Informaciones y director de informativos de TVE ${ }^{12}$.

En la sección de cartas al director de este periódico, varias decenas de ciudadanos expresaron su opinión acerca de las lenguas. Tenemos la suerte de contar con el excelente estudio emprendido por Franz Lebsanft (1990), que ofrece un análisis crítico y exhaustivo sobre la cuestión. En pocos años, entre mayo de 1976 y 1986, El País publicó hasta 591 cartas al director sobre tema lingüístico. En la monografia del profesor alemán, los datos son también muy relevantes concretamente en cuanto a los años 1976 (desde mayo) y 1982: en este corto lapso de tiempo, el periódico liberalprogresista

11. No hay unanimidad entre los autores a la hora de situar este tipo de piezas. No son pocos los que omiten las cartas al director a la hora de caracterizar los principales géneros periodísticos. Para algunos autores, las cartas al director ni tan siquiera se podrían considerar con propiedad un género periodístico, pues se les cuestiona la autoridad informativa (no son escritas por profesionales del periodismo) y el control del lenguaje periodístico (Yanes, 2004). Finalmente, para otros teóricos los lectores en general son considerados como copartícipes de la cualidad de la información y la opinión de un periódico. Sea como fuere, en el mundo profesional, todos los periódicos incluyen una sección específica, algunos desde sus orígenes, como el propio diario El País. En las mejores tradiciones periodísticas, como la anglosajona, el protagonismo de los lectores puede llegar a ser del más alto nivel: en un periódico de tanta solera como The Times, incluso se han publicado en portada cartas al director. Para una revisión crítica sobre esta cuestión, véase Córdova Jiménez (2011).

12. Avui fue el primer periódico editado en catalán desde el año 1939. Véase la historia del periodismo español de Juan Francisco Fuentes y Javier Fernández Sebastián (1997). Sobre El País durante la Transición, véase Sueiro Seoane (2009). 
publicó hasta 226 cartas al director sobre tema lingüístico, de las cuales unas 60 se podría considerar que están relacionadas más o menos directamente con la diversidad lingüística.

\section{Ideologías lingưísticas de los lectores}

El enfoque argumentativo de los lectores está directamente asociado al contexto cultural o político de cada momento. En el estudio sobre las ideologías lingüísticas, en palabras de del Valle (2016: 628), es muy pertinente "el modo en que este contexto les confiere pleno significado". Las opiniones sobre las lenguas defendidas por los lectores de El País evolucionan a medida que el contexto sociopolítico cambia: el tipo de debate de los años 1976 y 1977, por ejemplo, es sustancialmente diferente del que se producirá una vez se haya implantado la democracia. De modo auxiliar, y para dar un enfoque contrastivo, se van a analizar cartas al director de periódicos españoles de otras sensibilidades, como va a ser con el caso de Pueblo. Las ideologías lingüísticas de la Transición no fueron, sin lugar a dudas, ni lineales ni monolíticas.

En los siguientes apartados vamos a abordar en qué medida los lectores a través de sus cartas al director ayudaron "a naturalizar un determinado orden social, es decir, a crear una apariencia de inevitabilidad asociada con un grupo particular de categorías y procesos culturales, políticos o sociales" (del Valle 2016: 628). Dicho en otros términos, vamos a analizar qué tipo de opiniones y posicionamientos tuvieron los lectores en relación a los nuevos cambios que comportó la Transición en cuanto al fin del monolingüismo del franquismo y al inicio del reconocimiento y promoción de todas las lenguas de España.

\subsection{Las lenguas y su relación con aspectos políticos y teóricos}

A menudo las cartas al director de tema lingüístico están directamente relacionadas con los debates del momento, especialmente con todos aquellos que tienen que ver con el proceso de definición del futuro estado democrático autonómico. Durante los primeros años de la Transición, las cartas se centraron en aspectos bastante generales, incluso teóricos, como la denominación de las distintas variedades lingüísticas ('lengua nacional', 'lengua regional', 'dialecto'...), o la relación entre lengua e identidad. Obviamente, esta preocupación está íntimamente ligada a la definición en curso del futuro estado democrático, impulsada por las reformas políticas emprendidas durante los primeros años de la Transición: el estatus de las futuras lenguas tiene una relación directa con la cuestión territorial y la concepción del modelo de Estado y de nación. En cuanto a los argumentos que los lectores suelen aducir, unos apoyan su opinión sobre su interpretación de la historia, mientras que otros fundamentan su autoridad en académicos a los que se les atribuye un prestigio en su campo. 
Dentro de las cartas al director de enfoque más teórico, hay lectores que recurren a la distinción entre los adjetivos 'nacional' y 'regional' aplicados a las lenguas para defender la supremacía del castellano en España. El lector César Verilla de las Heras argumenta esta noción teórica desde su propia interpretación de la historia de las lenguas en España:

\begin{abstract}
Me llevé las manos a la cabeza cuando la "nacionalización” de idiomas que, como el vasco y el catalán, jamás fueron nacionales. Aparte el castellano, el único idioma que tuvo expansión de carácter nacional fue el galaico-portugués, idioma de uso corriente en tiempos de Alfonso el Sabio (lo usaba para el verso), pero que sin necesidad de decreto alguno de nacionalización, fue casi literalmente barrido por el castellano, precisamente en una época de decadencia política de Castilla [...] Algo parecido debió suceder al catalán y a los demás idiomas y dialectos levantinos. No conozco ningún decreto ni pragmática de los siglos XVI ó XVII ordenando el uso obligatorio del castellano o prohibiendo el uso de cualquiera de los otros idiomas peninsulares. Y lo cierto es, que ningun otro idioma tiene en España carácter nacional. En castellano existe la única épica de carácter nacional, además del Romancero. [...] No debieran olvidar los regionalistas que el castellano además de idioma nacional y universal (gracias a su literatura, que se cuenta entre las mejores hazañas del espíritu humano), es idioma regional y local mayoritario en todas y cada una de las regiones y pueblos de España. Y ese carácter no lo alcanzó en virtud de ningún decreto, sino por la propia fuerza expansiva del idioma (César Verilla de las Heras, “Idiomas nacionales y regionales", EP, 11 de agosto de 1976) ${ }^{13}$
\end{abstract}

Hay otros lectores que se centran en la interpretación de la historia de las lenguas para posicionarse respecto al momento presente. En este sentido, el caso del lector José Miguel de Azaola es el más claro: quiere ser una respuesta a un artículo de opinión sobre el renacer de la lengua vasca firmado por Carlos Santamaría. El lector discrepa de Santamaría acerca de las consecuencias positivas de la persecución del vasco durante el franquismo. Para el lector Azaola, la persecución no ha sido "a la larga" benefeciosa para el vasco, sino que suposo "frenar en seco el movimiento expansivo, de cultivo y enseñanza de la lengua vasca", a fuer de haber sembrado "en ciertos ambientes irresponsables de Vasconia... un espíritu de revancha lingüística, de traza inconfundiblemente bélica” (“Guerra de idiomas?", EP, 6 de marzo de 1977)

La autoridad del columnista se vió seriamente cuestionada en la carta del lector R. Ventura Melià, quien respondió al artículo de opinión "Lenguas nativas y sistema educativo” de José Blat Gimeno (27 de julio 1977). El lector cuestiona su visión de las lenguas y defiende la existencia de un estado con cuatro lenguas nacionales fundamentándose en los sociolingüistas catalanes de la época:

13. Todas las cartas al director que se analizan en el presente articulo están referenciadas en Lebsanft (1990). Además de ser un completo y meticuloso catálogo sobre las cartas publicadas, el hispanista alemán ofrece una interpretación contextualizada respecto a la cuestión lingüística en España, sobre la base de un gran corpus debidamente tratado, con resúmenes de todas las "cartas", indíces analíticos de autores de "cartas", autores mencionados, índice de palabras e índice de temas lingüísticos tratados. 
Hablar de «lenguas nativas», de «lenguas maternas», de «lenguas regionales» y solfear sobre «bilingüismo» es mostrar una empanada mental paternalista sin ningún apoyo científico, y con resabios de integrismo político.

Si algo queda ya claro es que este estado alberga cuatro nacionalidades. Cualquier "región" pertenecerá a una de ellas. No hay "lenguas regionales" sino "lenguas nacionales" [...]

El "bilingüismo" es una ideología del bloque dominante, así nos lo han descubierto Aracil, Ninyoles, Badia Margarit y Vallverdú (a quienes debería leerse este verano aún). Aquí hemos padecido y padecemos una situación «diglósica», no de «igualidad», sino de «dominación». No hay enseñanza bilingüe que sea. No la queremos nosotros. Queremos aprender en nuestra lengua y nuestra lengua, pero ya.

En un contexto lingüísticamente complejo como el catalán, la sociolingüística académica conoció una divulgación social importante, que superó sin lugar a dudas los límites universitarios. A modo de ejemplo, uno de los libros superventas de la década de 1970 fue la obra Dues llengües, dues funcions? del sociolingüista Francesc Vallverdú. La carta al lector analizada es un buen reflejo, pues, del impacto popular de esta disciplina universitaria entre la población informada.

Las ideologías lingüísticas que expresan numerosos lectores de El País también se encuentran en otros periódicos de la época. Nótese que ningún lector de El País cuestiona la cooficialidad de las lenguas no castellanas. Este tipo de planteamiento, en cambio, sí se encuentra en periódicos conservadores. Valga como ejemplo el análisis de un par de piezas publicadas en Pueblo. Tal y como se acaba de mostrar, las cartas a los lectores pueden venir motivadas por aspectos del contexto político general. Este es el caso del lector Anselmo Cid, un gallego residente en París profesor en la Universidad de La Sorbona que dice pasar sus "vacaciones en Gandía, donde ya empiezo a sentirme tan extranjero como en Francia”. Este lector parte del modelo de Estado que se está discutiendo (el modelo autonómico, con el que dice estar en desacuerdo), para expresar su opinión acerca de las lenguas: "cuando oigo hablar del gallego, catalán, valenciano y vasco como lenguas oficiales me siento herido en lo más hondo del alma" (Cid, Anselmo, "El desmadre de las autonomías", Pueblo 02 de septiembre de 1977).

Antes de la Constutición y de los estatutos que se derivarán de ella, hay lectores que intuyen que la cooficialidad irá de par con obstáculos para el ascenso social sin el previo conocimiento de la lengua de la comunidad. El lector Antonio Ruiz-Giménez alerta en Pueblo sobre "un grave problema” que va a suponer la cooficialidad del catalán, el del freno al ascenso social por parte de los ciudadanos castellanoparlantes de Cataluña: "Las plazas vacantes en bancos, oficinas y establecimientos comerciales nos están totalmente vetadas, y, por mucho que sepas, has de conformarte con puestos míseros" (“Discriminación en el trabajo", Pueblo, $1^{\circ}$ de marzo de 1977). 
Sería muy interesante explorar a fondo las reacciones de los lectores de todo tipo de periódicos y calibrar hasta qué punto hay una relación entre la orientación ideológica, o ámbito territorial de un periódico, y el tono general de las ideologías lingüísticas que sus lectores sostienen: críticas a la oficialidad, defensas de la lengua nacional, críticas a la diversidad, etc. Sin embargo, esta cuestión desborda los planteamientos del presente estudio y habrá que esperar a que futuros estudios cubran este terreno de investigación.

\subsection{Las lenguas y su relación con acontecimientos culturales}

Además de las cartas dedicadas a aspectos generales y teóricos, en El País también las hay que opinan sobre acontecimientos culturales del momento que suponen una novedad. En este sentido, un recital en catalán de Lluís Llach retransmitido por TVE, la reivindicación del catalán en el PEN Club celebrado en Estocolmo o incluso la fiesta del libro fueron motivo de que varios lectores escribieran al periódico.

Lluís Llach dio un concierto en el teatro Grec de Barcelona en 1974 y al cabo de dos años, TVE lo retransmitió. Este acontecimiento cultural provocó reacciones opuestas. Desde Ciudad Real la lectora M. Teresa Ontiveros pedía que la televisión hubiera tenido que "incluir unos subtítulos" para que los ciudadanos que no entendían las letras pudieran disfrutar más de "un cantante auténticamente interesante" "“El recital de Lluís Llach", EP, 19 de diciembre de1976). Por su parte, el lector Melchor Enrique Asenjo exclamaba desde Madrid que una cosa era "que desde hace algún tiempo ya no es pecado de leso españolismo hablar, escribir o cantar en catalán", pero otra muy diferente era "sacar al Lluís Llach en sábado y por la primera cadena para soltarnos sus canciones como si tal cosa hay un abismo que hace unos meses parecía imposible de cruzar" ("Un repentino y sospechoso amor por Cataluña", EP, 19 de diciembre de 1976). Parece claro que ante el monopolio del castellano en la televisión pública, la retransmisión de un concierto de música en catalán era percibida como una rareza e incluso una sorpresa por una parte del público. La televisión pública de la época hubiera podido preparar al público para recibir con normalidad un acontecimiento de estas características y aprovechar la ocasión para hacer pedagogía de la diversidad como una riqueza a potenciar en el futuro estado democrático.

En cuanto al PEN Club celebrado en Estocolmo, el lector Jesús Torbado utiliza un tono sarcástico para criticar la reivindicación del catalán como lengua de los escritores catalanes representados en la asociación internacional de escritores.

Los delegados catalanes en la conferencia del Pen Club (Club Internacional de Escritores) se opusieron a que el castellano fuese considerado lengua oficial de la institución, ya que únicamente es hablado por trescientos millones de analfabetos y cultivado por algunas docenas de resentidos plumíferos del planeta. Aunque la propuesta parecía bien a todo el mundo, incluídos los que escriben en swahili, que son africanos antiimperialistas, los catalanes la 
consideraron una ofensa para su país y para su pueblo por tratarse de la lengua sojuzgadora (“El circo catalán”, EP, 16 de junio de 1978).

En un modo mucho más explícito, el lector Albert Burgos Baruel denunciaba la falta de atención de los medios hacia el día de Sant Jordi y defendía su españolidad justamente por su condición de catalanoparlante (y "nacionalista"):

Permítame expresar en su diario mi más enérgica protesta, principalmente como español. Yo soy catalán, nacionalista, pero, como tal, también soy español, porque ser español es ser: gallego, andaluz, aragonés, catalán, etc. Ser español es sencillamente convivir todos juntos y estructurarnos libremente como Estado. Ser español no quiere decir tener que hablar sólo castellano, ni propugnar una celestial unidad carente de realidades más concretas y libres que libremente la constituya. [...]

Yo estaba también el día de Sant Jordi en la plaza de Sant Jaume pidiendo, en mi lengua, el Estatut (volem l'Estatut) y pensando, en catalán, soñé con una España nueva (“Cataluña y España", EP, 22 de mayo de 1977).

En este caso, la celebración de un acontecimiento festivo y cultural como el día del libro deriva hacia una opinión que mezcla lengua, identidad y el modo de concebir el Estado. Los acontecimientos culturales de signo diverso no estaban exentos de cargas extraculturales a la luz de las opiniones de los lectores.

\section{Ideologías lingưísticas de los lectores al inicio de la democracia}

Las ideologías lingüísticas de los lectores evolucionan en muy pocos años hacia nuevos temas y nuevos argumentos. Si al principio de la Transición dominan los temas generales y las relaciones entre lengua e identidad, a partir de 1979 se puede observar un cambio de orientación, sin duda ligado a las primeras concreciones institucionales y legislativas del nuevo Estado democrático. Por un lado, hay varios lectores que, con matices y argumentos diferentes, ponen el acento en el derecho de los inmigrantes castellanoparlantes en Cataluña y, por el otro, hay varios lectores que denuncian las incipientes políticas lingüísticas en democracia, al considerarlas lesivas respecto a los derechos lingüísticos, especialmente en el terreno de la educación en sus distintos niveles. En todos estos casos, el lector suele autodefinirse en términos lingüísticos, identitarios y políticos para dar validez a la argumentación general que defiende: son frecuentes las cartas en las que el lector se presenta como "catalanoparlante", "castellanoparlante", "no separatista”, "nacionalista”, etc. (Ya hemos visto que este tipo de autoidentificación también se explicitaba, de vez en cuando, en algunos modelos de carta analizados anteriormente.) 


\subsection{Los derechos de los castellanoparlantes}

En relación a la reivindicación de los derechos de los inmigrantes en comunidades con lengua propia, las primeras cartas sobre el tema son reacciones a la publicación en El País de un capítulo del libro Lo que queda de España de Federico Jiménez Losantos. Hay lectores que expresan su rechazo a las tesis del periodista y otros que replican a los lectores contrarios al periodista aragonés. Montserrat Caballé es la primera lectora que escribe una carta para replicar las tesis de Jiménez Losantos recordándole el artículo sobre lenguas en el anteproyecto de Estatuto de Cataluña:

En vista de estas normas, ¿cómo puede el señor Jimériez afirmar que el castellano "es una causa perdida en Cataluña"? Si los propios catalanes garantizan su uso y conocimiento, cosa que el régimen de Franco no supo hacer con el idioma catalán, sino todo lo contrario. ¿Es que el señor Jiménez pertenece al antiguo partido único, lengua única, sindicato único? (“Lecciones de catalán", EP, 3 de febrero de 1979).

El lector Juan J. Aguado escribe desde Barcelona para dar su opinión sobre las ideas de Jiménez Losantos, y explica su biografia personal: se presenta como un castellanoparlante que lleva "trece años trabajando" en Barcelona y a quien no le parece mal el artículo sobre lenguas previsto para el Estatuto. Sin embargo, habla en nombre de "los inmigrantes” para denunciar la catalanización de los ámbitos públicos y el catalanismo de los partidos de izquierda:

A los inmigrantes se nos pide que nos integremos "voluntariamente" en la cultura catalana. Pongo las comillas porque en la realidad esa voluntariedad no es tal, debido a la presión psicológica que hay por catalanizar todo. Dada la desigualdad económica y de poder en que se encuentra el inmigrante, no le queda más remedio que renunciar a su idioma, si no quiere llegar a ser un ciudadano de segunda clase. Y cuando digo renunciar a su idioma, no me refiero al uso coloquial y familiar, sino al uso oficial, político y social, es decir, en estricta igualdad de derechos con el catalán.

$[\ldots]$

Y no es que los catalanes estén imponiendo su lengua a los castellanos, no. No es eso. Son los que tienen los resortes del poder en sus manos, partidos, entidades, intelectuales..., los que están llevando a cabo esta política de asimilación. La responsabilidad histórica de los partidos de izquierda, como principales beneficiarios de los votos de los inmigrantes, es muy grave. ("Los emigrantes y el catalán”, EP, 21 de febrero 1979)

Por su parte, el lector Jesús Rodríguez Velasco se adhiere a las opiniones expresadas por Aguado y habla de "represión catalanista" (titulo de su pieza) y de "la actual integración dictatorial del charnego (xarnec)", "donde todo andaluz quiera o no quiera tiene que hablar una lengua extraña, olvidando la suya que se extiende desde el norte de Africa a la Tierra del Fuego". Rodríguez, que escribe desde Madrid, se presenta como un "trabajador inmigrante que sufrió en sí mismo y en su familia una serie de penalidades, sin cuento”. En su ataque a la incipiente catalanización de la sociedad, enumera va- 
rios ejemplos: desde recordar que "su verdadero nombre [del catalán] es lemosín", hasta las clases en catalán en la Universidad o el mantenimiento de esta lengua en presencia de castellanoparlantes. El lector cierra su carta de modo apocalíptico: "Como los catalanistas no saben bien el castellano y los andaluces no tienen idea del catalán, se está formando una mezcla de catalán-andaluz, que no hay cristiano que entienda y va en perjuicio de la pureza de ambas lenguas." "'La represión catalanista", EP, 23 de febrero de 1979). Esta carta es respondida por el lector Josep M. Ramis, que rebate la tesis lemosinista de Rodríguez apelando a autoridades filológicas como Josep Melià y Joan Coromines, y defiende la oficialidad del catalán y el derecho a hablarlo:

Es incómodo y difícil, para el inmigrante, aprender un nuevo idioma. Algo más que incómodo y difícil es que a un catalán se le niegue el derecho a hablar su propia lengua, como ha venido pasando estos últimos años ("Sobre el catalán", EP, 27 de febrero de 1979).

También se muestra a favor de las tesis de Jiménez Losantos la lectora Paula Farret, que se presenta como "persona catalana de origen y lengua... casada con castellano": afirma sentirse abochornada por "la campaña de mentalización catalanista a que se viene sometiendo a la gente de fuera" y cuestiona que se "obligue a hablar catalán a quienes tienen un idioma tan rico como el castellano" (“Entre castellano y catalán”, EP, 10 de julio de 1979).

\subsection{Lenguas de la enseñanza y debate en torno al bilingüismo y a la normalización}

A medida que el nuevo Estado democrático se va cada vez más concretando y desarrollando, más frecuente es la denuncia de las incipientes políticas lingüísticas autonómicas, al considerarlas lesivas respecto a los derechos de los castellanoparlantes, especialmente en el terreno de la educación en sus distintos niveles. En este sentido, se expresan varios lectores.

Rafael Ávila, que se presenta como un "licenciado en Filosofía y Letras por Salamanca [que] resid[e] en Cataluña desde hace seis años, siendo natural de Andalucía", explica su experiencia personal en el mundo laboral para denunciar que el hecho de no hablar catalán resulta "un obstáculo casi insuperable" para obtener trabajo en Andorra o en Cataluña ("Castellanohablante en Cataluña", EP, 7 de septiembre de 1979). Esta carta es contestada desde Andorra por el lector J.R. Serra, quien aconseja que "después de seis años, lo más correcto, lo más eficaz e incluso lo más inteligente, para un licenciado en Filosofía y Letras es que, si vive en Cataluña, aprenda catalán”. Serra también recurre a su experiencia personal, pero en su caso para defender que se debe aprender la lengua del país donde se vive, como lo hacen los trabajadores "franceses, portugueses y andaluces" que trabajan en su empresa: "Hablan catalán y así convivimos con un problema menos los hombres y las tierras de España..., perdón, de Europa” ("Castellano-hablante en Cataluña y... Andorra”, EP, 9 de septiembre de 1979). 
Hay numerosas cartas de lectores que critican las políticas lingüísticas de los territorios con lengua propia, incluso antes de aprobarse los respectivos estatutos de autonomía y las leyes de política lingüística que se derivarán posteriormente. Sobre este tema, las quejas proceden de varias CCAA y no solo de Cataluña, como en la mayoría de los casos vistos hasta ahora. Ya en 1977 un lector de Guipúzcoa se quejaba de la exclusión de un castellanoparlante en una ikastola ("Discriminación al revés", EP, 23 de abril de 1977). El lector Luis Miguel Jiménez Benito, por su parte, consideraba que la inversión del Estado en la enseñanza de "lenguas vernáculas" se debería compensar con "un esfuerzo [presupuestario] similar en otras regiones o nacionalidades" ("Lenguas vernáculas", EP, 3 de septiembre de 1980). Ante las informaciones publicadas en la prensa acerca de la preparación de la ley de política lingüística en Cataluña, el lector Manuel Villoslada veía en ella una amenaza para "la desaparición del bilingüismo" y alertaba de que no incurriera "en fallos discriminatorios que perjudiquen al medio de expresión hablado y escrito de la comunidad castellano-hablante, representada nada menos que por la mitad aproximada de la población de Cataluña" ("El enriquecedor bilingüismo", EP, 18 de julio de 1980). Este artículo mereció la respuesta desde Andorra del lector J. Ros Serra, quien le replicó que

el único bilingüismo total que existe es el de los catalanes. Es un bilingüismo enriquecedor y acorralado al tiempo. Los castellanohablantes deben ser en su mayoría partidarios de la pobreza, cuando no sólo en Cataluña rehusan la lengua de adopción, sino que la rehusan también en Andorra, donde es la única lengua oficial. ("Dos lenguas", EP, 29 de julio de 1980).

El proceso de normalización del catalán ya fue cuestionado de arriba abajo incluso unos años antes de la primera ley aprobada por el Parlamento de Cataluña, que fecha de 1983. Unos años antes, los lectores Juan Carlos Torrubia y Maria Mercè Sans, consideraban que la normalización "pretende despojar de su lengua y cultura a cientos de miles de inmigrantes, que constituyen la mitad de la población de Cataluña" "“Cooficialidad de las lenguas", EP, 7 de agosto de 1979). En algunos casos, se critica la normalización del catalán para criticar a los partidos catalanistas de izquierda y en palabras de los lectores Juan Carlos Torrubia y Maria Mercè Sans, "dar la bienvenida al PSA o cualquier otro partido del resto del Estado que defienda el derecho a la cultura y lengua propias de dos millones y medio de personas que viven y trabajan en Cataluña." "'Cooficialidad de las lenguas", EP, 7 de agosto de 1979).

Hay varios lectores que entran en un terreno más concreto y plantean la lengua de la enseñanza. El lector Aurelio Pérez Fustegueras pedía un sistema educativo "duplicado, es decir, escuela, instituto y universidad catalanes, por un lado, y escuela, instituto y universidad castellanos, por otro" ("Más sobre idioma", EP, 14 de agosto de 1980). La lectora Rosa María Carretero pedía en cualidad de maestra poder impartir en castellano varias asignaturas en las Islas Baleares y se hace muchas preguntas en cuanto a sus derechos lingüísticos individuales y a los de los castellanoparlantes en general: 
“No se puede enseñar las matemáticas o las ciencias en castellano, que al fin y al cabo es un idioma que tienen que aprender también? ¿O es que quizá tendrán que contruirse en Baleares colegios para niños españoles, separados de los colegios para niños mallorquines o ibicencos...? ¿Es que un español de la Península no puede abrirse camino en las islas españolas aunque con ello tenga que aprender mallorquín, pero con el tiempo? ¿Primero debe estar un año sin trabajar dedicándose a aprender mallorquín y luego puede ir allí?” (“Enseñanza en las nacionalidades", EP, 10 de julio de 1979).

El lector Antonio Cabezuelo utilizaba un lenguaje denigrante hacia las lenguas no castellanas al denunciar que "para ir a España, tenemos que ir a la escuela para aprender los dialectos, porque este año he estado en Barcelona y hasta las calles las han cambiado. Y en Palma y Valencia, igual. Y aún nos dicen que tenemos que esforzarnos por aprender". El lector escribe desde París y no duda en expresar su nacionalismo lingüístico: "Aquí, en el extranjero, tenemos que soportar la lengua del país, pero cuando vamos a España nos gusta poder hablar nuestra lengua, que para nosotros es la mejor". Cierra su carta para mostrarse "en contra de los dialectos" y para pedir que España se ponga "al nivel del mundo, porque aquí, en Francia, hay más dialectos, pero sólo se habla la lengua del país” (“Un solo idioma”, EP, 26 de septiembre de 1980).

El lector Manuel Villoslada criticaba la normalización desde el punto de vista de los problemas académicos de los alumnos y denunciaba que "muchos niños castellanohablantes han sido suspendidos en la asignatura de lengua catalana, impuesta, y que incluso en la universidad (me consta que así es en la Autónoma) los estudiantes de habla castellana no pueden seguir normalmente sus clases por dárselas en catalán". ("Más sobre bilingüismo", EP, 8 de agosto de 1980). Todavía en un terreno más concreto y más personal, se expresaba el lector Juan José Aguado, quien denunciaba la catalanización de las guarderías en Barcelona, donde "a pesar de visitar siete u ocho guarderías, en todas ellas la enseñanza y el trato colectivo ha de hacerse en catalán”. Aguado, que se presenta como un cántabro residente en Barcelona desde hacía 14 años, buscaba para su hijo una guardería "en la que se le empiece enseñando en castellano como primera lengua y luego, progresivamente, el catalán” (“Bilingüismo”, EP, 3 de abril de 1980).

Junto a las numerosas críticas a los cambios lingüísticos que se abrían con la España democrática, son solo unos pocos lectores de El País los que muestran su conformidad con las políticas lingüísticas autonómicas. Así lo expresa desde Logroño José María Ruiz en su carta al director. En la medida en que es un posicionamiento minoritario entre las cartas al director y en este caso procede de un territorio sin lengua propia, merece la pena reproducir su opinión de modo extenso:

El castellano es el idioma oficial de España, y todos los españoles tienen que conocerlo, sea cual sea su lengua materna. De acuerdo, pero el catalán es también -tanto como el castellano- idioma oficial del principado y todos los ciudadanos de Cataluña tienen que conocerlo, sea cual sea su lengua materna. Así de sencillo. Por supuesto que no se puede exigir de sopetón el conocimiento del catalán a la población inmigrante adulta, pero sí poco a poco, 
y desde ahora mismo, a las nuevas generaciones (“Más sobre idioma”, EP, 14 de agosto de 1980).

También tiene una opinión positiva el lector Jorge Madueño, quien escribe desde Bilbao para expresar su posición favorable al decreto-ley sobre bilingüismo, pues "tiene derecho el pueblo vasco a hablar su lengua y a poseer su propia bandera, que las tiene" ("A favor del euskera", EP, 9 de mayo de 1979).

Obsérvese, pues, que la mayoría de posicionamientos favorables a los cambios lingüísticos que se dieron con la implantación del nuevo Estado democrático son réplicas a cartas al director por parte de lectores, como el caso del lector J. Ros Serra, que expresan su desacuerdo con algún lector que previamente había escrito al periódico para quejarse sobre algún aspecto que ponía en cuestión la hegemonía del castellano, ya fuera en aspectos generales, ya fuera en ámbitos varios de la vida social, como la educación. La actitud positiva ante los cambios lingüísticos que se abrieron durante la Transición fue una expresión muy minoritaria dentro del conjunto de cartas al director.

\section{Conclusiones}

En los momentos de cambio sociopolítico las sociedades tienden a plantearse las bases sobre las que se habían fundamentado hasta un cierto momento. La Transición fue un período de profundas transformaciones que han dejado una honda huella en la España actual, por lo que ha merecido, sin cese, el interés de las más varias aproximaciones académicas (políticas, sociales, culturales...). En el terreno de las lenguas, la literatura académica sobre la cuestión se ha centrado en los cambios en el plano legislativo y en este sentido, ha puesto de relieve que la Transición supuso poner fin al monolingüismo instaurado por el franquismo y abrir una etapa de reconocimiento a la diversidad lingüística. Desde esta perspectiva, la Transición puede considerarse como el inicio de la de ruptura. Ahora bien, si se enfoca la cuestión desde el terreno de las ideologías lingüísticas de los ciudadanos, la Transición aparece menos como un momento de ruptura y se muestra más como un período de continuidad, lleno de dudas y reticencias hacia una futura etapa democrática abierta a la diversidad. El marco interpretativo de las lenguas en el plano legal e institucional no encaja en el análisis de las ideologías lingüísticas expresadas por los lectores en la prensa, que requiere de otras aproximaciones y otros parámetros interpretativos.

Este artículo pretende abrir una serie de estudios que planteen qué papel jugó la prensa a la hora de propiciar un cambio de mentalidades en el paso del franquismo a la democracia. Para ello, cabrá analizar en otros estudios las informaciones y las opiniones que se expresaron en los más variados periódicos españoles. En este artículo me he limitado a estudiar las ideologías lingüísticas de los lectores del periódico El País, expresadas a través de su sección de cartas al director. Durante unos pocos años, entre 1976 y 1982, se publicaron más de 200 cartas sobre el tema de la diversidad lingüística, una buena parte de las cuales están relacionadas con la diversidad lingüística. 
Las cartas al director, a pesar de ser un género periodístico académicamente controvertido, son un excelente termómetro para diagnosticar la opinión pública de los ciudadanos. Durante la Transición, los lectores de El País emitieron sus juicios en relación a las lenguas en estrecha relación a elementos de carácter extralingüístico, a veces relacionados con la evolución política, a veces con acontecimientos culturales muy varios. Como es propio en el estudio de las ideologías lingüísticas, hemos visto cómo la opinión y los juicios sobre las lenguas a veces están relacionados con el contexto, con las propias experiencias individuales y, naturalmente, con el posiconamiento de cada ciudadano en relación a su sociedad.

Las ideologías lingüísticas de la Transición no presentan un tono uniforme, sino que reflejan opiniones de todo tipo, a menudo antagónicas, sobre aspectos generales y teóricos (lengua nacional, dialectos, bilingüismo...), especialmente dominantes durante los primeros años de la Transición, pero también sobre temas más concretos relacionados con los primeros años de la democracia, tales como la promoción de las lenguas, la enseñanza o el planteamiento de los derechos lingüísticos en las comunidades con lengua propia. En un periódico tan importante durante la Transición como El País, la mayoría de sus lectores expresaron muchas reticencias, cuando no abierta oposición, a los cambios que conllevó la Transición respecto a varias lenguas. Entre las cartas al director, son minoritarios los planteamientos favorables a las incipientes políticas lingüísticas de las comunidades autónomas con lengua propia. La opinión pública española de la Transición todavía estaba ligada a las inercias monolingüistas del franquismo, aunque no fueron obstáculo para que en el plano legal y político se impulsara una promoción efectiva de varias lenguas en el espacio público, en la educación y en la vida social en general.

Si nos situamos en el binomio continuidad-ruptura, constitutivo de toda narrativa historiográfica, el presente artículo pone luz más sobre las continuidades que muestra la opinión pública española en relación a la diversidad lingüística, que sobre la ruptura que efectivamente se fraguó en el plano legal, tal y como ha subrayado hasta el momento la literatura académica. En cierto modo, el presente artículo ilumina una temporalidad, la de "le temps long", que ha quedado ocultada por la perspectiva macropolítica de la Transición como un período de ruptura o cambio radical. En este período tan complejo, coexistieron distintos planes y varias temporalidades, que a la luz del análisis sobre las ideologías lingüísticas de los lectores de prensa, proyectan con nitidez un nivel oculto para la mayor parte de la literatura académica y, a su vez, el carácter dinámico y multiestrático de la historia de las lenguas. 


\section{Referencias bibliográficas}

Bastardas, Albert y Emili Boix (eds.) (1994), ¿Un estado, una lengua? La organización política de la diversidad lingüística, Barcelona, Octaedro.

Benet, Josep M. (1995), L'intent franquista de genocidi cultural contra Catalunya, Barcelona, Publicacions de l'Abadia de Montserrat.

Brumme, Jenny (2006), "Las regulaciones legales de la lengua (del español y las otras lenguas de España y América)", en Rafael Cano (ed.), Historia de la lengua española, Barcelona, Ariel, p. 945972.

Castillo Lluch, Mónica y Johannes Kabatek (ed.) (2006), Las lenguas de España: política lingüística, sociología del lenguaje e ideología desde la Transición hasta la actualidad, Madrid/Fráncfort, Iberoamericana/Vervuert.

Castro Torres, Carmen (2010), La prensa en la transición española (1966-1978), Madrid, Alianza Editorial.

Córdova Jiménez, Alejandro (2011), “Las cartas al director como género periodístico”, ZER, n³0, p. 189-202.

Cotelli, Sara (2009), "Sociolinguistique historique: un tour d’horizon théorique et méthodologique", en Dorothée Aquino-Weber, Sara Cotelli y Andres Kristol (eds.), Sociolinguistique historique du domaine gallo-roman: enjeux et méthodologies, Berne, Peter Lang, p. 3-24.

Curdt-Christiansen, Xiao Lan (2016), "Conflicting language ideologies and contradictory language practices in Singaporean bilingual families", Journal of Multilingual and Multicultural Development, n³7, vol. 7, p. 694-709.

Del Valle, José y Vitor Meirinho-Guede (2016), "Ideologías lingüísticas”, en Javier Gutiérrez-Rexach (ed.), Enciclopedia de Lingüística Hispánica, New York, Routledge.

Del Valle, José (2007), La lengua, ¿patria común? Ideas e ideologías del español, Madrid/Fráncfort, Iberoamericana/Vervuert.

Del Valle, José (2013), A Political History of Spanish: The Making of a Language, Cambridge, Cambridge University Press.

Ferrando, Antoni y Miquel Nicolás (2011), Història de la llengua catalana, Barcelona, UOC.

Fuentes, Juan Francisco y Javier Fernández Sebastián (1997), Historia del periodismo español: prensa, política y opinión pública en la España contemporánea, Madrid, Síntesis.

González Ollé, Fernando (1978), "El establecimiento del castellano como llengua oficial”, Boletín de la Real Academia Española, vol. 58, n²14, p. 231-282.

Gallofré i Virgili, Maria Josepa (1991), L'edició catalana i la censura franquista (1939-1951), Barcelona, Publicacions de l'Abadia de Montserrat. 
Gomis, Lorenzo (2008), Teoría de los géneros periodísticos, Barcelona, UOC.

Iglésias, Narcís (2019), "Language policies in contemporary Catalonia: a history of linguistic and political ideas", en Pompeu Casanovas, Montserrat Corretger y Vicent Salvador (eds.), The rise of Catalan identity: social commitment and political engagement in the twentieth century, Cham, Springer, p. 79-105.

Kroskrity, Paul V. (2000), "Regimenting languages: Language ideological perspectives", en Paul V. Kroskrity (ed.), Regimes of language: Ideologies, polities, and identities, Santa Fe, School of American Research, p. 1-34.

Lebsanft, Franz (1990), Spanien und seine Sprachen in den Cartas al Director von El País (1976-1987): Einführung und analytische Bibliographie, Tübingen, Günter Narr Verlag.

Lebsanft, Franz (1997), Spanische Sprachkultur: Studien zur Bewertung und Pflege des öffentlichen Sprachgebrauchs im heutigen Spanien, Tübingen, Niemeyer.

Lebsanft, Franz (2017), "Lingüística populary codificación del español”, en Wolfgang Dahmen, Günter Holtus, Johannes Karmer, Michael Metzeltin, Claudia Polzin-Haumann, Wolfgang Schweickard y Otto Winkelmann, Sprachkritik und Sprachberatung in der Romania: Romanistisches Kolloquium XXX, Tübingen, Narr Francke Attempto, p. 103-118.

Leduc, Jean (1999), Les historiens et le temps: conceptions, problématiques, écritures, París, Seuil.

Marcet, Joan (2013), “La política lingüística de l'Estat Espanyol: una aproximació a la incomprensió del pluralisme cultural", Revista de Llengua i Dret, n59, p. 59-74.

Moreno Fernández, Francisco (2005), Historia social de las lenguas de España, Barcelona, Ariel.

Pericay, Xavier (ed.) (2007), ¿Libertad o coacción? Políticas lingüísticas y nacionalismos en España, Madrid, FAES.

Sánchez Erauskin, Javier (1994), El nudo escurridizo: Euskal Herria bajo el primer franquismo, Tafalla, Txalaparta.

Schieffelin, Bambi B., Kathryn A. Woolard y Paul V. Kroskrity (eds.) (1998), Language ideologies: practice and theory, New York/Oxford, Oxford University Press.

Sueiro Seoane, Susana (2009), "El papel del diario El País en la Transición”, en Rafel Quirosa-Cheyrouze y Muñoz (ed), Prensa y democracia: los medios de comunicación en la Transición, Madrid, Editorial Biblioteca Nueva, p. 151-160.

Tusell, Javier (1997), La Transición española: la recuperación de las libertades, Madrid, Temas de Hoy.

Wodak, Ruth (ed.) (1989), Language, power, and ideology: studies in political discourse, Amsterdam, John Benjamins.

Woolard, Kathryn (2008), "Les ideologies lingüístiques: una visió general d'un camp des de l'antropologia lingüística", Revista de Llengua i Dret, nº 49, p. 179-199. 
Yanes, Rafael (2004), Géneros periodísticos y géneros anexos: una propuesta metodològica para el estudio de los textos publicados en prensa, Madrid, Fragua.

Ysàs, Pere (2013), "Ni modèlica ni immodèlica. La transició des de la historiografia", Franquisme \& Transició, n 1, p. 273-308. 


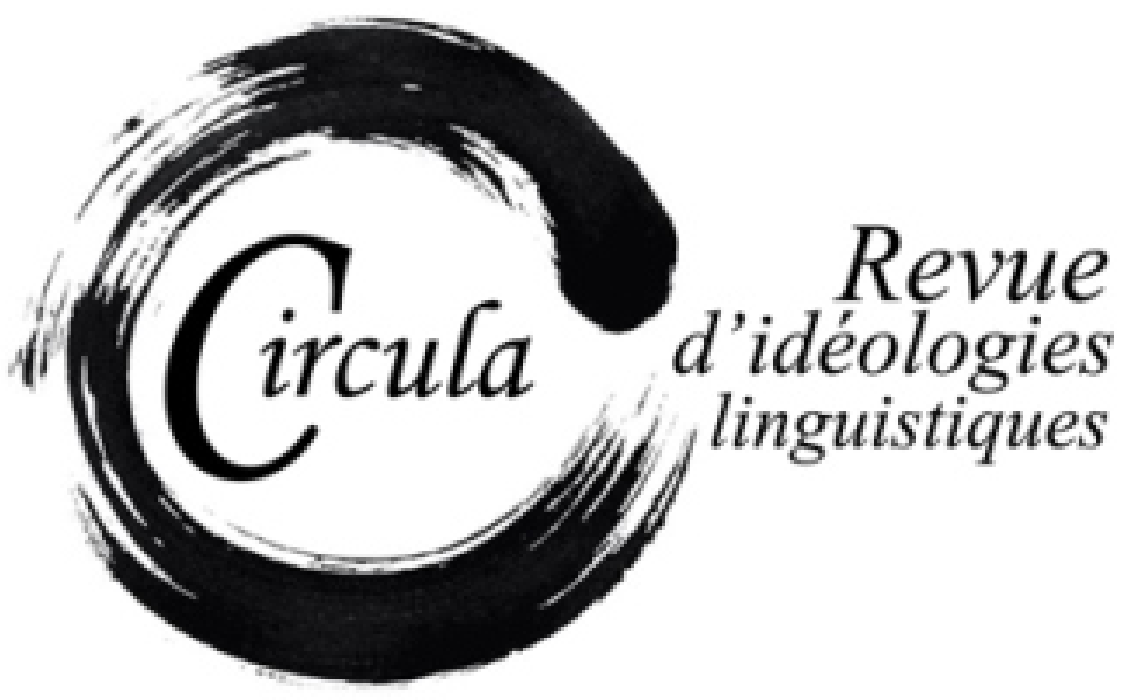

TITRE: PRIMI SPUNTI PER UN'ANALISI DEL DISCORSO SULLA QUESTIONE MERIDIONALE: MATERIALI, METODI, PROSPETTIVE

Auteur: Paolo OrRù, UniversitÀ di Debrecen

Revue: CIRCULA, NUMÉRO 10

PAGES: $22-40$

ISSN: 2369-6761

URI: HTTP://HDL.HANDLE.NET/11143/16772

DOI: HTTPS://DOI.ORG/10.17118/11143/16772 


\section{Primi spunti per un'analisi del discorso sulla questione meridionale: materiali, metodi, prospettive}

Paolo Orrù, Università di Debrecen

paolo.orru@arts.unideb.hu

Riassunto: Il dualismo tra Nord e Sud Italia ha avuto un ruolo importantissimo per la costruzione dell'identità nazionale e ancora oggi struttura gran parte dei discorsi politici e mediatici sullo stato del Paese. È un luogo comune ritenere che, al momento dell'Unità d'Italia, il Paese fosse diviso in un Nord progredito e moderno e un Sud arretrato economicamente e socialmente. Tali costruzioni di senso sono radicate in più ampie correnti di pensiero europee che a cavallo tra XVIII e XIX secolo hanno contribuito a tratteggiare la profonda alterità del meridione europeo e hanno in parte alimentato le imprese risorgimentali italiane. Il presente contributo intende svolgere alcune riflessioni sulle ideologie linguistico-discorsive che hanno alimentato il dualismo Nord-Sud e delineare un percorso di ricerca di lunga durata.

Parole chiave: questione meridionale; analisi del discorso; meridione; dualismo nord-sud; Italia; discorsi politici; Risorgimento

Abstract: The dualism between North and South Italy has played a very important role in the construction of national identity and structures most of the political and media discourse on the state of our country still today. It is commonplace to assume that at the time of the Unification of Italy, the country was divided into an advanced modern North and an economically and socially backward South. Such constructions of meaning are rooted in broader currents of thought that at the turn of the eighteenth and nineteenth centuries have contributed to outlining the profound otherness of the European south and have partly fuelled the Italian Risorgimento. The present paper intends to trace some reflections on the linguistic-discursive ideologies that have nourished the North-South dualism and outlines a long-term research path.

Keywords: southern question; Italy; discourse analysis; north-south dualism; political discourse; Risorgimento 


\section{Nord-Sud: dualismo, potere e discorso ${ }^{1}$}

Salvatore Lupo (2015), uno dei più autorevoli studiosi del Mezzogiorno, in un suo noto volumetto di qualche anno fa dedicato alla questione meridionale decise di inserire un eloquente sottotitolo, che è insieme anche un'idea programmatica: Come liberare la storia del Mezzogiorno dagli stereotipi. L'obiettivo di Lupo è quello di dimostrare come alcuni degli assi portanti della storiografia - da lui definita mainstream - sull'Italia unita siano stati a lungo viziati da eccessive generalizzazioni, basate su letture parziali e, proprio come gli stereotipi² ${ }^{2}$ tramandate acriticamente nel tempo, fino a costruire luoghi comuni ampiamente condivisi anche nel dibattito pubblico e assai difficili da mettere in discussione. Tra tutti è sicuramente centrale il mito dell'arretratezza economica, sociale e culturale del Sud rispetto al Nord. L'opera si inserisce in un più ampio filone di studi ormai trentennale inaugurato da Lupo insieme a Piero Bevilacqua e all'Imes (Istituto meridionale di storia e scienze sociali) che ha trovato spesso sbocco nella rivista Meridiana. Il dibattito scientifico sul tema è certamente ancora aperto e tutt'altro che unanime; tuttavia, l'idea statica, acquisita in decenni di tradizione storiografica, di un meridione omogeneamente immobile, arretrato, fuori dalla modernità, è ormai con convinzione messa ampiamente in discussione ${ }^{3}$. Ciò, ad ogni modo, non significa negare che il Sud al momento dell'Unità non presentasse una moltitudine di problemi e un sostanziale ritardo infrastrutturale e sociale ${ }^{4}$.

La ricostruzione dei dati storiografici è fuori dalle nostre competenze e dagli scopi di questo contributo; quello che ci preme sottolineare, invece, è che tali studi ci indicano una strada per interpretare le dinamiche Nord-Sud, che l'estrema attualità chiama in causa continuamente, sia in merito alla situazione dell'Italia, sia gettando lo sguardo oltre il Mediterraneo.

Gli apporti originali e critici alla materia non si esauriscono nel solo versante delle scienze sociali. Recentemente, si può assistere a un rinnovato interesse verso lo studio del Mezzogiorno da varie angolazioni metodologiche soprattutto nel campo degli studi letterari e culturali. Se è vero che il Sud è stato oggetto continuo di indagine in vari campi delle scienze umane e sociali per tutta la storia

1. Un ringraziamento è dovuto a László Pete, Marco Pignotti e Carmine Pinto per i preziosi commenti e consigli sul quadro storiografico e per i tanti suggerimenti relativi alla composizione del corpus

2. Ci riferiamo qui alla natura cognitiva dello stereotipo, come meccanismo di sovrageneralizzazione di una credenza, che acquisisce nel tempo il valore di senso comune in una comunità (Moscovici, 1981).

3. Luciano Cafagna parla ad esempio di una "modernità passiva", con riferimento alla mancanza di una coesione degli impulsi modernizzatori e di una élite che li aggregasse (Cafagna, 1988). Francesco Barbagallo (2013) preferisce parlare di "questione italiana", per mettere al centro le molteplici spinte disgregatrici in atto sia da Nord sia da Sud; inoltre, ricorda come il divario economico del Mezzogiorno rispetto al Settentrione vada inquadrato nell'ottica di un complessivo ritardo di quest'ultimo rispetto alle altre nazioni industrializzate europee. Le differenze esistenti al momento dell'Unità tra le due aree del Paese non parrebbero, dunque, cosi significative come la tradizione le ha sempre rappresentate. A conclusioni simili è giunto anche Guido Pescosolido (2017a), che inoltre mette ben in evidenza le interconnessioni sul fronte economico venutisi a creare dopo l'Unità e il ruolo che il Mezzogiorno ha avuto nell'avvio dell'industrializzazione delle regioni settentrionali.

4. Per una sintetica ma efficace disamina, si veda Pescosolido (2017b) 
unitaria del Paese; è altrettanto corretto sottolineare la sostanziale novità, per lo meno prospettica, degli studi recenti. Ciò che condividono tali variegate esperienze di ricerca sembra essere proprio, da una parte, la volontà di ridiscutere finalmente le basi degli stereotipi che hanno tormentato la storia unitaria; dall'altra parte, di mettere al centro una visione del Mezzogiorno non più in chiave dualistica, come polo opposto a un Nord, ma come soggetto attivo, da osservare per le proprie peculiarità. Sempre Lupo riassume bene tale intenzione nell'introduzione: «il Mezzogiorno va considerato, al pari di un qualsiasi luogo di questo mondo, come un frammento della modernità. E sui modi della sua modernizzazione che occorre confrontarsi» (Lupo, 2015: xii).

Partendo da traiettorie decisamente differenti, anche Luigi Cazzato (2017) si pone un obiettivo simile nel ripercorrere l'influenza della letteratura di viaggio anglosassone nella costruzione dell'identità nazionale italiana. A tal fine, l'elaborazione teorica di alcuni delle voci più influenti del discorso poste de-coloniale, quali Aníbal Quijano (2007), Walter Mignolo (2007) e lain Chambers (2007), diventa lo strumento per leggere più in profondità la formazione storica e culturale dei discorsi egemonici che ancora oggi strutturano il confronto tra il Nord "virtuoso" e il Meridione "colpevole".

Cazzato applica al contesto storico-politico qui in esame il concetto di «colonialità del potere», mutuato da Quijano. Se il colonialismo va giustamente inteso come un ben preciso prodotto storico delle azioni delle potenze europee, la colonialità è piuttosto la costruzione ideale della superiorità dell'Occidente sulle altre nazioni, ciò che di fatto ha alimentato le imprese coloniali, ma che ne supera i motivi e i luoghi storici. Alcuni dei tratti della differenza tra dominatore e dominato vengono applicati a regioni, nazioni, imperi (come quello russo od ottomano) che non possono essere di fatto colonizzati, ma ai quali viene comunque assegnato un marchio di inferiorità o arretratezza:

[...] il potere della colonialità non si esaurisce con la visione razzista dei rapporti tra colonizzati e colonizzatori, ma esso pervade anche l'interno del mondo moderno occidentale. Nello specifico, meccanismi del potere coloniale hanno governato anche i rapporti tra i popoli che avevano un impero (Inghilterra e Francia) e coloro che non ce lo avevano (ancora: Italia, o più: Spagna), scendendo la scala gerarchica (Cazzato, 2017: 29).

In questo quadro, il dualismo Nord-Sud si sovrappone gradualmente a quello più tradizionale tra Est e Ovest5: allo scontro tra barbarie e civiltà, utile a giustificare le imprese coloniali, si aggiunge quello tra progresso e arretratezza, impiegato invece come strumento per la creazione dell'identità europea; la differenza non è più, dunque, unicamente spaziale e geografica ma anche temporale.

Il viaggio degli intellettuali e diplomatici inglesi (ed europei) è anche un viaggio alla ricerca dei confini meridionali del continente, tracciati di volta in volta prima in corrispondenza delle Alpi, poi di Roma e infine di Napoli. I discorsi elaborati in questa chiave avranno un effetto sulla percezione di

5. È impossibile in questo caso non citare almeno Edward Said (1978). 
sé dell'Italia stessa ${ }^{6}$ : in un contesto in cui le province napoletane rappresentavano un oggetto quasi del tutto ignoto, gli intellettuali italiani si confrontano con le ricostruzioni dei viaggiatori stranieri e attraverso questo contatto inizia a filtrare il dualismo tra Nord e Sud.

Il differenziale di potere tra impero e non-impero avrebbe agito, secondo Cazzato, mediante le stesse logiche coloniali impiegate per conquistare le aree esterne all'Europa. La prospettiva offerta da questo campo di studi è senza dubbio affascinante e ricca di suggestioni, ci preme però allo stesso tempo sottolineare che in nessun caso si vuole in questa sede teorizzare una diretta trasposizione degli elementi culturali, storici e politici delle esperienze coloniali alla dinamica tra Nord e Sud Italia. L'immagine del "Sud colonia del Nord", inoltre, ha fatto e ancora fa parte di un revisionismo che senza dubbio non ci appartiene. Ė bene chiarire ciò per evitare scomodi fraintendimenti dettati in gran parte dalla terminologia impiegata. Rimane rilevante ai nostri fini, invece, la centralità dell'elemento discorsivo nella costruzione delle impalcature concettuali che domineranno il confronto tra le due macro-aree della Penisola. Un differenziale che potremmo definire in questo caso discorsivo tra chi è in grado di imporre un discorso egemonico e chi, invece, finisce per subirlo. Con una metafora militaresca, Cazzato sostituisce alle "cannonate" fisiche impiegate per sottomettere i popoli colonizzati, le più astratte, ma non meno efficaci

[c]annonate della conoscenza che hanno portato chi le ha subite a una sorta di auto-coIonizzazione, fino a considerare per esempio il proprio presente, la propria modernità non all'altezza di tale parola: la modernità è sempre quella degli altri (Cazzato, 2017: 30).

Ma facciamo un passo indietro. II 2011 ha visto un fiorire di iniziative editoriali e scientifiche in occasione del $150^{\circ}$ anniversario dell'Unità; tra queste merita sicuramente un cenno in questa sede l'Atlante culturale del Risorgimento (Banti et al., 2011): organizzato come un lessico del linguaggio politico dal Settecento all'Unità, il volume si propone di riassumere e illustrare sinteticamente alcuni dei lemmi fondamentali alla base della costruzione culturale del Risorgimento. La lista dei vocaboli, divisi in quattro sezioni (percezione del tempo storico, campi dell'esperienza, soggetto nazionale, immaginario istituzionale), si apre con decadenza. La sensazione di una perdita di rilevanza culturale, letteraria, scientifica si fa strada sul finire del XVII secolo ${ }^{7}$ negli scritti dei viaggiatori francesi e olandesi, che ne rintracciavano le cause nell'eccessiva ingerenza della Chiesa nella vita degli italiani e nella dominazione spagnola. Tali impressioni ben presto vengono assorbite anche dagli intellettuali italiani e assumono il carattere di un vero e proprio topos.

6. Cf. De Seta (2014).

7. Del resto, già Fernand Braudel in un suo fondamentale studio ricordava che dalla metà del 1600 in poi «il Mediterraneo si posiziona in modo saldo al di fuori della corrente storica dominante, la quale per secoli l'aveva visto padrone quasi assoluto» (1992: 79). 
Decadenza divenne la parola chiave di ogni analisi della realtà della penisola e di ogni possibile discorso degli italiani sull'Italia: un discorso che dal riconoscimento del distacco della penisola dai paesi considerati ad un livello più alto di sviluppo civile, sociale e culturale voleva individuare le vie di una possibile rinascita - risorgimento; riforma (Verga, 2011: 7).

E la stessa prospettiva interna è ormai in qualche modo viziata: in questa fase lo sbilanciamento egemonico verso nuove potenze che si affacciano all'orizzonte è ormai in atto. II discorso italiano oscillerà tra l'accettazione del modello borghese e liberista delle nazioni settentrionali e la piccata difesa incentrata sulla rivendicazione del primato delle arti e della cultura italiana, di cui il giobertiano Del primato morale e civile degli italiani (Gioberti, 1848) rimarrà l'esempio più fulgido; sarà, tuttavia, la prima di queste due opzioni a prevalere. In questo senso, la rappresentazione della decadenza ha anche un effetto indubbiamente propulsivo e di stimolo culturale: la discesa delle truppe napoleoniche e l'intreccio con i valori illuministici aprono poi nei pensatori italiani l'opportunità per riannodare il rapporto con l'élite d'oltralpe. Col passare degli anni però «le accuse [...] di decadenza, di corruzione, di debolezza, di passività politica e morale rivolte all'Italia» si fecero «sempre più frequenti e dure» (Venturi, 1973: 999).

Nell'area degli studi culturali, Nelson Moe (2004) ha ricostruito l'evoluzione dei discorsi sull'Italia del periodo che va dal 1750 al 1850 in ambito letterario (e non solo) e il loro effetto sui pensatori italiani e sul processo risorgimentale. Partendo anch'egli dall'analisi della letteratura di viaggio, Moe ripercorre il doppio binario su cui scorre l'immagine del Paese ${ }^{8}$ : da una parte la rievocazione della sua grandezza storica, della sua ricchezza culturale, di cui i nuovi imperi (soprattutto quello inglese) vogliono presentarsi come i legittimi eredi, contrapposta continuamente alla miseria, alla sciatteria e allo stato di abbandono coevo. L'Italia diviene niente più che un museo a cielo aperto, in cui passeggiare tra le splendide rovine di un passato glorioso. Dall'altra parte, invece, si sviluppa un'immagine positiva della penisola attraverso il canale del pittoresco. Le bellezze naturali e il clima mediterraneo vengono però via via contrapposte ai caratteri morali degli italiani; tra tutti il più noto è indubbiamente quello dell'“indolenza”.

Le contrapposizioni, cui si è fatto riferimento, sarebbero rimaste ben salde, ma avrebbero interagito con un nuovo modo di concepire il tempo e lo spazio, il quale poneva le regioni occidentali e centrali del continente alla guida del progresso umano, sempre più misurato in termini di benessere materiale e progresso tecnologico (Moe, 2004: 28).

Secondo Moe, insomma, lo sguardo interno verso l'Italia e il Meridione si è alimentato e in parte viene plasmato proprio dal discorso impostato dalle nascenti nazioni che, sulla scorta di una visione teleologica della storia, dividono il continente tra progresso e barbarie, al fine di alimentare e giu-

8. Sul versante linguistico si vedano invece Serianni (2002) e Banfi (2017).

9. Interessante rilevare come tale tratto distintivo fosse specifico dell'Oriente, prima ancora che del Mediterraneo. Ancora più in generale, la pigrizia e l'indolenza sono tratti stereotipici di molte rappresentazioni razzializzanti contemporanee (Reisigl e Wodak, 2001). 
stificare le proprie imprese coloniali e il proprio primato. La volontà di recuperare il divario con le potenze imperiali non è altro che l'accettazione stessa della propria inferiorità, che sconfina progressivamente verso l'assimilazione supina dei valori borghesi del benessere economico e del progresso nord-occidentale. Parole come virtù, civiltà, progresso, opposte a barbarie, indolenza, arretratezza struttureranno il rapporto polarizzante tra Nord e Sud d'Europa, scaveranno un solco nella coscienza dei patrioti (meridionali e non) esuli oltre Manica, supportati dalla diplomazia britannica prima e dall'opinione pubblica poi.

Sarebbero ancora tanti gli esempi di studi, iniziative, progetti più o meno recenti o in corso, purtroppo non è questa la sede in cui è possibile offrire un esaustivo stato dell'arte sulle analisi delle traiettorie delle rappresentazioni del Sud e della costruzione delle sue identità culturali ${ }^{10}$. Si tratta di un campo assai fecondo e si direbbe dai "confini", questi sì, assai larghi e permeabili.

Le vicende storiche che hanno strutturato il dualismo Nord-Sud anticipano l'Unità, l'attraversano e la superano: dall'età moderna alla globalizzazione, passando per la Rivoluzione francese, il Risorgimento, l'esperienza coloniale. Così come molteplici sono i fatti sociali che hanno dato forma all'identità nazionale ${ }^{11}$ : I'unificazione linguistica; la grande emigrazione esterna ed interna; l'esperienza del fascismo; il boom economico e infine l'immigrazione e la nuova grande crisi economica e istituzionale di fine Novecento e inizio XXI secolo. Proprio tali ultimi fatti ci richiamano ancora una volta a una dialettica Nord-Sud di ordine nuovo, o forse, rinnovato: il Sud del Mediterraneo guarda all'Italia e all'Europa come a un Nord carico di speranze e possibilità; viceversa, dall'altra sponda si scorge invece nell'Africa un elemento ansiogeno ${ }^{12}$, per un'invasione che non si è mai veramente realizzata ${ }^{13}$ se non nell'immaginario pubblico, come hanno raccontato le indagini demoscopiche degli ultimi anni.

La crisi economico-finanziaria originatasi negli Stati Uniti nel 2007/2008 e la successiva crisi del debito sovrano nel 2011 hanno riportato prepotentemente alla luce l'armamentario di stereotipi sui paesi mediterranei dell'Unione, sintetizzati nell'acronimo spregiativo Pigs, che se in una fase iniziale comprendeva anche la decisamente settentrionale Irlanda, si è ben presto ridotto a identificare unicamente Portogallo, Italia, Grecia e Spagna. La retorica moralizzante, inoltre, assunta dagli stati del

10. Vale la pena però menzionare almeno Lombardi-Diop e Romeo (2012); Contarini et al. (2018) e il recente numero di Narrativa curato da Marras e Pias (2017).

11. Concetto sicuramente assai sfuggente e precario, problematico e fuorviante, tuttavia, affascinante e onnipresente nei discorsi sullo stato delle nazioni.

12. Ci si consenta a tal riguardo di rimandare almeno al volume in cui si affronta proprio la trattazione mediatica della questione migratoria recente (Orrù, 2017).

13. Nel momento in cui scriviamo, le stime sulla popolazione straniera residente in Italia registrano una percentuale di circa l'8\% sul totale, in linea con il resto del continente, di cui circa la metà è di origine europea. Impossibile allo stato attuale, invece, definire il numero dei cosiddetti irregolari, le ipotesi più recenti parlano di circa 530mila persone (Ismu, 2019). 
Nord all'insegna dell'austerità ${ }^{14}$ da imporre ai paesi "spreconi" ${ }^{15}$ del Sud, altro non è che una versione aggiornata della visione egemonica del Nord a cui si faceva prima riferimento.

Per tornare, però, alla natura di questo contributo e ai suoi (limitati) scopi, quello che ci proponiamo di fare in questa sede è sondare un possibile percorso di studi che vada alla ricerca delle radici degli stereotipi discorsivi sulla "questione meridionale", o sul dualismo Nord-Sud, che dir si voglia, nelle indagini conoscitive, nei racconti sullo stato delle regioni meridionali, nelle corrispondenze e nei dibattiti parlamentari all'indomani dell'Unità. L'obiettivo è quello di offrire una riflessione critica che metta al centro il discorso, inteso nella sua duplice accezione di lingua in uso, cara alla linguistica, e di stratificazione e addensamento di pratiche linguistiche su un determinato fenomeno sociale, impiegata invece dalle scienze sociali, influenzate soprattutto dal pensiero foucaultiano e post-strutturalista.

Gli eventi recenti e le migrazioni ci interrogano sempre più sull'identità nazionale italiana, sempre ammesso che essa possa, o debba, essere veramente definita, ma viviamo un capitolo delle vicende collettive del Mediterraneo da cui è impossibile chiamarsi fuori, anche solo per ovvi motivi di vicinanza geografica, come studiosi e parte attiva della nostra società. Per affrontare questa sfida è però indispensabile provare a rileggere un momento significativo della storia moderna, nel momento in cui certe formazioni discorsive hanno preso corpo. E se da un lato sono stati mossi già passi importanti in altri campi delle scienze umane, l'analisi linguistica ci sembra ancora assente da questo genere di riflessioni critiche sui testi.

Nelle prossime pagine proveremo, dunque, ad offrire una piccola ricognizione dei periodi, dei testi e degli autori da sondare per avviare questo percorso di ricerca.

\section{Materiali e metodi per un'analisi della questione meridionale}

Prima di procedere a indicare una pur sommaria messe di testi e autori da indagare, sarà utile fornire una scansione temporale ragionata dei periodi da osservare. Come anticipato nell'introduzione, infatti, si tratta di almeno tre secoli di storia nazionale, dal XVIII al XX. Va da sé che ognuno di questi può essere poi ulteriormente frazionato e scandagliato più in profondità. Ci limiteremo qui a una prima suddivisione di massima, seppur grezza, assolutamente indispensabile per rendere maneggevole la domanda di ricerca.

14. Si veda a tal proposito l'analisi delle metafore della crisi economica su un corpus di articoli italiani e tedeschi in Ceffa e Rovere (2015).

15. Per citare solo due esempi recenti si pensi ancora alle dichiarazioni rilasciate alla Frankfurter Allgemeine Zeitung nel marzo del 2017 dell'allora Presidente dell'Eurogruppo Jeroen Dijsselbloem sul Sud Europa che "non può spendere tutti i soldi per alcol e donne e poi chiedere aiuto" (https://www.faz.net/aktuell/wirtschaft/wirtschaftspolitik/nach-interview-in-der-f-a-z-dijsselbloem-ich-bedauere-dass-es-als-nord-gegen-sued-aufgefasst-wurde-14937857.html) o al titolo di Der Spiegel del 24 maggio 2018: Die Schnorrer von Rom ovvero "Gli scrocconi di Roma". 
Il periodo pre-risorgimentale che va dal 1750 al triennio giacobino è fondamentale per la formazione di un'identità europea incentrata sul dualismo tra Nord e Sud del continente. Inoltre, l'esperienza dell'llluminismo e della Rivoluzione saranno cardinali per l'emersione del nazionalismo moderno. Come abbiamo accennato poco sopra, è questo il periodo in cui le descrizioni dell'Italia da parte dei viaggiatori stranieri iniziano a farsi più consistenti e allo stesso tempo più dure.

Molti storici individuano l'inizio della fase risorgimentale con la discesa della napoleonica Armata d'Italia nella Penisola, che diede l'avvio al cosiddetto "triennio giacobino" e a un profondissimo rimescolamento degli assetti politici e istituzionali esistenti. Come ricorda Banti, poi, «fu in quel periodo che alcuni ambienti politico-intellettuali formularono per la prima volta chiari progetti di costruzione di uno stato unitario, intorno ai quali si tentò anche di mobilitare energie e individui» (Banti, 2004: XII). La concitata fase segnata da ripetuti tentativi rivoluzionari che culminerà con le due guerre di indipendenza italiane e con il traguardo dell'Unità è per ovvi motivi quella più rilevante ai nostri fini; essa può essere estesa fino ai primi decenni successivi all'Unità, che vedranno da un lato una serie di iniziative importanti ${ }^{16}$ per il Mezzogiorno e una convulsa fase politica - contrassegnata dal trasformismo e dai governi della Sinistra storica - che rischierà a più riprese di porre fine anticipatamente alla neonata nazione.

La scelta per ora è quella di dare la precedenza proprio al periodo risorgimentale e ai primi 50 anni di Unità, prendendo in considerazione, dunque, il XIX secolo fino ai primi anni del Novecento, e dando per assodata la costruzione delle coordinate essenziali di Nord-Sud proposta dai paesi egemoni, soprattutto Inghilterra e Francia. II pensiero intorno alla questione meridionale inizia a delinearsi con nettezza immediatamente prima e dopo l'Unità. I primi 15 anni di esperienza unitaria sono quelli decisivi per l'origine del dualismo tra le due aree del Paese e vedono, soprattutto, lo svilupparsi del pensiero meridionalista attraverso le opere di Pasquale Villari, Leopoldo Franchetti e Sidney Sonnino.

Le ultime due fasi, che qui indichiamo solo in linea generale, corrispondono al Novecento, e più specificamente dalla fine della libertà con l'avvento del fascismo fino alla crisi istituzionale degli anni Novanta, e al primo ventennio degli anni Duemila. II XX secolo ha conosciuto momenti significativi del dualismo Nord-Sud: le migrazioni interne, il boom economico, la fondazione dei movimenti politici regionalisti e indipendentisti (di cui la Lega Nord è solo il caso più conosciuto). La stretta contemporaneità, come già menzionato, ha visto l'emergere di due fenomeni sociali e politici di indubbia salienza come l'immigrazione e il processo sempre più stretto di integrazione europea.

16. Facciamo qui riferimento ad esempio al varo delle leggi speciali per lo sviluppo di alcune regioni (Calabria, Sardegna) e dell'area industriale di Napoli, pensate e avviate da Francesco Saverio Nitti, tra i primi meridionalisti a ricoprire incarichi di governo nel periodo tra il 1911 e il 1920. Per un'agile ricostruzione del ruolo di Nitti e delle sue politiche si veda almeno Barbagallo (2016). 


\subsection{Materiali}

Detto del periodo da noi prescelto per le prime indagini, possiamo ora iniziare a indicare con più precisione una composita tipologia di testi da sottoporre all'analisi linguistica. Si tratta di una ricchissima varietà di generi testuali, che possiamo intanto raggruppare così:

- Testi istituzionali:

- inchieste conoscitive sulla situazione del Mezzogiorno;

- studi e osservazioni;

- dibattiti parlamentari.

- $\quad$ Testi privati e diplomatici:

- memorie;

- epistolari.

- Testi mediali:

- stampa.

In questa sommaria ripartizione si noterà subito l'assenza piuttosto evidente della letteratura, che un indubbio contributo ha dato allo sviluppo delle narrazioni e dei simboli del Risorgimento e alla costruzione dell'identità nazionale, soprattutto in virtù del ruolo del tutto particolare che essa ha rivestito nella storia linguistica del Paese; tuttavia, in questa fase e per meglio servire i nostri scopi ci rivolgeremo a quei testi che per loro natura hanno avuto un effetto diretto sull'azione politica, soprattutto parlamentare.

La questione meridionale e i problemi riscontrati nel Mezzogiorno, come si accennava, rimangono in qualche modo sottaciuti dai primi governi unitari. La tabuizzazione del discorso ha lo scopo di non mettere a rischio la precaria unità raggiunta con fatica e, inoltre, di non dare a vedere alle altre potenze europee le debolezze del Paese. Il passo di seguito, raccontato da Giustino Fortunato, ne dà una plastica esemplificazione:

tornata del 6 aprile 1865 della prima Camera italiana, quando un deputato piemontese, che non altro aveva osato dire se non di scorgere poca simpatia fra le varie regioni del nuovo Regno, dovè smettere tra' rumori e le generali disapprovazioni dell'assemblea! «Prego l'onorevole interpellante», esclamò corrucciato il presidente Cassinis, «di non esternare pensieri che sono altrettanto sconvenienti quanto infondati» \{Bene, bravo!). E il Lamarmora, presidente del Consiglio de' ministri: «Sorgo per protestare contro un'asserzione assolutamente contraria al vero, che mi fa credere che l'onorevole Michelini non sia andato più lontano di Moncalieri (Viva ilarità); perché se egli avesse come me viaggiato per le varie province del 
Regno, si sarebbe persuaso che l'Italia è unita molto più degli altri paesi da lungo tempo formati» (Ha ragione! Applausi) (Fortunato, 1911: 314).

Nonostante la tabuizzazione a cui abbiamo accennato, i dibattiti parlamentari dell'epoca possono sicuramente costituire un altro interessante versante di indagine; nella discussione di specifiche questioni contingenti, ad esempio le leggi speciali per la Calabria, la Sardegna, la Sicilia, i piani di industrializzazione di Napoli, ma anche i dibattiti sulle riforme elettorali e l'estensione del suffragio ${ }^{17}$.

La fase immediatamente successiva all'unificazione e all'annessione delle province meridionali fu affrontata minimizzando sostanzialmente i problemi che andavano via via emergendo nel rapporto tra le due aree del Paese. La pesante sconfitta elettorale delle destre al Sud nel 1874 significò una brusca presa di coscienza da parte dell'élite piemontese delle difficoltà di integrare in un quadro unitario e coeso realtà separate da secoli di storia. Si assiste così al fiorire di una serie di relazioni e corrispondenze di viaggio per accertare lo stato dei territori meridionali. Il fine è quello di comprendere meglio la situazione reale per individuare le aree maggiormente problematiche in cui intervenire.

Prende forma un vasto corpus di inchieste parlamentari e non - ma comunque di natura prettamente politica - sulle regioni del Sud. Tra tutte, le più note sono certamente quelle redatte da Leopoldo Franchetti e Sidney Sonnino che hanno trovato sistemazione nel volume La Sicilia nel 1876 (Franchetti e Sonnino, 1925), che comprende i due lavori Condizioni politiche e amministrative della Sicilia e i Contadini in Sicilia. Franchetti avviò tale impresa già nel biennio 1873-74 con i primi viaggi negli Abruzzi e nel Molise e successivamente in Calabria e Basilicata. Tra le prime inchieste vi fu, invece, la relazione preparata da Enrico Pani Rossi sulla Basilicata e pubblicata nel 1868. Altra opera fondamentale è quella del deputato Giuseppe Massari, figura di meridionale "piemontesizzato", che guidò l'inchiesta sul brigantaggio (pubblicata in Pedio, 1983).

Infine, va ricordata la monumentale opera della Inchiesta parlamentare sulle condizioni dei contadini nelle province meridionali e nella Sicilia, realizzata nei primi del Novecento, che in nove volumi raccoglie le relazioni svolte su richiesta del Parlamento sugli Abruzzi e il Molise, sulle Puglie, sulla Campania, sulla Basilicata e le Calabrie e sulla Sicilia. Di tutt'altro taglio è la ben nota trattazione di carattere antropologico-lombrosiano sulla devianza e sulla delinquenza in Sardegna di Alfredo Niceforo (1897 e ripubblicata nel 1977).

Alle inchieste si affiancano vari altri studi e raccolte di osservazioni personali di intellettuali e politici coevi, come, ad esempio, Governo e governati in Italia di Pasquale Turiello (1882) che «si occupò del Mezzogiorno non per capire e alleviare la sua miseria, ma perché il suo malessere sociale e politico era ritenuto il sintomo rivelatore di un vasto processo di disgregazione, che rischiava di rompere il già precario rapporto esistente tra governanti e governati» (Petraccone, 2000: 113), o gli scritti di Michele Torraca (1879) e Nicola Marselli (1882). Su stimolo di Pasquale Villari, anche scrittori come l'inglese

17. Si veda a questo proposito il lavoro di Pignotti (2017). 
Jessie White Mario e Renato Fucini si recarono a Napoli per riportarne le proprie sensazioni in opere come La miseria in Napoli (1877) e Napoli a occhio nudo (1877).

Il discorso politico è tra tutti quello che più ha la capacità di influire sulla realtà sociale e orientare l'opinione pubblica. Come accennato in precedenza, il parlamento unitario è uno dei luoghi più significativi per la formazione fattuale e discorsiva del dualismo. Ma è anche il luogo in cui a lungo, e soprattutto nella fase storica a cui facciamo riferimento, siede una rappresentanza altamente elitaria, espressione del ceto intellettuale e produttivo della nazione, formata e a contatto con le formulazioni discorsive di cui abbiamo ragionato in apertura di questo contributo. È nel parlamento che vengono prese le decisioni che saranno al centro delle rivendicazioni meridionaliste e dove vengono richieste e istituite le commissioni di inchiesta sullo stato delle province meridionali. È sempre in parlamento che prende vita la questione meridionale, affrontata inizialmente come una mera questione amministrativa e di ordine pubblico ${ }^{18}$, ma che dopo le tornate elettorali del 1874 e '76 diventerà una questione politica centrale fino ai giorni nostri ${ }^{19}$. Il portale storico della Camera dei deputati rende sicuramente agevole il reperimento di un vastissimo corpus di resoconti stenografici digitalizzati dal 1848 al 2018. Si tratta in questo caso di una mole di testi assai significativa, che richiede certamente un'ampia fase di ricerca, segmentazione e recupero dei dati.

Muovendo verso un'altra tipologia testuale, gli epistolari privati dei protagonisti politici dell'epoca e dei parlamentari si dimostrano una fonte interessante per confrontare il discorso pubblico con quello privato e rivelare aspetti ideologici e stereotipi condivisi dall'élite liberale. Da alcuni primi riscontri e dal confronto con la letteratura specializzata, l'epistolario di Cavour20 può rappresentare un buon punto di partenza; sembrerebbe essere, infatti, ricco di missive con alcuni tra i suoi più stretti collaboratori contenenti pareri, descrizioni, suggerimenti sullo stato delle cose nelle province napoletane. Tali scambi hanno svolto tra l'altro anche una funzione fortemente direttiva e hanno contribuito a orientare l'azione del governo. Un'analisi linguistico-discorsiva sul corpus del biennio ‘60-61 potrebbe in tal senso offrire nuovi interessanti sviluppi.

Altro oggetto di indagine tra i testi che abbiamo definito privati possono essere le memorie e i diari. Alcuni esempi, ricavati dalle fonti storiografiche ${ }^{21}$, sono le memorie, poi pubblicate, di alcuni ex garibaldini, come Da Quarto al Volturno di Giuseppe Cesare Abba²2, I Mille di Giuseppe Bandi o le Lettere garibaldine di Ippolito Nievo. Nei testi affiorano di tanto in tanto giudizi sprezzanti sullo stato delle province napoletane e sugli usi della popolazione. Ma le rappresentazioni stereotipiche del

18. Un primo sondaggio sul periodo tra marzo e dicembre del 1861 è stato svolto in Orrù (2019).

19. Per una ricostruzione della nascita della questione meridionale nel parlamento unitario si vedano Sagrestani (2014) e Pignotti (2019).

20. Le versioni integrali degli anni 1860 e '61 sono state pubblicate dall'editore Leo Olschki rispettivamente nel 2005 e nel 2008.

21. Cf. Petraccone (2000).

22. Ripubblicato da Sellerio nel 2010. 
Mezzogiorno possono essere rintracciate in testi apparentemente meno significativi come Le tribolazioni di un insegnante di Ginnasio di Placido Cerri²3, in cui un giovane insegnante piemontese viene mandato a prendere servizio a Bivona, piccola località della Calabria, e ne descrive le condizioni di totale sussistenza e inciviltà.

Infine, non possono essere esclusi da una ricerca di questo genere i testi mediali, e nello specifico la stampa. Del resto, l'opera fondamentale per l'avvio del meridionalismo, Le lettere meridionali di Villari, era il frutto proprio di una corrispondenza giornalistica. Pur nella precarietà dei mezzi, spesso artigianali, nelle ristrettezze imposte dalla censura dei governi locali e con l'enorme ostacolo dell'analfabetismo diffuso in tutta la penisola ${ }^{24}$, il periodo risorgimentale ha visto una notevole espansione delle pubblicazioni e ha contribuito alla creazione di uno spazio di discussione pubblica per gli intellettuali. Oltre ad essere lo strumento ufficiale di diffusione delle notizie politiche e delle novità legislative (attraverso le gazzette), i periodici del tempo ospitavano interventi e corrispondenze sul processo di unificazione e sulle difficoltà incontrate nel governo delle nuove province. Solo per fare un esempio, sui giornali torinesi, come la Gazzetta di Torino o la Gazzetta del popolo, appaiono nei primi mesi del 1861 numerosi articoli critici sulle popolazioni napoletane e sulla loro indole, così come più avanti fu data ampia copertura all'esplosione del brigantaggio. Tali fonti sono tanto più rilevanti se si considera lo strettissimo legame intrattenuto con il governo.

L'elenco di fonti qui fornito è da considerarsi meramente esemplificativo. Data l'estrema varietà e quantità di testi potenzialmente oggetto di analisi, l'inventario proposto non può che essere ancora parziale, in continuo ampliamento e soggetto a futura revisione. Tuttavia, nonostante le difficoltà imposte dalla ricchezza di tipologie testuali, essa è necessaria per poter valutare a pieno la forza e il radicamento degli stereotipi sul Mezzogiorno e l'effetto cumulativo nel loro potenziale presentarsi nelle medesime forme in contesti discorsivi differenti.

\subsection{Analisi del discorso}

Rimangono, infine, da delineare i metodi di analisi per una ricerca di così ampio raggio. La tradizione ormai assestata in Europa dell'analisi del discorso sarà senza dubbio il cardine dell'indagine. Il legame tra produzione linguistica e contesto d'uso nella sua accezione più ampia, includendo le forme dell'interazione, le conoscenze enciclopediche, gli aspetti cognitivi. Gli obiettivi dell'indagine che abbiamo prospettato nei paragrafi precedenti, però, ci inducono allo stesso tempo ad adottare una prospettiva non semplicemente descrittiva, di osservazione degli strumenti linguistici nel loro contesto situazionale e funzionale, ma che sia anche critica $^{25}$ e metta in relazione gli usi della lingua

23. Per una lettura più approfondita in questo senso rimandiamo a Stefanelli (2017).

24. Si rimanda a Serianni (1989: 33-ss) per una ricostruzione del ruolo della stampa nella diffusione e nell'evoluzione dell'italiano, e a Masini (1994) per una dettagliata analisi linguistica.

25. E della sua variante più impegnata, ovverosia l'analisi critica del discorso, la quale si configura più come una prospettiva e un movimento culturale che non una metodologia o un approccio sistematico (Van Dijk, 2001: 353-354). 
con il suo farsi veicolo di trasmissione di ideologie. Esse vanno intese qui non nella loro accezione comune di sistemi concettuali alla base delle varie formazioni politiche. Ci rifacciamo piuttosto alla teorizzazione delle ideologie come profonde e strutturate forme di «socially shared belief systems» elaborata da Teun Van Dijk (2013). Tale specificazione è utile a separare il funzionamento cognitivo delle ideologie dalla loro effettiva applicazione quotidiana, è parimenti fruttuosa per comprenderne meglio i meccanismi o di analizzarle concretamente nella loro realizzazione discorsiva. La struttura delle ideologie incorpora una serie di categorie fondamentali che orientano le credenze sociali dei gruppi e dei singoli soggetti26.

- Identità: Chi siamo? Chi appartiene al nostro gruppo? Chi sono i membri e chi può entrare nel gruppo?

- Attività: Che cosa dobbiamo fare? Qual è il nostro ruolo nella società?

- Obiettivi: Qual è l'obiettivo delle nostre attività?

- Norme e valori: Quali sono le norme che regolano le nostre attività? Cosa è buono e cattivo per noi?

- Relazioni tra gruppi: Chi sono i nostri amici e chi i nostri nemici?

- Risorse: Quali risorse simboliche o materiali formano le basi del nostro potere (o della sua assenza) e della nostra posizione nella società?

Le ideologie trovano dunque sbocco nel discorso quotidiano, quale che sia il canale, e, quando assumono i caratteri di un discorso egemonico, sedimentano fino a diventare senso comune. Il controllo sulla produzione discorsiva, soprattutto quando invisibile, viene progressivamente incamerato nella conoscenza condivisa, fino alla sua stereotipizzazione. Esattamente come avvenuto ai primordi della questione meridionale, quando l'élite settentrionale (in controllo del discorso) compone un mosaico di rappresentazioni che si consoliderà tanto nell'immaginario collettivo quanto nella successiva storiografia mainstream sull'Unità d'Italia.

L'analisi storico-discorsiva, messa a punto da Reisigl e Wodak, ${ }^{27}$ può offrire al ricercatore gli strumenti teorici e metodologici necessari per ricostruire questo percorso. Essa si basa un quadro comprensivo dei vari livelli linguistici di indagine, corroborati da una puntuale integrazione contestuale di dati storici, sociologici. Il livello macro ha come oggetto le condizioni storico-politiche ed economiche dello specifico contesto in cui agiscono e si formano i discorsi in oggetto. A livello intermedio, meso, vengono, invece, selezionate le pratiche discorsive e le tipologie testuali che caratterizzano i testi presi in esame e in accordo, va da sé, con l'obiettivo dell'analisi. Il livello micro consisterà, infine, nell'esame linguistico puntuale dei testi e sulla ricerca degli elementi caratterizzanti delle pratiche discorsive, prendendo in considerazione i vari livelli di analisi del linguaggio (lessico, retorica e metafore, deissi,

26. Nostra traduzione dello schema presentato in Van Dijk (2013: 178).

27. Si veda Reisigl e Wodak (2001). 
sintassi) e le strutture argomentative. Concretamente, per i nostri scopi, il livello macro corrisponderà al periodo storico e politico definito nella sezione precedente (dall'inizio del Risorgimento alla fine del XIX secolo); il livello meso comprenderà principalmente in una prima fase le tipologie testuali delle inchieste, dei dibattiti parlamentari e degli epistolari; il livello micro affronterà un'analisi linguistica il più accurata e comprensiva possibile.

Impresa non semplice, data la veste grafica di molti di questi testi, è quella di coniugare metodi di indagine qualitativa e quantitativa; ci riferiamo soprattutto all'impiego degli strumenti per l'analisi informatica dei testi elaborati nella tradizione della linguistica dei corpora. La ripulitura e sistemazione del corpus si rivelerebbe in certi casi assai complessa e richiederebbe una grande quantità di tempo. Tuttavia, la digitalizzazione e ripubblicazione di alcune fonti permette di combinare senza eccessiva difficoltà la classica analisi linguistica e stilistica con un approccio corpus based (Baker et al., 2008; Partington, 2004). I dati quantitativi e la ricerca statistica della preminenza linguistico-discorsiva di lessemi, collocazioni e costrutti sintattici in un corpus di testi omogenei per tipologia testuale o semplicemente semantica possono offrire chiavi di lettura che la sola intuizione personale potrebbe tralasciare. Ciononostante, può essere rilevante rimarcare come questo genere di analisi non sia intesa da noi come una sostituzione di metodi di lettura e indagine più tradizionali, ma vada considerato piuttosto un utile strumento integrativo (Biber, Conrad et Randi, 1998: 7-8). L'approccio quantitativo da solo, infatti, non può essere sufficiente a esaurire un'analisi linguistico-discorsiva.

\section{Considerazioni finali}

L'obiettivo del presente contributo è stato quello di avviare una riflessione che avvicini gli studi linguistici a una sempre più ampia bibliografia critica sulla questione meridionale. Riteniamo che il dualismo tra Nord e Sud del Paese sia uno dei temi sociali e politici più rilevanti nella storia italiana; la sua presenza attraversa l'intera storia unitaria fino ai giorni nostri, in cui il divario economico tra le due aree non fa che ampliarsi progressivamente.

La "questione" però non può essere ricondotta al solo caso italiano e alle sue vicende storiche, si inserisce in correnti di pensiero ben più ampie che hanno iniziato ad agire nei decenni precedenti al Risorgimento e che ancora oggi influenzano le dinamiche internazionali tra Nord e Sud del mondo.

Il programma di ricerca qui delineato, ancora in fieri, si intende aperto a modifiche e integrazioni, e trova spazio nel quadro degli studi sulle ideologie linguistiche, intese come manifestazioni linguistico-discorsive di sistemi cognitivi più ampi, costituiti da idee, stereotipi, atteggiamenti sui fenomeni extralinguistici. Attraverso la pervasiva presenza in tipologie testuali particolarmente salienti dal punto di vista della creazione e del mantenimento di posizione egemoniche, alcune forme linguistiche filtrano nel dibattito pubblico quotidiano, assumendo via via la caratura di conoscenza stereotipica condivisa e diventando vere e proprie costruzioni di senso comune. 
In un periodo storico come quello recente, in cui la posizione e il ruolo dell'Italia nel "mare di mezzo" sono tornati di estrema attualità, un'indagine ad ampio raggio sulla formazione dei discorsi che hanno strutturato la percezione odierna del dualismo Nord-Sud può apparire di sicura utilità epistemologica. 


\section{Bibliografia}

Abba, Giuseppe Cesare (2010), Da Quarto al Volturno, Palermo, Sellerio.

Baker, Paul et al. (2008), "A Useful Methodological Synergy? Combining Critical Discourse Analysis and Corpus Linguistics to Examine Discourses of Refugees and Asylum Seekers in the UK Press», Discourse and Society, vol. 19, n’3, p. 273-306.

Banfi, Emanuele (2017), Italiano e altre varietà italo-romanze in Europa e nel Mediterraneo nel secolo XIX, Firenze, Franco Cesati.

Banti, Alberto Mario (2004), Il Risorgimento italiano, Roma-Bari, Laterza.

Banti, Alberto Mario et al. (eds.) (2011), Atlante culturale del Risorgimento. Lessico del linguaggio politico dal Settecento all'Unità, Roma-Bari, Laterza.

Barbagallo, Francesco (2013), La questione italiana: il Nord e il Sud dal 1860 a oggi, Roma-Bari, Laterza.

Barbagallo, Francesco (2016), «Nitti e il Mezzogiorno tra politica ed economia», in Sabino Cassese (ed.), Lezioni sul meridionalismo. Nord e Sud nella storia d'Italia, il Mulino, Bologna, p. 103-114.

Biber, Douglas, Conrad, Susan et Randi Reppen (1998), Corpus Linguistics: Investigating Language Structure and Use, Cambridge, Cambridge University Press.

Braudel, Fernand (1992), Civilization and Capitalism, 15-18th Century, Los Angeles, University of California Press.

Cafagna, Luciano (1988), «Modernizzazione attiva e modernizzazione passiva», Meridiana, 2, p. 229240.

Cavour, Camillo (2005), Epistolario. Vol. XVII (1860), Firenze, Leo Olschki.

Cavour, Camillo (2008), Epistolario. Vol. XVIII (1861), Firenze, Leo Olschki.

Cazzato, Luigi (2017), Sguardo inglese e Mediterraneo italiano. Alle radici del meridionismo, Milano, Mimesis.

Ceffa, Sabina e Giovanni Rovere (2015), «La crisi economica europea nella stampa tedesca e italiana. questioni metodologiche di analisi discorsiva», Studi italiani di linguistica teorica e applicata, vol. 44, n², p. 199-226.

Chambers, Iain (2007), Le molte voci del Mediterraneo, Milano, Raffaello Cortina.

Contarini, Silvia et al. (eds.) (2018), Da ieri a oggi. Tragitti del Sud nella cultura italiana contemporanea, Firenze, Franco Cesati.

De Seta, Cesare (2014), L'Italia nello specchio del Grand Tour, Milano, Rizzoli.

Fortunato, Giustino (1911), Il Mezzogiorno e lo stato italiano. Discorsi politici (1880-1910), vol. II, Bari, Laterza. 
Franchetti, Leopoldo e Sidney Sonnino (1925), Inchiesta in Sicilia, Firenze, Vallecchi.

Fucini, Renato (1921), Napoli a occhio nudo, Firenze, Vallecchi.

Gioberti, Vincenzo (1848), Del primato morale e civile degli italiani, Napoli, Stabilimento Tip. e Calc. di C. Batelli e comp.

Ismu (2017), Ventiquattresimo rapporto sulle migrazioni (2018), Milano, Franco Angeli.

Lombardi-Diop, Cristina e Caterina Romeo (eds.) (2014), L'ttalia postcoloniale, Firenze, Le Monnier.

Lupo, Salvatore (2015), La questione. Come liberare la storia del Mezzogiorno dagli stereotipi, Roma, Donzelli.

Marras, Margherita e Giuliana Pias (eds.) (2017), Nuove frontiere del Sud Genesi e sviluppo di un pensiero plurale sul Sud nella letteratura e nella cultura dell'ttalia contemporanea, Narrativa, vol. 39.

Marselli, Nicola (1882), La politica dello Stato italiano, Napoli, Morano.

Masini, Andrea (1994), «La lingua dei giornali dell'Ottocento», in Luca Serianni e Pietro Trifone (eds.), Storia della lingua italiana, vol. II: Scritto e parlato, Torino, Einaudi, p. 635-665.

Mignolo, Walter (2007), «Delinking. The rhetoric of modernity, the logic of coloniality and the grammar of de-coloniality», Cultural Studies, vol. 21, n² 2-3, p. 449-514.

Moe, Nelson (2004), Un paradiso abitato da diavoli. Identità nazionale e immagini del Mezzogiorno, Napoli, L'ancora del Mediterraneo.

Moscovici, Serge (1981), «On Social Representation», in Joseph P. Forgas (ed.), Social Cognition: Perspectives on Everyday Understanding, London, Academic Press, p. 181-210.

Niceforo, Alfredo (1977), La delinquenza in Sardegna: note di sociologia criminale, Cagliari, Edizioni della Torre.

Orrù, Paolo (2017), Il discorso sulle migrazioni nell'Italia contemporanea: un'analisi linguistico-discorsiva sulla stampa (2000-2010), Milano, Franco Angeli.

Orrù, Paolo (2019), «Leggere la questione meridionale alle sue origini: analisi linguistica e discorsiva dei dibattiti parlamentari nell'Italia postunitaria», in Id. (ed.), Vecchie e nuove questioni: il dualismo Nord-Sud in epoca contemporanea, Firenze, Franco Cesati, p. 105-132.

Partington, Alan (2004), «Corpora and Discourse, a Most Congruous Beast», in Alan Partington, John Morley and Louann Haarman (eds.), Corpora and Discourse, Bern, Peter Lang, p. 11-20.

Pedio, Tommaso (1983), Inchiesta Massari sul brigantaggio, Manduria, Lacaita.

Petraccone, Claudia (2000), Le due civiltà. Settentrionali e meridionali nella storia d'Italia dal 1860 al 1914, Roma-Bari, Laterza.

Pignotti, Marco (2017), La moltitudine apolitica. Culture politiche e voto alle masse in età giolittiana (1904-1913), Firenze, LeMonnier. 
Pignotti, Marco (2019), «Dall'inchiesta Franchetti-Sonnino sulla Sicilia ai dibattiti parlamentari: il Mezzogiorno nel dibattito pubblico dell'Italia postunitaria», in Paolo Orrù (ed.), Vecchie e nuove questioni: il dualismo Nord-Sud in epoca contemporanea, Firenze, Franco Cesati, p. 195-204.

Quijano, Anibal (2007), «Coloniality and Modernity/Rationality», Cultural Studies, vol. 21, n² 2-3, p. 168-178.

Reisigl, Martin e Wodak, Ruth (2001), Discourse and discrimination: Rhetorics of Racism and AntiSemitism, London and New York, Routledge.

Sagrestani, Marco (2014), «La questione meridionale nel dibattito parlamentare della prima legislatura unitaria», in Gabriele Paolini (ed.), La prima emergenza dell'Italia unita. Brigantaggio e questione meridionale nel dibattito interno e internazionale nell'età della destra storica, Firenze, Polistampa, p. 51-78.

Said, Edward (1978), Orientalism, London, Penguin.

Serianni, Luca (1989), Il primo Ottocento, Bologna, II Mulino.

Serianni, Luca (2012), «Lingue e dialetti d'Italia nella percezione dei viaggiatori sette-ottocenteschi», in Id., Viaggiatori, musicisti, poeti. Saggi di storia della lingua italiana, Milano, Garzanti, p. 55-88.

Stefanelli, Diego (2017), «Le Tribolazioni di un insegnante di Ginnasio di Placido Cerri», in Stefano Lazzarin e Agnès Morini (eds.), Maitres, précepteurs et pédagogues. Figures de l'enseignant dans la littérature italienne, Bern, Peter Lang, p. 83-100.

Torraca, Michele (1879), I meridionali alla Camera, Napoli, De Angelis.

Turiello, Pasquale (1882), Governo e governati in Italia, Bologna, Zanichelli.

Van Dijk, Teun Adrianus (2001), «Critical Discourse Analysis», in Deborah Schiffrin, Deborah Tannen and Heidi Hamilton (eds.), Handbook of Discourse Analysis, Oxford, Blackwell, p. 352-371.

Van Dijk, Teun Adrianus (2013), «ldeology and Discourse», in Michael Freeden, Lyman Tower Sargent and Marc Stears (eds.), The Oxford Handbook of Political Ideologies, Oxford, Oxford University Press, p. 175-196.

Venturi, Pietro (1973), «L'Italia fuori d'Italia», in Ruggiero Romano e Corrado Vivanti (eds.), Storia d'Italia, vol. III, Torino, Einaudi, p. 987-1481.

Verga, Marcello (2011), «Decadenza», in Alberto Mario Banti, Antonio Chiavistelli, Luca Mannori e Marco Meriggi (eds.), Atlante culturale del Risorgimento. Lessico del linguaggio politico dal Settecento all'Unità, Roma-Bari, Laterza, p. 5-18. 


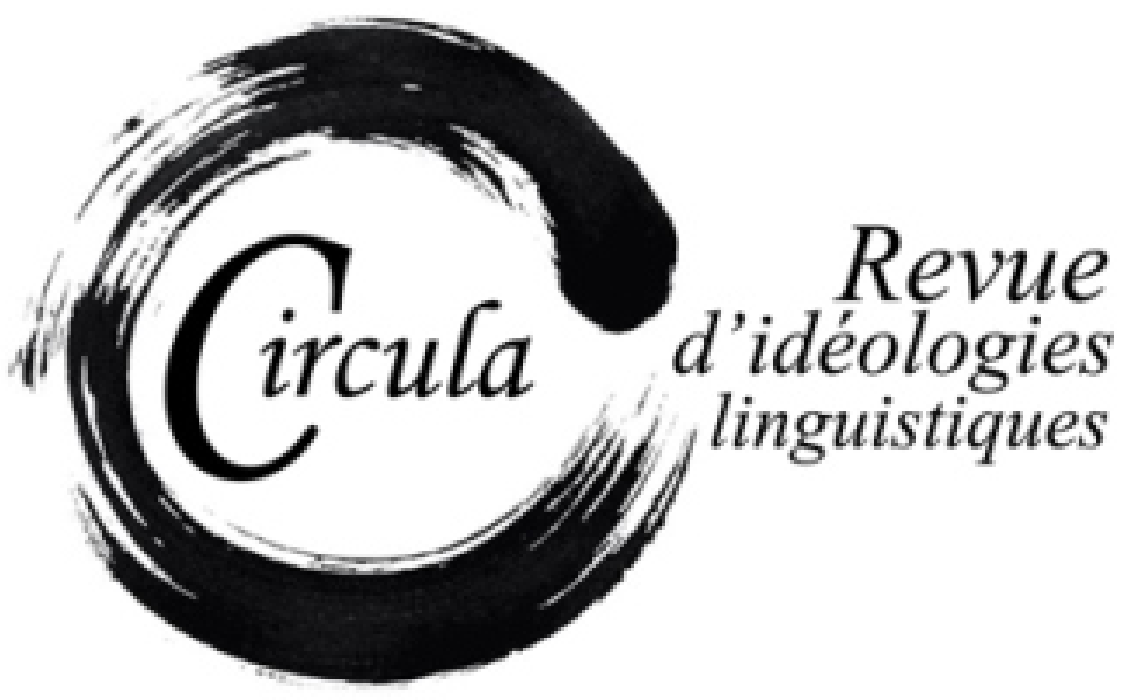

TITRE: NUOVE IDEOLOGIE, NUOVE AUTORITÀ IN CONTESTO EUROPEO: I DISCORSI POLEMICI DI GRILLO E DIEUDONNÉ

Auteures: Sara Amadori, Università di Bergamo et Cristiana De Santis, Università di Bologna Revue: CIRCULA, NUMÉRO 10

PAgES: $41-63$

ISSN: 2369-6761

URI: HTTP://HDL.HANDLE.NET/11143/16773

DOI: HTTPS://DOI.ORG/10.17118/11143/16773 


\title{
Nuove ideologie, nuove autorità in contesto europeo: i discorsi polemici di Grillo e Dieudonné
}

Sara Amadori, Università di Bergamo sara.amadori@unibg.it

Cristiana De Santis, Università di Bologna cristiana.desantis@unibo.it

Riassunto: Il lavoro analizza e mette a confronto le strategie comunicative di due comici prestati alla politica: il francese Dieudonné e l'italiano Beppe Grillo. I nuovi canali messi a disposizione dal web hanno consentito ai due personaggi di superare l'ostacolo rappresentato dalla "messa al bando" dai media tradizionali e di diffondere in modo virale discorsi ad alto potenziale polemico, la cui forza impressiva si affida anche alla dimensione iconica e al gesto ad effetto. Si è constatato che l'ethos da polemista, che caratterizza i discorsi di entrambi i leader, tende a sfociare in scelte retoricoargomentative riconducibili al genere del pamphlet. L'articolata retorica discorsiva dei due leader si è dimostrata capace di risvegliare un pathos negativo nei rispettivi seguaci, che, riconoscendo in loro figure dotate di una nuova autorità, tendono ad aderire incondizionatamente a nuove ideologie, di cui, sebbene in contesti socio-culturali diversi, i nuovi media sanno farsi potente veicolo di diffusione.

Parole chiave: analisi del discorso; discorso polemico; lingua della politica; autorità; vecchi e nuovi media

\begin{abstract}
This study focuses on the communicative strategies that Dieudonné and Grillo use in their public discourse. Both the Italian and the French leader have been comedians, and have recently become protagonists of public debates in their countries. Both of them exploit the Web to spread their polemical discourses, which have proven to be viral in the era of liberalization of obscene language, insults, cries, and provocative gestures against the establishment. The polemical ethos which characterizes Grillo's and Dieudonne's discourses tend to become more and more violent, and to acquire features typical of the pamphlet. This study shows that their well-organized rhetoric has been able to awaken a negative pathos in their followers, who appreciate their new and more modern forms of authority. That is why they become all-out supporters and easily tend to adhere to new ideologies, which become viral due to the new media.
\end{abstract}

Keywords: discourse analysis; polemics; political discourse; authority; traditional and new media 


\section{Introduzione ${ }^{1}$}

L'avvento del web 2.0 ha profondamente modificato gli spazi pubblici dedicati al dibattito democratico, determinando un cambiamento radicale delle sue forme così come il manifestarsi di nuove pratiche militanti e fenomeni di mobilitazione di massa. In quanto spazio di libera espressione, Internet ha alimentato il mito della possibile realizzazione di una 'democrazia digitale', favorendo la diffusione virale di discorsi ad alto potenziale polemico (Paveau, 2016) che acquistano spesso i tratti di una 'iper-polemica' mediatica (Amossy / Burger, 2011), il cui carattere distintivo è la forma di comunicazione 'spettacolare'.

Questo contesto ha favorito l'emergere sulla scena politica di nuovi attori contestatari e la formazione di movimenti politici guidati da nuovi leader carismatici, che in alcuni casi provengono proprio dal mondo dello spettacolo: ne sono esempi Beppe Grillo in Italia e Dieudonné in Francia.

In entrambi i casi, si può parlare di «populismo digitale» (Santoro, 2012), con la differenza che il popolo cui Grillo fa riferimento è il popolo 'sovrano', che viene incitato a ribellarsi contro la 'casta' dei politici e a riprendersi il potere tramite la partecipazione diretta consentita dalla Rete ${ }^{2}$; la comunità di protesta di Dieudonné, invece, si definisce innanzitutto in termini di appartenenza etnica: criterio cui il leader fa appello al fine di individuare un nemico comune.

L'affinità tra i due risiede soprattutto nella capacità di sfruttare la loro presenza mediatica re-investendola sul Web, nonché nelle strategie comunicative scelte per veicolare i propri contro-discorsi polemici. Entrambi insistono infatti sulla censura di cui sarebbero vittime, e sulla loro 'messa al bando' dai canali di comunicazione 'istituzionali', che per Grillo risale al 1986 (quando il comico fu espulso dalla RAl per aver attaccato durante uno spettacolo di varietà l'allora leader del Partito Socialista Bettino Craxi). Gli spettacoli teatrali sono diventati da allora il canale privilegiato di comunicazione col suo pubblico, fino alla creazione nel 2005 di un fortunato blog (beppegrillo.it) da cui Grillo lancia i suoi proclami politici - sia attraverso post (scritto trasmesso) sia in forma di videomessaggi (parlato trasmesso) -, commenta fatti di attualità e prende posizione su temi che gli stanno a cuore (salute, ecologia, mobilità). A partire dal 2009, anno di nascita del Movimento 5 stelle (d'ora in poi M5s), il blog di Grillo è diventato il principale spazio di socializzazione, discussione e organizzazione tra gli iscritti al nuovo movimento politico (Sedda, 2015).

Dieudonné è stato uno dei comici più amati e seguiti in Francia negli anni Novanta, sia a teatro sia sugli schermi televisivi (Robin 2014: 10), fino alle affermazioni antisemite fatte nel 2003, nel corso di un talk show televisivo trasmesso da una rete nazionale, che hanno determinato la messa al bando del comico dalla tv e l'interdizione di alcuni suoi spettacoli. Di qui la ricerca di uno spazio di libera

1. Le autrici hanno discusso insieme i temi di questo articolo e scritto a quattro mani Introduzioni e Conclusione. II $\$ 2$ si deve a Sara Amadori, il \& 3 a Cristiana De Santis.

2. Sul populismo "all'italiana" rimandiamo inoltre ai lavori di Campus (2006) e Cedroni (2010). 
espressione sul web e la creazione di un canale Youtube, battezzato iamdieudo, che ha avuto milioni di visualizzazioni, con un livello di audience comparabile a quello delle principali reti televisive nazionali francesi (Robin, 2014: 168). Chiuso nel 2014 (in seguito alla pubblicazione del video Feu Foley, in cui ironizzava sulla decapitazione di un giornalista americano da parte dello stato islamico) è stato riaperto con un nuovo nome, Dieudonné Officiel ${ }^{3}$.

L'oggetto di questo articolo è l'analisi di alcuni video dei due polemisti, ascrivibili all'«ipergenere» (Maingueneau 2014: 136-138) del «video-blogging» (Burgess / Green, 2009: 94).

Per quanto riguarda il comico francese, focalizzeremo la nostra attenzione su una selezione dei video pubblicati da Dieudonné sul canale Youtube iamdieudo prima della sua chiusura $(2014)^{4}$ e di nuovi video comparsi più recentemente sul nuovo canale Dieudonné Officiel (2019)5. Si tratta di video autoprodotti in cui Dieudonné, grazie alla tecnica del collage e al montaggio di discorsi decontestualizzati, mette in ridicolo i suoi avversari.

Di natura più eterogenea i video contenuti nel blog di Grillo (alcuni dei quali ritrasmessi su La cosa, la web tv del $\mathrm{MSs}^{6}$, e talvolta anche su Youtube): dirette di riunioni dei gruppi parlamentari o degli interventi in aula dei deputati del M5s, estratti dei comizi di Grillo e dei suoi spettacoli, video in cui Grillo monologa di fronte alla videocamera. Una selezione di questi monologhi - esempi di «video-blogging» comparabili con quelli del comico francese e riferiti allo stesso arco temporale costituirà l'oggetto dell'analisi, insieme ad alcuni post pubblicati da Grillo negli stessi periodi presi in esame per il comico francese?

Il quadro teorico e metodologico di riferimento è quello dell'analisi del discorso di scuola francese. Fondamentale sarà la prospettiva retorico-argomentativa proposta da Amossy (2017, 2010a), che invita a ripensare la polemica come una modalità argomentativa a tutti gli effetti. L'analisi del corpus sarà di tipo prettamente qualitativo, e farà emergere diversi punti di affinità tra le strategie argomentative e le scelte linguistiche e retoriche ricorrenti nei discorsi di Grillo e Dieudonné. La volontà di condurre un'analisi qualitativa deriva, da un lato, dall'esistenza di precedenti studi di tipo quantitativo (Amadori, 2014, 2016), che prendono in considerazione la diffusione virale dei discorsi dei due comici nei relativi contesti socio-culturali, e dall'altro, dal desiderio di rendere evidente quanto i

3. Consultabile all'indirizzo: https://www.youtube.com/channel/UCHRPg4LxfQGag83gQWfXYAQ [ultima consultazione 23/10/2019]

4. I video 'censurati', scaricati e salvati offline prima dell'eliminazione dalla piattaforma, sono ancora disponibili online, poiché ricaricati dallo stesso Dieudonné sul suo nuovo canale Youtube.

5. Si veda nella sitografia finale la parte relativa al "Corpus francese".

6. http://www.chickybox.com/LaCosa. Sul sito si legge la seguente presentazione: «LaCosa è un Web Channel nato il 22 gennaio 2013. Ė un canale di contenuti video e di dirette streaming, con all'interno rubriche e programmi originali prodotti o selezionati dalla Rete. LaCosa presenta, senza filtri, una visione sociale e politica unica con produzione di programmi in diversi settori dell'informazione e dell'intrattenimento con l'obiettivo di realizzare un palinsesto a $360^{\circ}$ su economia, ambiente, società ed altri ambiti alternativi all'omologazione dei tradizionali strumenti di comunicazione di massa».

7. Si veda nella sitografia finale la parte relativa al "Corpus italiano". 
nuovi media favoriscano il ricorso da parte di questi nuovi capi carismatici a un discorso polemico di natura plurisemiotica particolarmente suggestivo.

\section{Ethos discorsivi a confronto}

\subsection{La postura del panflettista}

Il ricorso da parte di Grillo e di Dieudonné allo strumento del «video-blogging» è di per sé significativo: si tratta di una scelta anti-istituzionale, che esprime un'esigenza di orizzontalità, in accordo con una nuova visione dell'autorità politica di cui diremo più avanti (§3).

Il contro-discorso polemico di Dieudonné è apertamente critico nei confronti della classe politica francese e dei media tradizionali: Dieudonné si presenta come il portavoce e il difensore delle vittime di una democrazia ai suoi occhi irrimediabilmente corrotta, che non merita più di essere definita tale. Nel video Dieudonné répond à Yann Barthès (noto presentatore televisivo francese) il polemista parla della democrazia francese come di una «vieille prostituée» a cui «aujourd'hui on n[e] croit plus» (min. 1.40-1.45). Secondo il polemista, la Francia sarebbe stata discreditata da un complotto americano-sionista, e la lobby sionista sarebbe l'unica vera detentrice del potere politico e mediatico. In questo stesso video (a partire dal min. 2.03), parlando della visita di Hollande in Israele, Dieudonné ironizza sull'atteggiamento di prostrazione del capo di Stato francese, che si atteggia come uno scolaretto davanti ai suoi maestri. Nel più recente video Gilets jaunes: contre la dictature, torna la critica alla democrazia francese, decadente e corrotta, definita fin dal titolo «dictature», poi una «farse» (min. 2.54) e un «empire» (min. 2.39). L'attacco ad hominem al Presidente della Repubblica resta una costante della retorica dell'umorista: «Le très controversé Emmanuel Macron» sarebbe, a suo dire, «président d'un peu moins de 5\% des français et de quelques irréductibles zombies» (a partire dal min. 3.03). Macron, proprio come Hollande, sarebbe inoltre manipolato dal sistema sionista, e viene definito una «marionette de la finance» (min. 3.43).

Nei discorsi di Dieudonné svolgono un ruolo di primaria importanza, oltre alla visione crepuscolare della società attuale, all'atteggiamento vittimista e alla teoria del complotto, diverse logiche argomentative messe in evidenza in uno studio di Marc Angenot (2010): il ragionamento fondato sull'utopia, ad esempio, o l'appello costante - che si nutre delle logiche del risentimento - a una rivoluzione imminente e inevitabile ${ }^{8}$. Così recita una canzoncina intonata con la moglie nel video Merci Manu!, che può essere considerata un vero e proprio inno rivoluzionario: «Le vent du changement, révolution naturelle, / Il est là, je le sens, [...] c'est le vent du combat / Pour l'émancipation des populations nègres, / Et des jaunes et des blancs pour l'humanité». Nel video Gilets jaunes: quenelle christique (a partire dal min. 2.37), Dieudonné riprende a distanza di tempo le parole della canzone, rinnovando

8. Come spiega Angenot (2010: 40), «la rhétorique du ressentiment sert deux fins concomitantes: démontrer la situation présente comme injustice totale, persuader de l'inversion des valeurs qui se trouve à son principe et expliquer la condition inférieure des siens en renvoyant ad alteram partem tous les échecs essuyés». 
l'appello alla rivolta: «Un vent nouveau, oui, un vent nouveau souffle sur la planète et balaye sur son passage l'ordre établi, les ordres établis, [...] au service du mensonge, du vice, de la perversion [...] Ce vent nouveau nous pousse chaque semaine à enfiler un gilet jaune, [...] pour manifester notre espoir de dignité, de vivre dignement putain! c'est trop demander??? ».

Affermazioni di questo tipo sono finalizzate a costruire quello che Angenot definisce «ethos du pamphlétaire», i cui tratti caratteristici sono:

[l]'image paradoxale que le pamphlétaire se donne de son mandat, la vision crépusculaire du monde qui lui est axiomatique, la coexistence établie entre persuasion et «violence verbale», la liaison entre vérité-liberté-solitude, le fait que le pamphlet se présente comme un discours opposé à celui de l'Autorité et du Pouvoir tout en reproduisant de façon terroriste leurs traits [...] (Angenot, 1982: 337).

Grillo, per parte sua, supportato e ispirato dall'ideologo del M5s Roberto Casaleggio, ha da sempre presentato la sua impresa come anti-sistema e anti-politica, proiettando nei i suoi discorsi un ethos comparabile a quello di Dieudonné (Amadori, 2014). Quella che i 5 stelle chiamano 'democrazia digitale', 'diretta', 'dal basso', si configura come il tentativo di riappropriarsi, attraverso la ridefinizione del sistema democratico, di tutto ciò di cui i cittadini sono stati defraudati. Come sottolinea Angenot (1982: 41):

Le pamphlétaire est quelqu'un à qui on a "volé" son langage. Il parle de [...] "liberté", de "démocratie"... Mais ceux qu'il attaque, les défenseurs de l'imposture, n'en ont-ils pas plein la bouche de ces mots-là ? Certes, il lui faudra [...] reconquérir un langage pris en otage par le monde du scandal.

La nascita della 'democrazia digitale' è l'utopia che fonda tutti i discorsi degli esponenti del M5s'. Ogni tentativo di ostacolarne l'avvento è, per il M5s, una forma di complotto da parte di una classe politica corrotta, che non è disposta a rinunciare ai suoi privilegi. Nel suo Messaggio di fine anno 2014, Grillo riprende le principali logiche argomentative cui abbiamo appena accennato: dopo aver parlato di un «attentato alla democrazia o alla Costituzione» (min. 1.05) ad opera di partiti complottisti come «Forza Italia o Forza Mafia» (min. 3.15), afferma: «Noi siamo quelli per la democrazia dal

9. Come spiega Casaleggio (Danna, 2013) «La Rete rende possibili due estremi: la democrazia diretta con la partecipazione collettiva e l'accesso a un'informazione non mediata, oppure una neo-dittatura orwelliana in cui si crede di conoscere la verità e di essere liberi, mentre si ubbidisce inconsapevolmente a regole dettate da un'organizzazione superiore. [...] Vanno ripensate le istituzioni e la società nel medio termine. Tutto cambierà [...]. Ė una rivoluzione prima culturale che tecnologica, per questo, spesso, non viene capita». 
basso, condivisa» (min. 4.37), fondando cosi la sua argomentazione sulla ridefinizione di democrazia ampiamente circolante nell'“interdiscorso"10 del M5s.

Nel video, Grillo appare solo all'interno di una grotta, in una penombra che allude alla visione crepuscolare della società attuale (tema che caratterizza tutti i suoi discorsi) ${ }^{11}$ e contribuisce a creare l'atmosfera sovversiva confermata dalle sue parole (a partire dal min. 0.10):

Siamo nel nuovo ufficio della Casaleggio Associati. Siamo qua dentro in una specie di catacomba dove aleggiano gli spiriti, [...] quelli buoni. Noi siamo qua dentro per [...] cospirare, parlare di cose che sono assolutamente proibite fuori, o pericolose: onestà, lealtà [...] queste cose che ormai fuori vengono percepite come rivoluzionarie o eversive. Noi siamo i veri eversori.

Con queste parole, Grillo si presenta come il portavoce di una verità accecante e assoluta, che i detentori del Potere e dell'Autorità rifiutano. La sua, così come quella dei suoi seguaci, è una «vox clamans in deserto», come direbbe Angenot (1982: 42), una voce profetica e solitaria, che gli altri non vogliono ascoltare perché troppo fastidiosa nella sua autenticità. Lo conferma del resto Grillo in questo stesso video (min. 3.33): «noi in Parlamento ci hanno preso in giro, ci hanno messo in un angolo, andiamo sui tetti, facciamo provocazioni, [...] cerchiamo di far conoscere quello che succede veramente dentro».

\subsection{Il ricorso all'insulto gestuale}

Il contro-discorso di Grillo si fonda su una doxa diffusa in Italia che rappresenta la classe politica come oligarchica, corrotta e decadente. Esibendo la sua indignazione e la sua collera, il polemista cerca di risvegliare un 'pathos negativo' nel suo pubblico (Santone, 2014: 90), per provocarne l'indignazione e suscitarne il risentimento. I partiti rappresentano una forma di complotto legalizzato e costituiscono per Grillo «l'ennemi unique» (Angenot, 2010: 41). Il leader attacca ossessivamente quella che chiama la 'Casta', servendosi del potente strumento retorico-argomentativo dell'amalgama', strategia che consiste nel "fare di ogni erba un fascio", ovvero nel riunire sotto un vocabolo sintetico (spesso ambiguo), e in un'unica categoria, un insieme di persone o cose di diversa natura,

10. II termine francese interdiscours, che abbiamo qui tradotto alla lettera, fa riferimento a un concetto dell'analisi del discorso di scuola francese. Come spiega Dominique Maingueneau (2002, 324), «tout discours est traversé par l'interdiscursivité, il a pour propriété constitutive d'être en relation multiforme avec d'autres discours, d'entrer dans l'interdiscours. Ce dernier est au discours ce que l'intertexte est au texte».

11. L'analisi realizzata da Sedda dei comunicati politici di Grillo pubblicati sul suo blog nella sezione dedicata al M5s conferma ampiamente la visione decadente del sistema politico attuale propugnata dal leader: «L'analyse menée sur ce corpus nous a [...] permis de constater une primauté absolue du lexique 'négatif' (renvoyant à la mort, au passé, au néant, à la fiction) par rapport au lexique 'positif' (renvoyant à la vie, au futur, à l'activisme, à l'authenticité). La quasi totalité des expressions négatives s'adresse à la classe politique du pays, identifiée en tant que source primaire de domination et d'aliénation politique mais aussi d'injustice, d'immobilisme et de crise économique et morale» (Sedda, 2015) 
o di fenomeni distinti, talora ritenuti estranei tra di loro'12. È alla Casta, ai suoi privilegi e alle sue gerarchie, alle sue scelte di politica interna ed estera, al suo controllo dei media tradizionali, che Grillo rivolge l'insulto del vaffa (anche accompagnato o sostituito dal cosiddetto 'gesto dell'ombrello'): sberleffo giullaresco che, da forma di provocazione verbale, si trasforma presto nella parola-chiave di una «lingua dell'esasperazione» (Ceccarelli, 2012) ${ }^{13}$, nonché in "parola-slogan"14 (Santone, 2015: 16) perno della polemica antigovernativa e simbolo identitario del M5s (specie nella versione abbreviata e attenuata $V$, integrata nel logo del moVimento). Non a caso, il linguista Giuseppe Antonelli (2017: 6) ha inserito il vaffa tra i cosiddetti «emologismi», "parole-icone» che veicolano in modo diretto le emozioni (in questo caso l'urlo di rabbia) ${ }^{15}$. Con questi valori la parola e il gesto del vaffa ricorrono al min 7.48 del video Messaggio di fine anno 2014.

Anche Dieudonné fa ampio ricorso alla strategia argomentativa dell'amalgama per colpire il suo 'nemico unico': la presunta lobby sionista. Nei suoi video, così come nei suoi spettacoli, l'umorista gioca sulla coincidenza implicita tra gli aggettivi 'antisemita' e "antisionista», astuzia che gli ha permesso in diverse occasioni di non essere perseguito penalmente. L'analisi dei video Youtube consente di rilevare il ricorso frequente da parte del polemista agli stereotipi che definiscono i miti fondatori della giudeofobia moderna secondo Taguieff (2008: 247-248). È sufficiente ascoltare i primi due minuti del video Dieudonné répond à Valls 2 per constatarne l'elevata frequenza: è agli ebrei che si rivolge la quenelle $e^{16}$, il gesto virale e offensivo diffuso da Dieudonné (al min. 0.35 di questo stesso video). Il gesto diventa in questo contesto anche una riproduzione blasfema della croce, con riferimento implicito all'accusa rivolta agli ebrei di essere gli assassini di Cristo, ed è rinforzata dall'affermazione che segue: «Jésus a chassé les marchands du temple [...] Le problème est qu'il sont revenus. Ils ont rasé le temple et ils ont construit une banque à la place» (a partire dal min. 0.52).

12. «L'amalgame [...] consiste à rassembler sous une vocable synthétique un mélange de personnes ou de choses perçues d'abord comme de natures différentes. Des phénomènes distincts, parfois tenus pour étrangers les uns aux autres, sont intégrés dans une catégorie unique - pour parler vulgairement, ils sont mis dans le même sac» (Angenot, 1982: 127).

13. In questa lingua ricorrono spesso del resto verbi corrispondenti all'insulto come (s)fanculare o (s)fanculizzare.

14. Sulla sloganizzazione nel discorso politico contemporaneo si rimanda a De Santis (2019).

15. lo grido si intitola del resto una sezione del blog di Grillo. In un'intervista recente, rilasciata a Sky news UK il 15 gennaio in occasione dell'accordo parlamentare sulla Brexit (sostenuto da Grillo), il comico è tornato inoltre sulla valenza politica del gesto, definendolo espressione di un diritto all'urlo: «La gente era arrabbiata e il Movimento 5 stelle ha dato loro il diritto di urlare "andate via", il diritto il urlare "ne abbiamo abbastanza" di quello che sta accadendo in Parlamento. Ne abbiamo abbastanza dei politici di carriera che da 50 anni sono li dentro».

16. La quenelle è un gesto creato dall'umorista che consiste nel mettere una mano aperta sul braccio opposto, distendendo al contempo quest'ultimo verso terra. Come nel caso del vaffa di Grillo, la quenelle di Dieudonné è un insulto gestuale. Definita dal suo inventore come un gesto anti-sistema, ha scatenato una vera e propria polemica pubblica in Francia, perché ritenuta da molti una forma dissimulata di saluto nazista. Dieudonné insiste nei suoi video sulla connotazione anti-sistema e rivoluzionaria del gesto, non ne nega il carattere ingiurioso, volgare e osceno, ma ne smentisce il valore antisemita. Per lui si tratta di un atto di condanna ideologica che esprime una volontà di denigrazione, di derisione e di dominio di un'alterità percepita come minacciosa. Si veda, per uno studio dettagliato dei valori retorici e simbolici del gesto, Amadori (2016). 
Affermazioni di questo tipo, associate al gesto della quenelle, sono una costante nella retorica di Dieudonné. Ne troviamo un altro esempio nel video Gilets jaunes: quenelle christique, in cui si vede alla sinistra dell'umorista la locandina del suo ultimo spettacolo: vi è raffigurato un Cristo in croce che indossa un gilet jaune. Le parole di Dieudonné chiariscono la provocazione implicita nell'immagine della locandina (a partire dal min. 4.52):

En chassant les marchands du temple, Jésus ne nous a-t-il pas montré le chemin ? [...] Le mouvement des gilets jaunes n'appartient à personne [...] excepté celui qui nous a donné sa vie par amour. Jésus est plus moderne que jamais [...] Jésus porte-parole des gilets jaunes, vous imaginez ? [...] C'est vrai que des quenelles, on en voit, dans le mouvement des gilets jaunes.

È evidente l'identificazione ricercata da Dieudonné, conforme all'ethos de pamphlétaire da lui scelto: come Gesù, profeta del cristianesimo, è stato crocifisso dagli ebrei, così Dieudonné, che ha cominciato a porsi nei suoi video più recenti come nuovo profeta dei gilets jaunes, sarebbe oggi 'perseguitato' dagli ebrei, nuovi capi di una Francia sionista, cui l'umorista non può che rivolgere la sua quenelle christique.

Se la connotazione antisemita presente nel gesto dell'umorista francese è assente nel vaffa di Grillo, sono comunque evidenti le affinità tra i valori retorico-argomentativi dei due gesti. Sia il vaffa di Grillo sia la quenelle di Dieudonné sono, al contempo, un gesto e una parola ${ }^{17}$, e rappresentano lo strumento principe di quella che Amossy (2017) chiamerebbe la «retorica del dissensus» dei due polemisti. In entrambi i casi l'insulto, nella sua duplice versione verbale e gestuale, ha la funzione di creare coesione all'interno del gruppo nella lotta contro un'alterità sapientemente demonizzata. Come nel caso della quenelle di Dieudonné, che i suoi fan riprendono per manifestare sostegno alla sua causa, naturalizzandone l'esecuzione nello spazio pubblico, la «retorica del vaffa» (Santone, 2014: 97), funziona da cemento identitario tra i seguaci di Grillo.

In entrambi i casi, inoltre, si tratta di un insulto volgare, con risvolti sessuali. Il ricorso all'oscenità allude all'impossibilità di trovare altre forme di comunicazione con un sistema perverso, di cui non si condividono i valori. L'obiettivo simbolico di questa scelta è dunque quello di rovesciare i rapporti di potere, contribuendo alla ripresa di controllo dello spazio pubblico da parte del popolo (Orkibi, 2012). Si aggiunga che nel caso di Dieudonné, come in quello di Grillo, il ricorso alla volgarità si inscrive nel tentativo di ricercare una parola che suoni come autentica, lontana dagli eufemismi e dalle manipolazioni del Potere. Tale scelta contribuisce a rendere l'ethos di entrambi i polemisti un potente strumento di identificazione, capace di far sì che «le citoyen, au travers d'un processus d'identification irrationnel, fond son identité dans celle de l'homme politique» (Charaudeau, 2005: 105). Infine, il vaffa e la quenelle hanno una componente derisoria non trascurabile. La scelta di ridicolizzare l'avversario è del resto una strategia retorica potentissima, che favorisce la coesione del

17. Il termine quenelle è di fatto diventato in contesto francese una «formula», nel senso proposto da Krieg-Planque (si veda a proposito Amadori, 2016: 87-88). 
gruppo, rinsaldando la certezza che ci si possa affermare a scapito dell'altro (Orkibi, 2012). L'insulto, tanto più se accompagnato dal gesto, diventa così un modo per rendere spettacolare l'affermazione del proprio dominio sull'altro.

\subsection{L'attacco ad hominem visivo}

Nel caso di Dieudonné, come in quello di Grillo, il ricorso all'insulto gestuale è anche una forma particolarmente efficace di attacco ad hominem visivo ${ }^{18}$. Nel video Dieudonné répond à Valls 2 (min. 12.10) una donna rivolge il gesto della quenelle al presidente francese Hollande, che si trova al suo fianco: in questo caso il gesto esprime una precisa volontà di derisione e delegittimazione di un sistema, rappresentato dal presidente stesso, considerato un'emanazione del complotto americano-sionista. L'anti-sionismo dell'umorista è peraltro indissociabile dal suo antisemitismo, come dimostra l'ananas che nasconde la testa della donna nel video. L'immagine del frutto è un altro simbolo che ricorre nella retorica del polemista (che ha tratti affini a quella negazionista: cf. Taguieff, 2008: 38). L'ananas è infatti spesso associato alla canzone Shoahnanas ${ }^{19}$ con l'intenzione evidente di sminuire l'olocausto e di denunciare un presunto «Shoah-business».

La specificità del medium permette inoltre a Dieudonné di innovare le forme di violenza verbale che si possono considerare caratteristiche del discorso polemico, rendendo i suoi attacchi ad hominem particolarmente incisivi. Interessante a tal proposito l'immagine introdotta dall'umorista al min. 7.42 del video Dieudonné répond à Valls 2, una «citazione digitale» (Amadori, 2013) che segue immediatamente quella di un estratto di un comizio del Partito Socialista, in cui il primo ministro francese Manuel Valls attacca l'umorista avvicinandolo all'estrema destra neonazista. II polemista contrattacca 'incollando' una vecchia foto in cui Valls appare in compagnia di un presunto neonazista britannico (come chiarisce la didascalia): un argomento ad hominem visivo finalizzato a minare la credibilità dell'uomo politico. Argomento che risulta particolarmente efficace dal momento che «visual rhetoric can be simultaneously emotional and rational seeking to persuade the viewer by means both of pathos and of a pragmatic argument» (Roque, 2008: 185).

L'ad hominem è una strategia frequentissima anche nei discorsi di Grillo, così come il ricorso ad appellativi discreditanti rivolti contro gli avversari politici20. Così nel Messaggio di Fine anno 2014 Renzi è definito da Grillo «l'ebetino» (min. 2.46). Lo stesso Renzi è il protagonista del video-montaggio intitolato Discorso agli italioti, in cui è possibile ascoltare la voce di Renzi che si esprime in un inglese di discutibile qualità, coperta dai belati di un gregge. L'attacco, in questo caso, si appunta sulle

18. Come spiega Amossy, «L'insulto fa parte degli argomenti contro la persona: esprime infatti un forte disaccordo rispetto al discorso o al comportamento dell'altro» (2017: 169).

19. Si tratta di una canzone inventata dall'umorista a partire dalla melodia Chaud Cacao di Annie Cordy, che è possibile ascoltare al link: https://www.youtube.com/watch?v=fDNlO8xSEug.

20. Secondo Santone (2014: 95) l'uso di questi appellativi è un'emanazione della «retorica del vaffa», che crea una catena di risonanze in grado di far leva, in assenza di autentiche argomentazioni, sulla componente emotiva. 
carenze linguistiche del leader. La presenza di un gufo (elemento ricorrente nella narrativa renziana, per simboleggiare i detrattori del governo) costituisce un'autocitazione digitale in quanto richiama l'accusa rivolta da Grillo nel suo blog ai «leader civetta», «faccioni pigliatutto». Anche gli elettori di Renzi sono bestializzati: le pecore alle sue spalle rappresentano gli italiani che votano PD, gli italioti appunto. L'attacco ad hominem di questo video è testimonianza di un'esplicita volontà denigratoria e caricaturale, che si iscrive perfettamente nelle dinamiche argomentative e discorsive di quello che è stato definito il «grillese» (Santone, 2015: 12-13), i cui tratti principali sono stati ben descritti e quantificati da Ondelli (2016).

\subsection{La ricerca di un ethos collettivo}

Sia Grillo sia Dieudonné fanno ricorso con grande frequenza nei loro discorsi a un noi la cui natura di «amplificazione dell'io» è chiarita da una riflessione di Amossy:

\footnotetext{
élargissement du noyau initial que constitue le moi, d'une ouverture vers l'autre que le pronom pluriel englobe dans la constitution d'une nouvelle entité. [...] L'ethos des discours en "nous" témoigne donc de la façon dont le moi s'étend et s'amplifie pour offrir une image de groupe (Amossy, 2010b : 159).
}

Il noi utilizzato da Grillo nel suo Messaggio di fine anno realizza un'amplificazione di questo tipo: è in primo luogo il noi esclusivo di Grillo e degli adepti del M5s, per diventare poi un noi inclusivo esteso all'intero popolo italiano:

Comunque noi stiamo portando in Parlamento una legge di iniziativa popolare che ci permetterà di chiedere un referendum consultivo per uscire dall'Euro! Perché essere schiavi? Vogliamo diventare un Paese... ora lo dico... normale, normale! Avere la nostra sovranità monetaria, la nostra sovranità economica, essere normali, avere il nostro fisco senza che sia delegato a una banca a mille chilometri. Lo so che è chiedere una cosa gigantesca! Vogliamo rimanere in un' Europa bella, diversa, con i francesi, con i tedeschi, vogliamo starci in mezzo a questa gente qua, perché siamo diversi, siamo italiani!

Anche nei video di Dieudonné, l'uso del nous produce un effetto di amplificazione: in quelli più datati (inizialmente pubblicati sul canale iamdieudo) il pronome di prima persona plurale unisce Dieudonné ai suoi fan e ai suoi sostenitori, che lui stesso chiama i quenelleurs o membri della Dieudosphère. Più di recente, l'umorista ha tentato di far confluire il suo movimento di protesta all'interno di quello dei gilets jaunes, le cui rivendicazioni hanno tuttavia un carattere politico di più ampio respiro. Alcuni gilets jaunes, durante le manifestazioni parigine di inizio 2019, hanno fatto il gesto della quenelle, inneggiando apertamente a Dieudonné e diffondendo i simboli della sua retorica negazionista. L'identificazione con il movimento dei gilets jaunes ha finito per dare una rinnovata vi- 
sibilità alle posizioni del polemista ${ }^{21}$, che appare del resto consapevole della potenza di circolazione mediatica associata all'identificazione della sua causa con quella del nuovo movimento di protesta: nel video Gilets jaunes - l'Ascension, a partire dal minuto 10.40, afferma:

le mouvement va entrer dans sa phase ascensionnelle. [...] II n'est plus uniquement selon moi un phénomène social ou politique, c'est une véritable marche existentielle. Pour une bonne partie d'entre nous, d'entre les gilets jaunes, [...] ce mouvement qui s'est formé en réaction au départ d'une injustice s'est transformé rapidement en une quête de vérité [...] les gilets jaunes [...] ressentent au plus profond d'eux-mêmes qu'il est là, le chemin, la vérité, la vie.

\section{L'autorità del polemista}

Torniamo ora all'ethos del polemista, inteso come immagine di sé che l'oratore costruisce nel proprio discorso per acquistare credibilità e autorità attraverso la scelta (più o meno consapevole e studiata) di particolari strategie discorsive. Questo aspetto - insieme ad alcuni topoi del discorso quali la denuncia del discorso autoritario (inteso come discorso del Potere) associata all'uso di un contro-discorso polemico che ne riproduce i tratti tipici - ci induce a riflettere sul tipo di autorità cui i nuovi capi mediatici (ovvero i leader che costruiscono mediaticamente il proprio carisma e su di esso basano l'aggregazione del consenso) fanno riferimento.

Ci concentreremo qui sul caso di Grillo, personaggio che ha saputo inserirsi e rimanere sulla scena politica sfruttando abilmente quel cambiamento nel paradigma dell'autorità che in Italia si era verificato con il passaggio dalla Prima alla Seconda Repubblica, quando alla superiorità dell'anteriore sul posteriore era subentrato il «luogo del nuovo» - il cambiamento inteso come valore (Santulli, 2005: 124). Da questo punto di vista, il grillismo affonda le proprie radici nel berlusconismo (pur nella differenza dei presupposti ideologici) poiché «raccoglie i frutti della disgregazione berlusconiana dell'idea di partito e della sua funzione sociale» (Recalcati, 2016: 49)22. Di fatto, Grillo estremizza la sfiducia nel sistema democratico di rappresentanza in nome di un ideale di purezza e trasparenza assolute, nonché della possibilità di gestire direttamente e dal basso la cosa pubblica, grazie alla dimensione orizzontale e partecipativa della Rete.

21. La partecipazione alle manifestazioni dei gilets jaunes ha dato una visibilità estrema, come rileva il politologo JeanYves Camus (2019), a personaggi 'secondari' nel panorama mediatico francese. Anche il M5s italiano ha cercato di avvicinare nel gennaio 2019 il movimento dei gilets jaunes, offrendo sostegno alle loro proteste, forse nel tentativo di ravvivare la propria immagine anti-sistema, ma senza successo.

22. Si veda anche Recalcati (2013): «il carisma di Grillo [...], sebbene antropologicamente assai differente da quello berlusconiano, condivide la stessa rivendicazione di se stesso come di un corpo estraneo e separato dalle istituzioni democratiche della rappresentanza. In Grillo il vento dell'antipolitica è suscitato non da un fantasma di libertà, ma da quello di purezza e di incontaminazione sostenuto da un confine immunitario rigido e fondamentalmente paranoico che rende impossibile qualunque trattativa con chi non appartiene alla casta identitaria dei puri. Qui non è il potere, né il sesso, né il denaro, né una visione iperindividualista della libertà, a fondare il carisma». 
Al contempo, il grillismo si pone in continuità con il berlusconismo per quanto riguarda il culto narcisistico di un leader 'prestato alla politica' (non un politico di professione e neppure un 'tecnico') e dotato di un carisma mediatico (nel suo caso, quasi ipnotico). Dietro la parvenza di orizzontalità (Grillo si presenta come aggregatore di un movimento, anziché come candidato leader di partito), si nasconde una leadership incondizionata, che combina orizzontalità e verticalità, estremismo verso l'esterno e autoritarismo verso l'interno del Movimento. Se le affermazioni degli adepti devono essere controllate e vagliate dalla 'democrazia digitale', quelle del capo non sono discusse prima; se le prese di posizione e le decisioni sono l'esito di consultazioni collettive, il capo (in qualità di 'garante') si riserva di espellere dal Movimento chiunque si allontani da opinioni e scelte condivise (non sono tollerate forme di dissenso o correnti alternative).

Il cambiamento nel paradigma dell'autorità ha effetti sulle scelte comunicative: dalla lingua franca e "affettiva" di Berlusconi, veicolata prevalentemente dalla tv²3, si passa a una lingua 'di pancia' che accentua la dimensione populistica e la componente emotiva ricorrendo a un linguaggio politicamente scorretto, volgare e offensivo, diffuso grazie a mezzi vecchi e nuovi di comunicazione diretta: la piazza e la rete, l'oralità teatrale (o da predicatore) dei comizi-spettacolo o dei video e il parlato-scritto dei post.

\subsection{L'autorità del dire}

Grillo - come osservava acutamente Pontiggia (2016 [1994]: 64) - ha una straordinaria «capacità di sfruttare le risorse dell'oralità con improvvise accelerazioni, rialzi di tono, abbassamenti improvvisi, stacchi»: una padronanza di linguaggio che «funziona anche se lo si legge» (ibidem).

Questa capacità si manifesta nella voce a effetto (resa vibrante dalle contrazioni laringee, con toni che vanno dall'urlato al sussurrato) ma anche nello sguardo spiritato, nella mobilità caricaturale del viso (che simula di volta in volta stupore, rabbia, ilarità, sdegno), nella gestualità frenetica e spettacolare: elementi che a un tempo rinforzano il messaggio e attivano nel pubblico dei simpatizzanti un'adesione empatica alle emozioni veicolate dal 'corpo del capo'24.

Abbiamo già parlato del gesto del vaffa (cf. § 2.2), che costituisce un elemento di continuità sia tra il discorso del comico (da sempre incentrato sull'insulto al potere) e quello del politico, sia tra il contro-discorso del politico violentemente avverso al sistema e quello del capo morale privo di incarichi e responsabilità all'interno di un Movimento arrivato infine al Governo (e rappresentato politicamente da un altro leader: Luigi di Maio). Anche in questa nuova veste, Grillo non rinuncia a

23. D'obbligo il riferimento a Antonelli $(2000,2017)$ che ha efficacemente sintetizzato il passaggio dalle oscurità del 'politichese' (che basava la sua presunzione di autorevolezza su una finzione di scientificità: Pedullà, 2011: CII) a un parlare franco (e financo volgare), in cui qualunque cittadino possa rispecchiarsi. Sulla lingua di Berlusconi si veda Dell'Anna (2017).

24. Questo tratto, come anche il turpiloquio, collega il discorso di Grillo alla retorica mussoliniana (sulla quale cfr. Desideri, 2011). 
sfruttare il corpo ed elementi iconici di forte impatto, come si evince dal video del discorso pronunciato con una benda nera sugli occhi di fronte agli studenti della Oxford Union a pochi giorni dalla firma dell'accordo sulla Brexit ${ }^{25}$.

Un'altra performance teatrale recente è presente nell'intervento video trasmesso dal palco dell'Arena Flegrea di Napoli il 12 ottobre 2019 in occasione della manifestazione "Italia 5 Stelle" (per il decimo anniversario del Movimento). Grillo, truccato da Joker, ha rivendicato il suo ruolo di foolish, che non è tenuto a rispondere a domande sui piani del Governo, semmai a scompaginarli («ll caos è la più grande forma di democrazia di questo secolo e io sono il caos»). Tale affermazione sembra fare eco a quella recente di Dieudonné vista sopra («L'empire n’aura jamais été aussi beau, aussi flamboyant qu'à l'éveil de son chaos qui nous apparait aujourd'hui comme imminent», cf. § 2.1). In linea con le affermazioni provocatorie dell'umorista francese, Grillo inneggia all'avvento del caos come soluzione auspicabile per gettare il disordine in un sistema che è impossibile risanare.

Il ricorso che in questi video Grillo fa alla citazione 'popolare', con riferimento a noti film di cassetta (Bird Box, Joker), è un elemento non casuale, che caratterizza il discorso dei nuovi leader politici che cercano di avvicinarsi all'uomo comune (è il caso anche di Renzi: cf. De Santis, 2016). Nel Messaggio di fine anno 2014 Grillo ricorreva del resto anche alla citazione colta: il racconto 'profetico' di Italo Calvino La pecora nera ${ }^{26}$.

Grillo, inoltre, non disdegna l'autocitazione: al contrario, intesse il suo discorso di rimandi ai propri spettacoli e a slogan del passato. Un esempio significativo è dato dal videomessaggio diffuso il 16 maggio 2018, a pochi giorni dalla conclusione dell'accordo politico con la Lega che avrebbe portato alla stesura del contratto per il 'governo del cambiamento'. Nel video Grillo è ripreso nella sua cucina, intento a preparare «una ricetta veloce veloce e facile da realizzare»: tonno con schiacciatina. Riprendendo un motivo già utilizzato durante la prima campagna politica per le elezioni del 2013 quando l'ingresso del M5s in Parlamento era stato paragonato all'apertura di una scatoletta di tonno di cui si sarebbe dovuto svelare il contenuto - Grillo offre, attraverso una metafora visiva, la ricetta semplice del M5s per un accordo complesso. Il videomessaggio si conclude con un generico «C'avete rotto il cazzo», rivolto a una Casta con la quale è ormai diventato necessario scendere a patti ${ }^{27}$.

25. Nel video (14 gennaio 2019) diffuso da Grillo attraverso il suo blog, la benda diventa metafora della cecità collettiva («di ciò che stanno diventando l'America, l'Europa, il mondo») e allusione criptica a quanto sia «pericoloso guardare la realtà» (con riferimento al film americano Bird Box, del 2018).

26. L'uso parodico di un altro, più celebre, testo letterario è presente in un post di Grillo del 2014: la poesia Se questo è un uomo di Primo Levi viene riscritta con un azzardato e discutibile paragone (anche visivo) tra P2 e lager: «Voi che vi disinteressate della cosa pubblica / come se vi fosse estranea e alla vita delle persone / meno fortunate che vi circondano / nelle vostre tiepide case, / voi che trovate tornando a sera / il telegiornale di regime caldo e visi di mafiosi e piduisti sullo schermo / mentre mangiate insieme ai vostri figli / che educate ad essere indifferenti e servi. / Considerate se questo è un Paese $[\ldots] \gg$.

27. Il video è commentato da Nobili (2019: 64 s.). 
L'autocitazione è sfruttata anche da Dieudonné, che nei suoi video Youtube non esita a inserire stralci dei suoi spettacoli. Il caso più emblematico di ricorso all'autocitazione è tuttavia quello delle «citazioni digitali» delle foto inviategli dai suoi fan, dove questi eseguono il gesto della quenelle. Essendo il polemista l'inventore del gesto, l'inserimento di tali immagini può essere considerato come una forma di rafforzamento della propria autorità attraverso la moltiplicazione indiretta delle esecuzioni del gesto nello spazio pubblico. Ė questa una delle strategie che consentono all'umorista francese di sedurre il suo pubblico (cf. Amadori, 2016: 94 s.).

Anche l'argomento ad hominem usato dai due polemisti come forma di attacco sistematico all'ethos dell'avversario (cf. § 2.2) può essere collegato alla ricerca di una nuova forma di autorità: in primo luogo perché rappresenta il rovesciamento del classico argomento di autorità basato sulla citazione (Reboul, 1991: 183); in secondo luogo perché «per svalutare l'opinione o il punto di vista dell'altro, il discorso polemico deve far vacillare l'autorità di colui che se ne fa porta-parola o che lo rappresenta» (Amossy, 2010a: 60). Abbiamo visto che l'erosione dell'autorità altrui nei video esaminati può arrivare fino alla cancellazione del nome proprio: nel Messaggio di fine anno 2014, Renzi diventa l'ebetino che salterà agli ostacoli alle prossime Olimpiadi, rincorso dalla popolazione.

Abbiamo osservato inoltre che il discorso dei due polemisti si basa sulla delegittimazione dei media ufficiali a favore dei nuovi media. Significativo in tal senso un episodio recente in cui Grillo, che d'abitudine tende a sottrarsi all'interazione con i giornalisti, sfrutta l'occasione di un'intervista per screditare l'interlocutore in quanto rappresentante di una categoria professionale considerata responsabile dell'ignoranza diffusa e del degrado morale del paese. La risposta a domande 'scomode, sulle responsabilità di amministratori locali del M5s o sull'agenda politica del governo di cui il Movimento è co-protagonista, si trasforma in un violento attacco ad personam:

Ė possibile che non riusciamo ad avere uno scambio tranquillo, normale con l'informazione, parlare di cose che siano importanti per il Paese come la transizione energetica, la desertificazione delle città? Voi continuate a parlare di cazzate. [...] Siete dei congetturisti: una parte di responsabilità dell'ignoranza e della non conoscenza da parte di tantissime persone è vostra. Non siete dei media, siete dei mediocri: ci vedremo tra cinque anni e faremo il resoconto di quello che sarà successo. (Intervista di Alessandro Poggi, 10 giugno 2019)

Nella costruzione di questo tipo di discorso conta anche l'autoattribuzione di uno status diverso da quello dell'uomo comune (nonché del politico): così Grillo, che si definisce «L'Elevato» all'interno del Movimento, spiega l'attributo in un post comparso sul suo blog all'indomani della kermesse napoletana che lo aveva visto nelle vesti di Joker:

Cos'è un Elevato? Sicuramente un individuo eccezionale, un grande uomo. Come lo si riconosce? In base all'interesse che suscita nel popolo. L'Elevato è un individuo che possiede autorità sull'uomo comune. Questa autorità può essere solo di tre generi, però, estetica, etica e religiosa. Altrimenti parliamo solo di politici, non di Elevati. 
Grillo prosegue analizzando le tre categorie, che si basano tutte su una 'necessaria ineguaglianza' e sulla superiorità riconosciuta di un individuo sugli altri, che gli dovranno ammirazione e ubbidienza. Nell'Elevato etico si possono riconoscere qualità che, implicitamente, Grillo rivendica a sé: essere detentore di verità e distributore di conoscenza in quanto «ponte» tra la «gente comune» e «la Verità».

Le affermazioni di Grillo trovano ancora una volta corrispondenza nella retorica, non solo verbale, ma anche visiva, di Dieudonné. Significativa a questo proposito è l'immagine con cui si aprono molti dei video più recenti dell'umorista francese. Il volto del comico si impone sullo schermo di Youtube attraverso un primo piano delle narici, da cui esce fumo. Ė velata l'allusione alla figura mitologica del Minotauro, mentre più esplicito è il riferimento interdiscorsivo allo spettacolo del 2014 di Dieudonné, intitolato appunto La bête immonde. Sotto le narici fumanti di Dieudonné compare progressivamente, in maiuscolo, la parola «VERITÀ»».

\subsection{L'autorità del detto}

Tra le strategie di «autolegittimazione del dire» (Solaini 2000) ascrivibili a un linguaggio di tipo autoritario rientrano le forme di embrayage o di 'aggancio attanziale' del pubblico (Desideri, 1984: 23 s.; Maingueneau, 2009: 52). Esemplificando dal già citato Messaggio di fine anno 2014, notiamo l'affettazione iniziale di modestia («anche se non sono un fine dicitore») e l'uso della deissi personale (in particolare il ricorso al noi inclusivo/esclusivo: cf. § 2.4) abbinata ai frequenti appelli all'interlocutore («chiamatela come volete»; «fate quello che credete più opportuno»; «lo non voglio imporvi nulla, giudicate voi») e a interrogative retoriche e didascaliche, spesso con schema botta e risposta e unite a ripetizioni («Che cosa potremmo rimpiangere del 2014? Che se ne va? Renzi? Le balle di Renzi?»; «Chi è? Cos'è? Non si sa; Che rimpianti avremo? Io non lo so che rimpianti»). Significativo, nel discorso, il ricorrere dell'aggettivo vero («noi siamo i veri eversori»), di sottolineature discorsive («qua lo dico: normale») e chiose polemiche («il reddito di cittadinanza: Dio mio che concetto nella politica...»). Sembra funzionare da leva emotiva l'aggettivazione iperbolica (bellissimo, chilometrico), usata talora in chiave ironica (fantastico, meraviglioso). II ricorso alla deissi spazio-temporale (qua dentro, fuori ecc.; anni fa, sembrano anni luce ecc.) punta invece a disegnare (insieme alla scenografia a effetto del messaggio dalla caverna) un tempo e un luogo separati.

Nello stesso Messaggio troviamo esemplificate anche altre tipiche strategie enunciative che tendono a rafforzare l'autorità del messaggio perché suggeriscono una comprensione totalizzante del reale. Numerosi, in questo discorso, i pronomi come tutto/tutti e niente/nessuno, insieme ad aggettivi come unico e solo, che - nell'amalgama - isolano e mettono a fuoco l'eccezione. Compaiono inoltre avverbi come sempre e mai, nonché avverbi in -mente, che si prestano alla sillabazione ed esprimono di volta in volta radicalità dell'agire (assolutamente) o attenuazione ironica (leggermente). Contribuiscono altresì all'effetto d'autorità la brevità degli enunciati e il ritmo martellante dato dalle

28. Scorrono successivamente sullo schermo le prossime date degli spettacoli dell'umorista, che dà in questo modo appuntamento a tutti coloro che vogliano andare ad ascoltare il loro «profeta». 
ripetizioni («dove aleggiano gli spiriti, gli spiriti quelli buoni»; «succederà qualcosa, questo qualcosa [...] succederà qualcosa, succederà che noi l'abbiamo già fatta succedere»).

Molte di queste strategie, compresa la «manomissione delle parole» (Carofiglio, 2010), sono già state repertoriate dagli studiosi che si sono occupati dell'oratoria mussoliniana e della lingua dei leader politici tra Prima e Seconda Repubblica, Berlusconi e Renzi compresi. A conferma del fatto che le differenze ideologiche non si traducono necessariamente in scelte linguistiche antitetiche: al contrario, le soluzioni che contribuiscono alla perentorietà e all'effetto di verità tipici del linguaggio autoritario mostrano una relativa stabilità e omogeneità attraverso il tempo e gli orientamenti politici (va da sé che l'autoritarietà del linguaggio non va sempre e necessariamente insieme all'autoritarietà della forma di governo).

Il primo a sottolineare la presenza di moduli autoritari nel discorso di Grillo è stato Berlusconi che, in due occasioni, di fronte all'ascesa politica di Grillo, non ha esitato a paragonare l'avversario a Hitler, il leader totalitario per eccellenza, sulla base di una presunta coincidenza di argomenti e stile discorsivo:

questo partito [...] è una setta [...] il signor Grillo non tollera nessuna forma di democrazia, se qualcuno osa dissentire da lui viene espulso [...] io paragono Grillo ai tanti protagonisti in negativo della storia che noi conosciamo: da Robespierre [... al alla ideologia di Marx applicata da Lenin e Stalin, e poi ho finito due giorni fa di leggere i discorsi di un certo signore che si chiama Adolf Hitler. Se voi da questi discorsi togliete il riferimento a fatti concreti, locali, di allora, potreste cancellare il nome di Hitler e metterci quello di Grillo29.

[...] fa dei discorsi nei quali ho individuato certi passaggi identici a quelli di un certo signor Hitler, che questi passaggi li aveva nei suoi discorsi del '32 e del '33, quelli con cui conquistò il potere in Germania ${ }^{30}$.

Ma, ironia della sorte, a un politologo attento come Giorgio Fedel (2003: 467) non era sfuggita la predilezione dello stesso Berlusconi per stratagemmi retorici, come il polittoto temporale, già cari a Mussolini. L'autorità cambia, dunque, i suoi strumenti, anche se non (del tutto) le sue forme.

29. Discorso di Silvio Berlusconi a chiusura della campagna per le Europee (23 maggio 2014: https://www.youtube.com/ watch?v=vkEGGFuy7dU)

30. Discorso di Silvio Berlusconi in occasione della manifestazione "Liberiamoci e ripartiamo!", promossa dalla Lega Nord (Bologna, 8 novembre 2015): https://www.youtube.com/watch?v=aPOqo6fWxvU. 


\section{Conclusioni}

Avvertiva Giuseppe Pontiggia (2003: 210), acuto osservatore dell'autorità linguistica:

Quello che dovremmo esercitare prima di tutto nei confronti del linguaggio autoritario è una consapevolezza dei meccanismi con i quali agiamo, una cautela nell'ascolto e nella lettura, una consapevolezza che c'è una predisposizione in noi alla suggestione, che deve essere messa a freno, che deve essere sorvegliata.

Le parole dello scrittore ci invitano a riflettere sulle ragioni per le quali i discorsi veicolati da personaggi ritenuti oggi autorevoli possano diventare virali.

Andrà intanto tenuto conto del fatto che, nell'epoca del Web 2.0, il concetto di «autorevolezza» ha assunto connotazioni diverse, sempre meno legate alla qualità e verità delle argomentazioni e sempre più associate alla quantità di visualizzazioni o condivisioni di contenuti.

È opportuno inoltre considerare il fatto che i nuovi protagonisti della scena mediatica europea di cui ci siamo occupate manifestano entrambi nei loro discorsi un ethos di tipo polemico, evidentemente percepito come sempre più "accettabile" e "adeguato" nelle società democratiche contemporanee (Amossy, 2017): nei dibattiti televisivi, nei comizi in piazza, sui social network, del resto, si è spesso tanto più "visibili" quanto più si riesce a imporre in maniera categorica, se non violenta, il proprio punto di vista.

La novità che ci sembra di poter osservare riguarda infine il potere di suggestione di questi discorsi e la loro capacità di farsi veicolo di nuove ideologie. Tanto che ci sembra difficile, oggi, sottoscrivere quanto Italo Calvino (1974) affermava a proposito dell'oratoria di un politico austero come Palmiro Togliatti: «l'autorità degli uomini politici è spesso un mistero, ma un mistero che non ispira nessuna suggestione». 


\section{BIBLIOGRAFIA}

\section{Fonti primarie}

\section{Corpus francese}

Dieudonné répond à Yann Barthès, visibile al sito https://www.youtube.com/watch?v=8r97DKDmbCY [video di 17.14 minuti pubblicato nel 2014; ultima consultazione 23/10/2019].

Merci Manu, visibile al sito https://www.youtube.com/watch?v=yRkdChh1hwo [video di 11.20 minuti pubblicato nel 2014; ultima consultazione 23/10/2019].

Dieudonné répond à Valls 2, visibile al sito https://www.youtube.com/watch?v=0TQCnO-ZGyE [video di 15.41 minuti pubblicato nel 2014; ultima consultazione 23/10/2019].

Gilets jaunes: contre la dictature, visibile al sito https://www.youtube.com/watch?v=9NqQzYHqzgki [video di 10.10 minuti pubblicato nel 2019; ultima consultazione 23/10/2019].

Gilets jaunes: quenelle christique, visibile al sito https://www.youtube.com/watch?v=kgQSOR4ZDig [video di 12.40 minuti pubblicato nel 2019; ultima consultazione 23/10/2019].

Gilets jaunes: l'Ascension, visibile al sito https://www.youtube.com/watch?v=IRtV4rvk8IY [video di 12.43 minuti pubblicato nel 2019; ultima consultazione 23/10/2019].

\section{Corpus italiano}

Messaggio di fine anno 2014, video di 12.42 minuti attualmente disponibile sul sito https://www. youtube.com/watch?v=ysyeWVARCh0; per la trascrizione si veda il sito http://www.beppegrillo.it/discorso-di-fine-anno-2014-di-beppe-grillo-ioguardobeppe/ [ultima consultazione 23/10/2019].

Discorso agli italioti (2014), video di 24 secondi disponibile sul sito http://www.chickybox.com/discorso-agli-italioti-ALIXZ7hct4 [ultima consultazione 23/10/2019].

Se questo è un paese (2014), disponibile sul sito https://www.beppegrillo.it/se-questo-e-un-paese/ [ultima consultazione 23/10/2019].

Intervista a Sky news UK (2019), video di 3.06 minuti disponibile sul sito https://www.beppegrillo.it/ intervista-a-sky-news-uk/. "lo grido" si intitola del resto una sezione del blog di Grillo. [ultima consultazione 23/10/2019].

Beppe Grilllo at the Oxford Union (2019), video di 9.27 minuti disponibile sul sito https://www.beppegrillo.it/beppe-grillo-at-the-oxford-union/ [ultima consultazione 23/10/2019].

Grillo travestito da Joker (2019), video di 2.17 minuti disponibile sul sito https://www.beppegrillo.it/ beppe-grillo-at-the-oxford-union/[ultima consultazione 23/10/2019].

Beppe Grillo attacca i giornalisti (2019) disponibile sul sito https://www.fnsi.it/beppe-grillo-attac- 
ca-i-giornalisti-mediocri-fnsi-insulta-per-non-rispondere-alle-domande-scomode [ultima consultazione 23/10/2019].

Beppe grillo ritira fuori la scatoletta di tonno (2018), video di 1.23 minuti disponibile sul sito https:// video.corriere.it/governo-beppe-grillo-ritira-fuori-scatoletta-tonno-insulto-finale/ff35813c5924-11e8-a92f-c55317f6ffa7 [ultima consultazione 23/10/2019].

La trinità degli elevati (2019) disponibile al sito https://www.beppegrillo.it/la-trinita-degli-elevati/ [ultima consultazione 23/10/2019].

\section{Fonti secondarie}

Amadori, Sara (2016), «La "quenelle". Valeurs symboliques et rhétoriques d'une insulte gestuelle», Mots. Les langages du politique, no 110, p. 82-98, disponibile su https://journals.openedition. org/mots/22179. [Sito consultato il 23 ottobre 2019.].

Amadori, Sara (2014), «Democrazia digitale : usages politiques et rhétoriques d'une formule dans le cadre des élections politiques italiennes de 2013», in Ruth Amossy/ Alice Krieg-Planque et Paola Paissa (éds.), La formule en discours: perspectives argumentatives et culturelles, Repères DoRiF, 5, disponibile su https://www.dorif.it/ezine/ezine_articles.php?art_id=177. [Sito consultato il 23 ottobre 2019.].

Amadori, Sara (2013), «Forme del discorso in circolazione e della diafonia su Youtube», mediAzioni, XIV, disponibile su http://www.mediazioni.sitlec.unibo.it/index.php/no-14-2013/83-articoli2013/254-forme-del-discorso-in-circolazione-e-della-diafonia-su-youtube.html. [Sito consultato il 23 ottobre 2019.].

Amossy, Ruth (2017), Apologia della polemica, a c. di Sara Amadori, Milano, Mimesis. [Titolo originale: Apologie de la polémique, Paris, PUF, 2014. Traduzione e prefazione di Sara Amadori.].

Amossy Ruth / Marcel Burger (2011), «Introduction: la polémique médiatisée», Semen, XXXI, disponibile su https://journals.openedition.org/semen/9072. [Sito consultato il 23 ottobre 2019.].

Amossy, Ruth (2010a), «L'argomento "ad hominem": riflessioni sulle funzioni della violenza verbale», Altre modernità, 3, p. 56-70.

Amossy, Ruth (2010b), La présentation de soi, Paris, PUF.

Angenot, Marc (2010), «La pensée conspiratoire: Une histoire dialectique et rhétorique?», in Emmanuelle Danblon / Nicolas Loïc, Les rhétoriques de la conspiration, Paris, CNRS Éditions.

Angenot, Marc (1982), La parole pamphlétaire. Typologie des discours modernes, Paris, Payot.

Antonelli, Giuseppe (2000), «Sull'italiano dei politici nella seconda Repubblica», in Serge Valvolsem et al., L'italiano oltre frontiera. V convegno internazionale (Leuven, 22-25 aprile 1998), I-II, LeuvenFirenze, Leuven University Press-Cesati, I, p. 211-234. 
Antonelli, Giuseppe (2017), Volgare eloquenza. Come le parole hanno paralizzato la politica, BariRoma, Laterza.

Battistini, Andrea (2006), I/ «linguaggio autoritario» e l'arte della retorica, in Gino Ruozzi (ed.) Giuseppe Pontiggia contemporaneo del futuro, Bologna, Gedit, p. 31-55.

Bourdieu, Pierre (1988), La parola e il potere. L'economia degli scambi linguistici, Guida, Napoli (ed. orig. Ce que parler veut dire. L'économie des échanges linguistiques, Fayard, Paris, 1982; ed. ampliata: Langage et pouvoir symbolique, Seuil, Paris, 2001).

Burgess, Jean / Joshua Green (2009), «The Entrepreneurial Vlogger: Participatory Culture Beyond the Professional-Amateur Divide», in Pelle Snickars / Patrick Vondereau (éds.), The Youtube reader, Stockholm, National Library of Sweden.

Calvino, Italo (1974), «Ma ne sapevamo tutti poco», Corriere della Sera, 13 ottobre.

Campus, Donatella (2006), L'antipolitica al governo. De Gaulle, Reagan, Berlusconi, Bologna, Il Mulino.

Camus, Jean-Yves in Berteloot, Tristan (2019), «Les gilets jaunes, étouffés par la gangrène antisémite», Libération, 18 février, disponibile su https://www.liberation.fr/france/2019/02/18/les-gilets-jaunes-etouffes-par-la-gangrene-antisemite_1710174. [Sito consultato il 23 ottobre 2019.].

Carofiglio, Gianrico (2010), La manomissione delle parole, Milano, Rizzoli.

Ceccarelli, Filippo (2012), «ll linguaggio dell'esasperazione. Dal Vaffa day al Rigor Montis le parole dell'esasperazione negli sberleffi del leader 5 stelle», La Repubblica, 9 maggio.

Cedroni, Lorella (2010), Il linguaggio politico della transizione. Tra populismo e anticultura, Roma, Armando.

Charaudeau, Patrick (2005), Le discours politique, Paris, Vuibert.

Danna, Serena (2013), «Intervista con Gianroberto Casaleggio. La democrazia va rifondata», Corriere della sera, 23 giugno 2013, disponibile su http://lettura.corriere.it/la-democrazia-va-rifondata/. [Sito consultato il 23 ottobre 2019.].

Dell'Anna, Maria Vittoria (2017), Berlusconi: io, la gente e me, Speciali Lingua Italiana Treccani, disponibile su http://www.treccani.it/magazine/lingua_italiana/speciali/politici/Dell_Anna.html. [Sito consultato il 23 ottobre 2019.].

Desideri, Paola (1984), Teoria e prassi del discorso politico. Strategie persuasive e percorsi comunicativi, Roma, Bulzoni, 1984.

Desideri, Paola (2011) Linguaggio della politica, in Raffaele Simone (ed.), Enciclopedia dellitaliano, Istituto dell'Enciclopedia Italiana, Roma, 2011, p. 1112-1115.

De Santis, Cristiana (2015a), «Autorité et langage: études et réflexions dans l'ensemble culturel italien», in Elisabeth Gavoille et al. (éds.) L'autorité dans le monde des Lettres, Kimé, Paris, 2015, p. 59-80. 
De Santis, Cristiana (2015b), «ll linguaggio autoritario dalla biblioteca alla scrittura», in Alberto Cadioli et al., Giuseppe Pontiggia. Investigare il mondo. Atti del convegno internazionale (Milano, 30 ottobre 2013), Novara, Interlinea, 2015, p. 31-58.

De Santis, Cristiana (2016), «"Pensiamo, pensavamo e penseremo”: strategie di costruzione dell'autorità nel discorso dei nuovi leader», in Rita Librandi, e Rosa Piro (éds.), L'italiano della politica e la politica dell'italiano. Atti dell'XI convegno ASLI (Napoli, 20-22 novembre 2014), Firenze, Cesati, p. 311-322.

De Santis, Cristiana (2019), «Fortuna e circolazione discorsiva di alcuni slogan italiani», Kwartalnik Neofilologiczny, LXVI, p. 361-370.

Ducrot, Olivier (1984), «L'argumentation par autorité», in Olivier Ducrot (ed.), Le dire et le dit, Minuit, Paris 1984, p. 149-169.

Fedel, Giorgio (2003), «Parola mia. La retorica di Silvio Berlusconi», il Mulino. Rivista di cultura e di politica, III, p. 463-473.

Maingueneau, Dominique (2009), Les termes clés de l'analyse du discours, Le Seuil, 2009.

Maingueneau, Dominique (2014), Discours et analyse du discours, Paris, Armand Colin.

Maingueneau, Dominique / Patrick Charaudeau (éds) (2002), Dictionnaire d'analyse du discours, Paris, Seuil.

Nobili, Claudio (2019), I gesti degli italiani, Roma, Carocci.

Ondelli, Stefano (2016), «Esempi recenti della retorica populista in Italia: da Forza Italia al Movimento 5 stelle», in L'italiano della politica e la politica dell'italiano. Atti dell'XI convegno ASLI (Napoli, 2022 novembre 2014), Firenze, Cesati, p. 323-337.

Orkibi, Eithan (2012), «L'insulte comme argument et outil de cadrage dans le mouvement "anti-Sarko"», Argumentation et Analyse du Discours, n 8, disponibile su https://journals.openedition. org/aad/1335. [Sito consultato il 23 ottobre 2019.]

Paveau, Marie-Anne (2016), «Éthique du discours numérique», Línguas e Instrumentos Linguísticos (Brésil), RG Editora, n³7, p. 177-210.

Pedullà, Walter (2011), «Breve storia dell'oratoria politica nell'Italia Unita», Introduzione a Parole al potere. Discorsi politici italiani, Milano, Rizzoli.

Perelman, Chaïm /Olbrechts-Tyteca, Lucie (1966), Trattato dell'argomentazione. La nuova retorica, Torino, Einaudi (l ed., 1958).

Plantin, Christian (1996), «Les argumentations d'autorité», in Christian Plantin, L'argumentation, Paris, Seuil, p. 88-93.

Pontiggia, Giuseppe (2004), «ll linguaggio autoritario nell'uso quotidiano della parola», in I/ residence delle ombre cinesi, Milano, Mondadori, p. 199-211. 
Reboul, Olivier (1991), Introduction à la rhétorique, Paris, PUF.

Recalcati, Massimo (2013), «Da Grillo a Renzi. Il carisma orizzontale», La Repubblica, 26 novembre 2013, disponibile su https://www.repubblica.it/la-repubblica-delle-idee/polis/2013/11/26/ news/da_grillo_a_renzi_il_carisma_orizzontale-71978952/. [Sito consultato il 23 ottobre 2019.].

Recalcati, Massimo (2016), Patria senza padri. Psicopatologia della politica italiana, a cura di Christian Raimo, Roma, Minimum Fax.

Robin, Jean (2014), Soral et Dieudonné: la tentation antisémite, Blois, Éd. Tatamis.

Roque, Georges (2008), «Political Rhetoric in Visual Images», in Edda Weigand (ed.), Dialogue and Rhetoric, Amsterdam/Philadelphia, John Benjamins, p. 185-194.

Santone, Laura (2014), «Quand la politique tire la langue. Le Vaffa Day du M5s (Movimento 5 stelle)», Mots. Les langages du politique, no 106, p. 87-104, disponibile su https://journals.openedition. org/mots/21810.

Santone, Laura (2015), «Le blog de Beppe Grillo et les «tsunami tour(s)» du langage: polémique, violence verbale et effet «carnaval» via le web», in Julien Auboussier (éd.), L'Europe en contre-discours, Besançon, Presses Universitaires de Franche-Comté, p. 147-162.

Santoro, Giuliano (2012), Un grillo qualunque. Il movimento 5 stelle e il populismo digitale nella crisi dei partiti italiani, Roma, Castelvecchi.

Santulli, Francesca (2005), Le parole del potere, il potere delle parole. Retorica e discorso politico, Milano, Franco Angeli.

Sedda, Paola (2015), «Espaces numériques oppositionnels et mobilisation en Italie», Communication, technologie et développement, II, disponibile su http://www.comtecdev.com/fr/telecharger/ Sedda.pdf. [Sito consultato il 23 ottobre 2019.].

Solaini, Raffaele (2000), «L'argomento di autorità: fra l'autolegittimazione del dire e la verità del detto», Lingua e stile, 2, p. 229-248.

Taguieff, Pierre-André (2008), La judéophobie des Modernes: Des Lumières au Jihad mondial, Paris, Odile Jacob. 


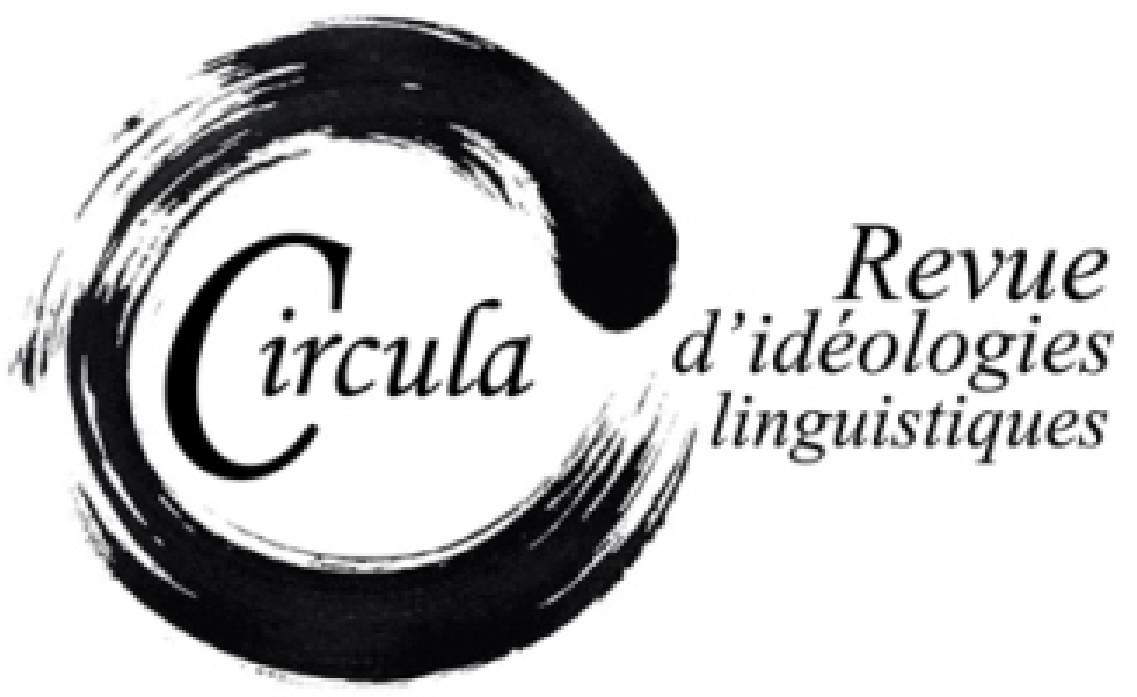

TITRE: LA LITTÉRATIE, UNE NOTION CHARGÉE IDÉOLOGIQUEMENT : LE TRAITEMENT DE L'ALPHABÉTISATION DANS LA PRESSE ACADIENNE

Auteure: LAurence ArRighi, Université de Moncton

Revue: CIRCULA, NUMÉRO 10

PAgES: $64-90$

ISSN: 2369-6761

URI: HTTP://HDL.HANDLE.NET/11143/16774

DOI: HTTPS://DOI.ORG/10.17118/11143/16774 


\title{
La littératie, une notion chargée idéologiquement : le traitement de l'alphabétisation dans la presse acadienne
}

\author{
Laurence Arrighi, Université de Moncton
} laurence.arrighi@umoncton.ca

[...] la langue sert de terrain de sélection mystifiable, puisqu'on avance la proposition qu'elle est accessible, tout en maintenant des mécanismes inégalitaires de définition de la compétence, mécanismes désavantageux pour tous ceux et toutes celles qui se font évaluer, et n'évaluent pas. (Heller, 2007 : 44)

Résumé : Une familiarité avec les discours sur la langue dans la presse acadienne m’a conduit à porter une attention particulière à un discours récurrent sur la question du niveau de littératie des francophones du Nouveau-Brunswick et des besoins en alphabétisation des membres de cette communauté. Par une analyse critique de discours, et en pensant avant tout la littératie comme une pratique sociale, je mets en lumière la charge idéologique de cette notion et de tout discours portant sur les questions d'alphabétisation. En lien avec la tendance grandissante dans nos sociétés à évaluer les pratiques linguistiques comme des compétences mesurables, ainsi que dans un contexte plus large de dénigrement permanent des pratiques du groupe étudié, je mets de l'avant la manière dont la notion de littératie et la question de l'alphabétisation sont investies discursivement, soit par un discours de l'emphase soit par un traitement intimiste, tous deux largement orientés idéologiquement. In fine, je cherche à déceler quelle(s) grande(s) idéologie(s) servent les discours étudiés.

Mots-clés : langue française en Acadie ; littératie ; alphabétisation ; idéologies linguistiques

Summary: Familiarity with language discourses in the Acadian Press led me to pay special attention to a recurrent discussion on the issue of the literacy level of Francophones in New Brunswick and the literacy needs of members of this community. Using critical discourse analysis, and analyzing literacy primarily as a social practice, I highlight the ideological nature of this position, and indeed of all discourses on literacy. After highlighting the growing tendencies of our societies toward the evaluation of linguistic practices as measurable skills, and the denigration of the practices of the group studied, I underline the extent to which the very notion of literacy is invested discursively and oriented ideologically. In short, I attempt to discover which ideology or ideologies the discourse studied serves.

Keywords: French language in Acadia; speeches on literacy; linguistic ideologies 


\section{Introduction ${ }^{1}$}

L'objectif de cette contribution est de présenter le traitement médiatique de la question de l'alphabétisation et, plus largement, du thème du niveau de littératie des francophones en Acadie. Les outils de la Critical discourse analysis (Fairclough, 1995) seront utilisés afin de comprendre un discours en général très consensuel sur les besoins en alphabétisation dus au niveau de littératie tenu pour piètre des francophones du Nouveau-Brunswick. Mon approche sera également nourrie par les théories de l'argumentation ainsi que par des travaux produits en sociologie de l'éducation et dans d'autres sciences sociales.

Mon travail sur les discours traitant de la question de l'alphabétisation en Acadie m'a amenée à comprendre que, dans les espaces discursifs (presse, discours gouvernemental, discours d'associations, etc.) de la francophonie acadienne, les concepts somme toute savants d'alphabétisation et de littératie sont utilisés sans plus être définis. Cet article interroge ces notions voire les remet partiellement en cause, celles-ci s'étant transformées, au fil des années, en un enjeu idéologique au profit duquel on est appelé à militer. A minima, il convient de ne pas oublier, comme le rappellent Collins et Blot dans Literacy and literacies : text, power and identity (2003), que les pratiques de littératie sont, comme toutes pratiques et performances socioculturelles, interdépendantes des ordres sociaux et des rapports de pouvoir particuliers où elles apparaissent².

En l'occurrence, la communauté dont il est question est celle des Acadiens et Acadiennes du Nouveau-Brunswick. Cette communauté minoritaire de l'est du Canada forme environ un tiers de la population face aux Anglophones; elle est périphérique au sein de la francophonie canadienne et qui plus est mondiale.

Certains motifs discursifs dans le traitement médiatique de la question de l'alphabétisation en Acadie analysés ici peuvent relever plus spécifiquement de la situation acadienne - c'est souvent ainsi que cela est posé - je montrerai toutefois certaines convergences avec d'autres situations. Je propose surtout que ce discours est à comprendre plus largement dans deux directions. Premièrement, il s'inscrit ici dans un discours plus vaste et récurrent de dénigrement et d'autodénigrement des pratiques linguistiques acadiennes (Boudreau, 2009, 2012, 2016 ; Arrighi et Violette, 2013 ; Arrighi et Urbain 2016/2017 et 2019). Deuxièmement, il se comprend comme épiphénomène d'une tendance grandissante dans nos sociétés à évaluer les pratiques linguistiques comme des compétences mesurables. Ce faisant, mon propos s'inscrit dans le cadre plus général d'une réflexion en cours sur les questions de langue qui consiste à interroger les conséquences de cette propension

1. Je tiens à exprimer ma reconnaissance à Émilie Urbain (Carleton University) pour ses conseils lors de la rédaction de cet article et à Naorën Vernouillet (Université de Moncton) pour l'aide précieuse tout au long de la collecte des données. Merci aussi aux deux évaluateurs/évaluatrices pour la révision minutieuse et les suggestions fort pertinentes.

2. Dans le sillage des New Literacy Studies (Street, 1996 et 2005) ma démarche appréhende la littératie « focusing not so much on literacy as a "technology of the mind" [...] or as a set of skills, but rather on what it means to think of literacy as a social practice » (Street, $2006: 1$ ). 
croissante à l'évaluation tout azimut des usages de la langue, mais in fine des individus. Ces études conduites surtout dans le sillage de la sociolinguistique critique montrent comment ces discours participent de processus de régulation sociale, hiérarchisent les locuteurs, sont naturalisés et posés comme un « allant de soi » sans être interrogés (voir Canut et Duchêne, 2011; Flubacher et Del Percio, 2017 ; Hambye et Romainville, 2013 ; et, spécifiquement pour le groupe acadien, Boudreau, 2016 ; McLaughlin, 2014). La présente contribution s'inscrit également dans ce courant, dans la mesure où je propose d'analyser ces discours en interrogeant les motivations des acteurs sociaux qui les tiennent, le cadre idéologique à partir duquel ils parlent, leurs enjeux et conséquences.

Dans cette contribution, je m'intéresse, dans un premier temps, à la façon générale dont le problème du niveau de littératie déficient des francophones en Acadie est construit discursivement. Dans un second temps, je regarde comment l'analphabète est représenté quand on s'attarde au cas particulier. En l'occurrence alors, c'est surtout l'ex-analphabète, devenu modèle de réussite et de résilience, qui est présenté. De fait, selon un mouvement déjà mis au jour dans d'autres travaux portant sur les discours sur la qualité de la langue (Arrighi et Violette, 2013 ; Arrighi et Urbain, 2016/2017), et plus largement les questions linguistiques, on passe de l'(auto-)dénigrement à l'éloge de ceux qui ne ménagent pas leurs efforts pour sortir de leur situation.

Avant cela, je propose, en guise de succincte contextualisation de la situation de la communauté, un bref aperçu des topos qui la traversent quand on en vient à traiter de la langue des Acadiens et des Acadiennes. Dans cette section, je présente aussi la presse francophone en Acadie. Nous verrons qu'elle est réduite à peu de choses, ce qui ne favorise pas la diversité d'opinion et peut certainement participer à expliquer la grande cohérence, pour une époque donnée, dans les propos tenus sur le sujet qui nous occupe. Enfin, dans cette section introductive, je m'arrête sur le cheminement des termes étudiés.

\section{Des pratiques linguistiques, de la presse francophone et de l'ap- parition du thème en Acadie}

De façon très générale, les Acadiens et les Acadiennes possèdent un répertoire langagier pluriel, dont un français qui peut être mêlé d'anglais et marqué de particularismes divers (Neumann-Holzschuh et Mitko, 2018). Cela est loin d'être perçu positivement et, à partir notamment de valeurs associées aux idéologies du monolinguisme et du standard, un certain discours public pointe des défauts de leur langue allant jusqu'à interroger leur qualification comme francophones (Arrighi et Boudreau, 2013, 2016 ; Boudreau, 2016). Au sein d'un concert de propos - souvent assez désobligeants - évaluant leurs pratiques linguistiques, le sujet de leur faible niveau d'alphabétisation et d'une littératie défaillante est récurrent. Le traitement discursif de ce thème présente une étroite parenté avec d'autres discours sur la forme, maitrise et qualité de la langue de ce groupe (Arrighi et Boudreau, 2013 ; Arrighi et Violette, 2013). Ce sont précisément mes analyses antérieures des discours publics sur la langue qui m’ont amenée à choisir d'analyser ce thème. Ce qui a également attiré mon attention, c'est la 
singulière unanimité dans le diagnostic : le niveau de littératie est au plus bas, les besoins en alphabétisation sont immenses. On relève aussi une certaine uniformité de ton et de formulation. Ce sont souvent les mêmes antiennes qui reviennent et elles sont fort proches de celles relevées dans d'autres espaces quand il est question d'alphabétisation (ainsi, en France, le travail de Lahire, 1999, 1992) ; or, comme l'ont déjà noté des chercheurs et chercheuses travaillant sur ce sujet sur d'autres terrains, entre la réalité des inégalités d'accès à l'écrit, bien réelles, et les discours qui en traitent, le rapport n'est pas toujours évident (Lahire, 1999).

Autant dans la situation commentée par Lahire que dans les journaux formant mon corpus, on assène des images choc : « $60 \%$ des francophones de la province auraient du mal à comprendre tous les articles qui se trouvent dans le journal d'aujourd'hui » (AN, 22 septembre 2016³). L'objet mis en discours a de quoi choquer et c'est bien l'objectif des discoureurs. Dans de nombreux textes, les auteurs montent au créneau pour dénoncer le « fléau » (AN, 22 septembre 2016) de l'illettrisme en Acadie, mal auquel le " public doit être sensibilisé » (AN, 25 juin 2011) et contre lequel il faut « partir en croisade » (AN, 12 mai 2000). L'on a affaire à un discours peu nuancé et assez homogène où l'espace du dicible sur le sujet est en quelque sorte prédéfini, comme si l'on avait affaire à une formation discursive qui « détermine ce qui peut et doit être dit» (Haroche, Henry et Pêcheux, 1971 : 102). Comme tout discours, contraint par ses conditions de production (Foucault, 1971), le discours public sur l'alphabétisation semble ce faisant «menacé d'exclusion s'il déborde du cadre permis et interprété quant au contenu, à la discipline, à la validité de son énonciation » (Achard, 1986 : 16).

Précisons qu'il ne s'agit avec ce travail ni de poser un nouveau diagnostic qui invaliderait celui que je viens de souligner, ni de balayer du revers de la main les efforts combinés des organismes en charge de l'alphabétisation et des bénéficiaires de ces services. Toutefois, il est sans doute important aujourd'hui de prendre du recul vis-à-vis de procédures évaluatives peu transparentes et, quoi qu'il en soit, mal comprises. Il convient de se demander qui mesure qui, quoi, comment et pourquoi pour en arriver aux chiffres cités et avec quelles conséquences ? II convient aussi d'interroger les discours qui valident ces évaluations, des propos trop consensuels et des démarches, certes généreuses, qui consistent à promouvoir une meilleure littératie, mais sans que cette notion soit plus avant définie. En fait, définie de différentes façons par divers courants de la recherche ${ }^{4}$, la littératie (et l'alphabétisation) a, sans conteste, besoin d'être critiquée scientifiquement pour être (ré-)affinée et surtout pour ne pas s'instituer comme doxa sociétale et pédagogique dont les protagonistes principaux, agents, agentes et bénéficiaires des services d'alphabétisation, ne comprendraient ni les tenants ni les aboutissants; ni les lecteurs et lectrices de la presse qui en traite d'ailleurs. On peut aussi interroger les positionnements parfois trop angéliques de ces discours et démarches. Sur un autre terrain

3. Dans le corps du texte les références au corpus se lisent comme suit : initiales du titre de presse et date de parution de l'article cité. En bibliographie, chaque référence est détaillée.

4. Je précise ici que, travaillant à partir d'un corpus journalistique, je n'entrerai pas dans un examen critique ni même une présentation de l'usage de ces termes dans le monde académique ou au sein des institutions. Très certainement productive, la confrontation des usages entre différents milieux, et au sein même d'un seul milieu, n'est pas du ressort de cet article. 
où règne un consensus qui frise la doctrine : la promotion institutionnelle de l'éducation plurilingue en Europe, des chercheurs et chercheuses qui par ailleurs sont parfois fortement engagés dans cette voie ne se privent pas de souligner le caractère convenu, angélique ou simplificateur de discours sur le thème. Ce faisant, ils enrichissent notre compréhension des défis qui se posent à ceux et celles qui veulent agir. Ce type de réflexion, en particulier celle de Clerc et Rispail (2008), a enrichi la mienne.

Je propose, comme l'indique mon titre, de considérer la littératie, telle que construite discursivement pour le grand public, comme une notion chargée idéologiquement. À la fin de ma contribution, je reviendrai sur cette proposition en m'interrogeant notamment sur l'idéologie ou les idéologies qui sauraient servir par des discours sur le niveau de littératie et les besoins en alphabétisation de tel ou tel groupe.

Ce n'est donc pas le concept savant de littératie 5 , ni les pratiques d'alphabétisation que j'interroge mais la façon dont il est souvent question de ces sujets auprès du grand public. Je vise à en montrer le caractère idéologiquement situé en lien avec des représentations plus générales sur les pratiques linguistiques en Acadie. On ne peut faire abstraction, en effet, du fait que l'on est face à un discours qui, comme toute prise de parole, ne s'inscrit pas dans un vacuum mais s'insère dans un paysage discursif particulier. En l'occurrence, la communauté étudiée est particulièrement en butte à des représentations négatives quand on en vient aux pratiques linguistiques de ses membres.

Bien des travaux ont pu montrer le rôle prépondérant de la presse dans l'élaboration et la diffusion d'idéologies à caractère linguistique (Johnson et Esslin, 2007 ; Johnson et Milani, 2010). De fait, en Acadie, la presse francophone est un véhicule de premier plan pour proposer et débattre de questions linguistiques. Plusieurs travaux avant le mien ont souligné et analysé le rôle patent des journaux et autres médias acadiens en la matière, dont Boudreau $(2009,2011,2012)$ et Boudreau et Urbain (2013).

Voici comment ces dernières justifient et expliquent le recours à la presse et en l'occurrence à la presse acadienne :

Le discours de la presse en milieu minoritaire est un objet d'étude d'autant plus pertinent que les journaux et les périodiques ont souvent été, pour les groupes historiquement dominés ou opprimés, une voie d'accès privilégiée au discours public [...]. Comme l'ont illustré certains travaux en Critical Discourse Analysis (CDA) ou en étude des communautés minoritaires, le fait même d'avoir accès à une prise de parole publique, et d'autant plus écrite ou imprimée - que ce soit comme producteurs ou objets des discours - illustre souvent des rapports de force entre différents groupes d'acteurs sociaux. Ces inégalités dans l'accès aux ressources symbo-

5. La littératie est, à l'instar de tout concept, sujette à une définition mouvante. Il n'en demeure pas moins qu'elle est parfois saisie de façon rigide et univoque. En fait, ou on ne la définit pas (on la prend comme un allant de soi) ou on la définit trop. Pareillement, vu que l'alphabétisation est empreinte d'idéologies, linguistiques et autres (Barton, Hamilton et Ivanić, 2000 ; Street, 1995), elle ne se réduit pas à une opération technique visant l'acquisition de compétences linguistiques. 
liques que constitue le discours de presse ont de nombreuses conséquences sur le plan des dynamiques sociolinguistiques et posent toutes une série de questions : qui s'exprime et qui peut s'exprimer (qui a le capital symbolique pour le faire) ? Quels sont les intérêts des acteurs qui prennent la parole? Quelles sont les stratégies adoptées, en visant quel public et dans quel but? (Boudreau et Urbain, 2013 : 25)

J'adopte dans ma recherche une perspective historique dans le but de suivre le cheminement du thème qui me préoccupe. Pour ce faire, j'opère un dépouillement exhaustif de trois journaux acadiens qui se sont succédé (où ont parfois coexisté) de 1867 à nos jours. Il s'agit de l'Acadie nouvelle, quotidien fondé en 1984 et toujours en activité ; de l'Évangéline qui publia de 1887 à 1982 ; du Moniteur acadien, fondé l'année même de la Confédération, il publiera des numéros de façon pas toujours quotidienne jusqu'en 1926. Dans la mesure où désormais plusieurs travaux ont porté sur ces trois organes de presse, j'invite le lecteur à consulter les titres opportuns ${ }^{6}$. On retiendra une offre de titre limitée qui ne permet peu d'études contrastives mais qui témoigne du rôle central de chacun de ces organes de presse pour la communauté.

Mon exploration de ces journaux se veut exhaustive. L'ensemble des numéros des journaux visés est dépouillé électroniquement ou manuellement, selon les journaux et les périodes visées. J'ai recherché tout écrit contenant les mots alphabétisation et dérivés, littératie (y compris sous la graphie littéracie), illettré et ses variantes et de façon plus aléatoire tout article consacré à la pratique de la lecture en Acadie ${ }^{7}$. Cette perspective historique me permet d'emblée de dire que le traitement de la question de l'alphabétisation a changé. Il y a eu en effet des tournants dans le traitement du thème, dont un majeur : quelque part au milieu des années 1990, l'alphabétisation a été constituée comme un problème social actuel et local. De fait pendant longtemps, l'analphabétisme c'était le problème des autres : un simple sujet mentionné à la faveur d'une actualité plaisante, ainsi dans l'Évangéline du 22 juillet 1977 on trouve une nouvelle quelque peu sensationnaliste : des étudiants de l'Université de Calgary ne sauraient pas lire, le 23 septembre de la même année c'est le cas similaire d'un diplômé de Seattle qui est mentionné. Le sujet est traité de façon bien moins anecdotique quand il s'agit de «l'analphabétisme dans le monde », à savoir dans les pays pauvres, pays pauvres qui sont alors à soutenir dans un mouvement empreint d'un colonialisme encore récent (plusieurs lettres ouvertes dans L'Évangéline vont dans ce sens, voir par exemple l'édition du 30 septembre 1971). Dans L'Évangéline daté du 16 mai 1962, c'est la situation préoccupante en matière d'analphabétisme en Amérique du sud, Asie et Afrique qui est portée à l'attention des lecteurs et lectrices. On souligne alors que cette réalité est inconnue dans les « pays riches, dont le Canada ». On met enfin de l'avant

6. Sur L'Acadie Nouvelle, voir Eddie (2011), sur L'Évangéline, voir Beaulieu (1997) et Eddie (2015). Voir aussi Beaulieu (1993) et Watine (1992 et 1993). Ces contributions éclairent notamment sur le lectorat et la politique éditoriale de ces organes de presse.

7. Le corpus récolté jusqu'ici (plusieurs années restant à reconsidérer) comprend 763 documents de presse (articles, éditos, lettres ouvertes, annonces publicitaires). 
le rôle capital que peut jouer l'Église catholique pour remédier à cette situation. Dans L'Évangéline du 24 octobre 1978, c'est le cas de l'Égypte qui est mis de l'avant, etc.

Bien entendu, il faut garder en tête qu'avant la fin du dernier quart du XXe siècle la notion de littératie (a fortiori le terme lui-même en français) n'était pas vraiment en circulation. De plus, à toute époque, l'on pouvait parler du niveau d'alphabétisation sans utiliser le mot. Ceci étant, les parties du corpus qui ont dû être dépouillées manuellement (les numéros de L'Évangéline entre 1959 et 1982 et ceux de L'Acadie Nouvelle de 1998 à 1984) me permettent de poser qu'il y a un changement observable.

Une transition discursive a donc lieu dans la presse acadienne au début des années $1990^{8}$. Selon la littérature sur le sujet pour la France, l'analphabétisme comme problème national pointe dans les médias et plus largement dans le discours public à partir du milieu des années 1980 (voir les études de Lahire 1992, 1999 ; voir aussi Espérandieu et Vogler, 2000). Si, en Acadie, il semble arriver un peu plus tard, le sujet s'impose avec la même rhétorique destinée à en démontrer la gravité. À partir de la moitié des années 1990, l'alphabétisation fait l'objet comme problème social d'une construction discursive. On peut ainsi établir nombre de parallèles avec le travail de Gusfield (1981) sur la construction sociale du problème de l'alcool au volant. Dans The Culture of Public Problems (1981), le sociologue cherche en effet à comprendre pour quelles raisons et sous quelles conditions la conduite automobile sous l'emprise de l'alcool est devenue une préoccupation sociétale. Il observe les conditions d'émergence de cette question, ensuite la constitution, la stabilisation et l'institutionnalisation.

À partir de mes données, je propose que l'on regarde cette période où l'alphabétisation est devenue un problème social ${ }^{9}$. Nous verrons alors que ce sujet est traité le plus souvent de deux façons presque opposées. On en propose une approche que je qualifierai de discours d'alarme où la gravité de la situation est posée à coup d'experts, de données quantitatives via la statistique et d'études internationales, nationales ou régionales convoquées pour poser la gravité de la situation. Le propos en est souvent un de condamnation et d'appel à réagir. Ce sont alors le plus souvent les mêmes ingrédients que dans d'autres discours sur la qualité de la langue en Acadie que l'on retrouve (appel à l'effort individuel, incrimination du bilinguisme et plus particulièrement du mélange de codes, blâme individuel ou collectif pour un manque de fierté linguistique, etc...). De façon contrastante, on trouve également un traitement que je qualifierai de discours d'espoir essentiellement qualitatif,

8. Jusqu'à un certain point, il est possible de relier l'apparition du thème à l'universalisation de la mesure de l'alphabétisation par les instances internationales type OCDE.

Sur un autre plan notons que le premier organisme en charge de l'alphabétisation au Nouveau-Brunswick (APA, Association provinciale d'alphabétisation) voit le jour en 1988 (voir L'Acadie nouvelle du 3 aout de cette année-là).

9. Mon objectif avec cet article n'est pas de proposer une explication d'ordre social et politique au cheminement du thème. J'adhère à une vision critique des politiques d'alphabétisation que je peux résumer ainsi : les transformations globales qui affectent, au moins depuis le dernier quart du XXe siècle, tous les secteurs professionnels induisent pour quasiment tous les postes de travail un usage professionnel de la langue, sous forme écrite et/ou orale, cette « part langagière du travail » (Boutet, 2001, 2007) appelle les tats à capitaliser sur les compétences linguistiques de leurs citoyens. Ceci étant, je conclurai ma contribution en présentant ce que je considère comme une clé de compréhension de la prégnance du thème en Acadie. 
très personnalisé, qui passe en particulier par l'exercice du portrait ou de l'autoportrait. L'espoir se donne alors à voir par le récit de parcours individuels particulièrement résilients. Ce sont ces deux façons d'aborder la question que je propose de regarder maintenant ${ }^{10}$.

\section{Le traitement alarmiste}

Dans le corpus de presse sur lequel je travaille, ceux qui traitent du sujet du niveau de littératie en Acadie en font très souvent un « sujet chaud ». Ils dressent un tableau alarmant qui vise à interpeller, émouvoir, choquer. On a affaire à un « cadrage de crise » tel que le décrit Cameron (2007) lorsqu'un sujet n'a pas directement les caractéristiques qui en font une «news value ». Cette technique qui marque bien des discours sur la langue dans les médias est employée pour faire d'un sujet a priori peu médiatique, un sujet mainstream et digne d'intérêt. Chez Cameron, il est question du thème des langues en danger et ce qu'elle décrit est très nettement applicable à mon sujet. La description est un peu longue mais mérite d'être citée :

During the past ten years, the plight of endangered languages has attracted increasing interest from the mainstream media. [...] Since the representation of any issue for a mass audience has implications for the way it is understood, it is of interest to inquire how - that is, through what kind of representation - language endangerment has been able to move into the mainstream. A useful parallel here is with climate change [...]. One thing the two issues have in common is that they do not fit the prototype for news stories [...]. To make such issues newsworthy, it is necessary to inject drama and urgency by framing them as grave crises which we ignore at our peril. But while « crisis » framing may give an issue greater mainstream visibility, it can also lead to unbalanced and misleading coverage [...] In an effort to fit the facts to the frame, statements about to extend of the problem may be reproduced shorn of the caveats their expert sources were careful to include ; disagreement among experts may be glossed over in formulations like « many scientists believe... »; prominence may be given to the most extreme and alarmist expert predictions, or even to predictions no expert has made, but which journalists have extrapolated from their inexpert reading of the evidence. (Cameron, 2007 : 268-269)

Nous allons voir que nous retrouvons des éléments similaires dans le traitement de notre sujet. Premier ingrédient qui permet de poser un diagnostic en apparence alarmant: l'utilisation de termes qui ne sont pas toujours transparents. Il est temps de faire le point sur les mots du débat : littératie et alphabétisation. Plusieurs sources montrent que l'usage du terme littératie explose après les années 1980. Malgré sa popularité, le terme reste encore un mot savant dont il n'est pas toujours aisé de dé-

10. Dans une contribution issue d'une recherche sur le milieu de l'alphabétisation en Ontario français, Budach (2003) identifie trois types de discours sur l'alphabétisation : un discours de l'alphabétisation populaire, un discours de l'alphabétisation culturelle et un discours de l'alphabétisation bureaucratique. Elle indique que chacun « exerce un certain pouvoir de domination à un moment donné de l'histoire et des débats sur l'alphabétisation aux adultes en Ontario. » (2003: 337). Il se peut qu'une telle répartition se retrouve dans mes données. Cette piste est certainement à creuser. 
finir les contours. La littératie a été qualifiée par l'OCDE de comportement, d'aptitude ou de capacité des adultes à utiliser et à comprendre l'écrit au quotidien. Elle est devenue ensuite une compétence clé en traitement de l'information. Cette notion « englobe une variété de compétences, depuis le décodage de mots et de phrases jusqu'à la compréhension, l'interprétation et l'évaluation de textes complexes» (OCDE, 2013:64) ${ }^{11}$. On comprend donc que littératie n'est pas équivalent d'alphabétisme et qu'un déficit de littératie ne fait pas de l'individu un analphabète. En fait l'individu en déficit de littératie serait un illettré mais le néologisme lettrisme (et ses dérivés), favorisé contre l'emprunt, n'a pas accroché au Canada français ${ }^{12}$. Les choses se compliquent dans la mesure où ce qui est proposé pour lutter contre un déficit de littératie, c'est de l'alphabétisation (et non de la *littérarisation). Ainsi, on en arrive souvent dans le discours à un certain mélange des genres où la non-équivalence entre alphabétisme et littératie n'est plus claire pour le lectorat. Est-elle claire pour celui qui mobilise ces termes? En fait, cette question n'est pas abordée minutieusement et techniquement mais souvent à grands traits. L'efficacité du propos compte sur d'autres ingrédients. D'abord, pour affermir son dire, le discoureur (auteur de l'article, expert cité dans l'article) construit son éthos. II se présente comme un citoyen éminemment concerné, à la conscience civique et communautaire doublée en général d'une expertise de premier plan parce que peu ou prou spécialiste de la langue (enseignant, écrivain, ...). On livre donc un discours de l'auctoritas. Nous avons aussi affaire à un discours de l'emphase : le problème est important quantitativement (plus de $60 \%$ d'inaptes à lire L'Acadie Nouvelle), mais il y a aussi sa dimension qualitative, ses conséquences: l'analphabète, le peu-lettré est dépourvu de toute capacité expressive, sans ressources linguistiques, enfermé dans l'inculture de l'oral, privé de toute prise de pouvoir sur sa vie, ce qui le conduit nécessairement vers les crises familiales à répétition (il est un parent dysfonctionnel, une famille monoparentale), la malnutrition (il est ou va devenir obèse, diabétique ..., il coûte cher au système de santé), le sous-emploi (inutile dans une société du savoir), le désintérêt citoyen (il ne vote pas), etc. Avant tout, on assène des chiffres écrasants :

Autre statistique alarmante, M. Jeune souligne «qu'en 2003, selon la dernière recherche menée par l'Enquête internationale sur l'alphabétisation et les compétences des adultes (EIACA), au N.-B., 66 \% des Acadiens et francophones se situaient dans les deux niveaux d'alphabétisme les plus bas! Ceci confirme l'importance d'une Journée internationale de l'alphabétisation afin d'informer la population qu'encore en 2011, la situation persiste, et même s'aggrave dans certains niveaux d'âge. » (AN, 8 septembre 2011)

11. Si la littératie fait l'objet de définitions institutionnelles changeantes c'est précisément parce qu'elle est un objet de lutte idéologique. Je ne débats pas ici de ses acceptions dans le discours institutionnel, ni dans le discours savant. Je présente toutefois a minina, quelques éléments définitoires, voir notamment les notes 2 et 4 , voir aussi ci-dessus).

12. Voir la fiche terminologie qui est consacrée à ce terme par l'Office québécois de la langue française, http://www. granddictionnaire.com/ficheOqlf.aspx?ld_Fiche=8363201 (fiche consultée le 23 avril 2019). 
une majorité de Néo-Brunswickois se situe sous la moyenne nationale en matière d'alphabétisme. La situation est pire chez les francophones de la province puisque $66 \%$ d'entre eux ont un niveau de lecture inférieur à 3 , niveau considéré comme étant nécessaire afin de fonctionner dans une société du savoir (AN, 8 septembre 2008)

Les chiffres sont éloquents. Au Nouveau-Brunswick, les deux tiers des adultes n’ont pas le niveau de littératie nécessaire pour fonctionner dans un milieu de travail. À l'école, de 20 à $30 \%$ des élèves ont de la difficulté à lire au niveau souhaité pour leur âge. (AN, 28 janvier 2014)

Selon la formule les chiffres parlent d'eux-mêmes, de nombreux articles sont émaillés de chiffres. Ceux-ci sont, comme toutes statistiques, fondés sur des méthodes d'échantillonnage. Ils sont pourtant donnés pour la réalité alors que ce qu'ils sont vraiment ce sont des estimations, estimations pas absolument représentatives dans la mesure où une partie ne peut jamais valoir pour le tout. Ces résultats, en passant du champ de l'expertise au champ médiatique, se simplifient encore. Ce faisant, ils captent l'attention. L'emphase se retrouve aussi sous la forme d'énumération des conséquences et des implications de ce problème : «l'analphabétisme cache souvent des problèmes plus profonds, allant des troubles d'apprentissage aux difficultés socioéconomiques qui constituent souvent le quotidien de cette population en quête d'un avenir meilleur » (AN, 9 septembre 2011). L'auteur peut proposer ensuite des solutions simples à des problèmes complexes. Si le taux de bonne littératie remonte, tout peut être réglé :

la province doit investir en littératie et en alphabétisation si elle veut voir des citoyens en bonne santé.

«Pour que la province devienne autosuffisante, il faut faire de l'alphabétisation un dossier prioritaire afin d'avoir des personnes en santé et une province en santé à tous les points de vue », a dit M. Doiron [...]

[selon la FANB] « l'alphabétisation est un déterminant de la santé globale » d'une population. Pour appuyer ses propos, l'organisme souligne que de nombreuses études ont montré que les gens aux prises avec des difficultés de lecture ont habituellement plus de difficulté à trouver un emploi bien rémunéré.

Les difficultés de lecture entraînent toutefois aussi des problèmes de santé. L'organisme explique que les gens avec un faible taux de littéracie éprouvent souvent des problèmes à repérer et à comprendre de l'information médicale. Ces difficultés peuvent entraîner l'incapacité de comprendre " une posologie ou encore des conseils médicaux ». À cet effet, le Conseil canadien sur l'apprentissage a établi un lien entre certaines maladies chroniques et la littératie en santé.

La FANB souligne que de telles difficultés de compréhension ont des répercussions sur les coûts du système de santé. [...] 
Ainsi, une étude américaine a montré que le coût nécessaire pour soigner un patient avec un bon taux de lecture est en moyenne deux fois moins élevé que le coût nécessaire pour soigner un patient qui éprouve des difficultés de lecture. (AN, 8 septembre 2008)

Ce qui caractérise ce discours, ce sont des inductions, généralisations, pseudo-évidences appuyées sur quelques chiffres ainsi que sur de «nombreuses études » souvent « américaines » dont on extrait quelques faits «choc ». On assène de grandes phrases, prêtées à des autorités, des écrivains souvent, venus d'ailleurs, ce qui assure leur autorité. Un journaliste nous rappelle ainsi que : «Prendre plaisir à la lecture vaccine contre l'échec à l'école et dans la vie. Un enfant n'aimant pas la lecture est en danger», avait exprimé Alexandre Jardin [lors de son passage à Moncton] » (AN, 28 octobre 2014). En fait, les mêmes ingrédients reviennent sans cesse : poids des chiffres, parole rapportée d'experts pas toujours nommés, mention d’organismes aux noms éloquents, renvoi à des études qui ont toute l'apparence du plus grand sérieux et dont on extrait des citations tronquées jamais référencées : « une étude, une récente étude, une étude américaine, de nombreuses études... » qui ont toutes « montré, démontré, prouvé ». On note aussi une multiplication des termes : analphabétisme, niveaux 2 ou 3 d'alphabétisation, analphabétisme fonctionnel, défaut de littératie, ... Les appellations ne manquent pas, mais ce qu'elles recouvrent n'est pas toujours clair. À la lecture des articles, il ressort un flou terminologique qui explique l'alternance souvent aléatoire de ces diverses appellations alors qu'il n'est pas aisé de cerner ce que les termes veulent dire pour leurs usagers et comment ils caractérisent ceux qui en sont affublés. Enfin, quand on en vient à proposer des explications des faits que l'on vient de poser c'est, comme souvent quand il est question de langue et de qualité de la langue en Acadie, sur le compte de la situation minoritaire que la faute retombe. À partir de l'idéologie très ancrée du monolinguisme (Boudreau, 2009), la présence de l'anglais dans la vie des Acadiens et des Acadiennes serait en cause. Ainsi, dans une lettre ouverte, le chiac est pointé :

puisque Acadieman, qui parle le chiac, est proposé à l'humanité comme " héros acadien », il conviendrait de se demander : «Quelle philosophie de vie sociale et culturelle, quelles valeurs humaines, civiques et spirituelles sont véhiculées par ce personnage ? » [...]

Faire la promotion du chiac dans un contexte scolaire, sans comprendre suffisamment, au préalable, la place qui lui revint en Acadie et l'utilisation que l'on doive en faire dans l'ensemble de la Francophonie risquerait, je le crains, d'enfreindre les efforts déployés vers la maîtrise du français standard, au niveau de l'alphabétisation des adultes et dans la lutte contre l'assimilation. (AN, 19 février 2009)

Au milieu de la kyrielle des maux linguistiques qui guettent les francophones en Acadie, il y a le mélange de langues, la difficile maitrise du français standard, le bas niveau d'alphabétisation qui n'a d'équivalent que le haut niveau d'assimilation. On fait comme si le diagnostic était imparable et le propos n'est plus interrogé, on parle sur le mode du constat : « le milieu minoritaire dans lequel on vit [est] très en arrière en termes d'alphabétisation et de littératie » (AN, 28 octobre 2014). Ce discours d'évidence fait partie de la matrice discursive dès lors que l'on parle de langue en Acadie. Les « il va de soi », « il est évident », et plus largement l'implicite sont de mise. Dans le corpus, on peut relever 
nombre de mots, expressions, formulations qui induisent l'idée que le discours de l'énonciateur repose sur des évidences, se fonde sur le sens commun. Un seul exemple nous montre le niveau de généralisation d'un propos qui se donne comme une sentence : « le fait de développer le goût des livres ne peut pas faire autrement que d'être positif pour l'alphabétisation dans la province » (AN, 28 octobre 2014). Alors même que le propos fait largement consensus, son énonciateur le présente de façon appuyée dans une logique de l'accumulation, ainsi dans une lettre ouverte une lectrice dénonce les maux du Nouveau-Brunswick:

Le Nouveau-Brunswick a la pire performance économique de toutes les provinces. Nos jeunes partent pour l'Ouest à un rythme alarmant. Les coûts des soins de santé sont immenses, car notre population vieillit et, en moyenne, nous pesons plus, fumons plus et buvons plus que la moyenne nationale. Plus de la moitié des adultes qui habitent ici n'ont pas le niveau d'alphabétisation ou les compétences de travail dont ils ont besoin pour trouver des emplois. (AN, 10 septembre 2014)

À travers ce concert d'accords reviennent certaines images, trois sont récurrentes : celles de la maladie, de la peur et de la lutte. Sans hiérarchie, on note la présence du vocabulaire de la maladie: citoyens infirmes, handicapés, souffrant d'un mal qu'il s'agit de dépister puis de traiter (rappelons l'usage du mot vacciner plus haut), de soigner ; citoyens peu lettrés souffrant aussi de maux physiques comme on a pu le voir plus haut; ceux qui la combattent sont des missionnaires, ceux qui la surmontent de véritables héros comme on le verra plus bas. Relevant du champ lexical de la maladie, on peut citer l'image des « séquelles » qui se « transmettent », du «mal dont on souffre » (dans l'extrait ci-après). La littératie devient alors un ingrédient du bien-être global. Une annonce pour un programme inter-générationnel de bien-être s’énonce ainsi :

Ce programme regorge d'activités amusantes et éducatives en lien avec tous les volets du mieux-être. Pendant 10 semaines, plusieurs intervenants se relayeront pour vous informer et vous guider, et animer une foule d'activités touchant divers aspects du mieux-être (yoga, zumba, activités physiques, alimentation saine, littératie, hygiène, santé mentale et émotionnelle, santé auditive, visuelle et dentaire, et sécurité). [...], les participants pourront s'occuper de divers aspects de leur bien-être (AN, 23 novembre 2018) 
On peut penser aussi à l'activité de levée de fonds communautaire Legs for Litteracy/Courir pour lire dont il est fait promotion de la dernière édition ainsi : «Voilà un événement qui jumelle le mieux-être, le conditionnement physique et la littératie, tous des ingrédients clés afin d’aider les Néo-Brunswickois à améliorer la santé de leur corps et de leur esprit » (AN, 3 novembre 2006) ${ }^{13}$.

On relève aussi le vocabulaire de la peur: une mauvaise littératie est associée à l'échec scolaire puis social et nuisible à l'Acadie tout entière et contre cela, il faut se mobiliser, d'où le thème de la lutte : l'alphabétisation devient une nouvelle terre de mission et la lutte prend les allures d'une véritable guerre sainte. On se rappelle du mot « croisade » cité plus haut ${ }^{14}$. Dans une longue lettre ouverte voici un extrait du portrait de la situation brossé par un acteur communautaire:

«Un peuple illettré est voué à l'assimilation » [... Voilà en quelques mots l'épée de Damoclès qui menace l'Acadie du Nouveau-Brunswick, en particulier.

Le rapport Landal, L'Évaluation intégrale des besoins en formation en alphabétisation au Nouveau-Brunswick, publié en octobre 2002, révélait que parmi les adultes francophones de cette province, 68 \% ne possèdent pas « des capacités suffisantes de lecture, d'écriture et de calcul pour survivre jour après jour dans un monde axé sur l'information écrite » [...]. Ce qui est plus alarmant encore, c'est que, de ce $68 \%$, les trois quarts, environ, sont âgés entre 16 et 25 ans.

Les conséquences de cette situation sont nombreuses et plus tragiques les unes que les autres. Le niveau économique étant directement relié au taux d'analphabétisme du milieu, c'est toute la communauté, toute la province, voire le pays entier, en fin de compte, qui en souffre. Et les séquelles se transmettent généralement d’une génération à l'autre, les capacités en littératie des jeunes adultes n'atteignant même pas, parfois, le niveau de celles de leurs parents, toute proportion gardée, compte tenu des exigences d'une société en mutation. (AN, 18 décembre 2004)

13. Je remercie l'évaluateur qui a suggéré que l'avènement d'un discours médicalisant ainsi que celui qui pose la littératie comme un élément de bien-être global (de l'individu mais aussi de la collectivité) pourrait être mis en lien avec tous les discours de l'art de vivre (« lifestyle») qui semblent parfois remplacer ou du moins doubler des discours plus politisés voire militants. Nous verrons plus loin le traitement très individualisant de la question avec les récits de vie des ex-analphabètes qui se donnent à voir, comme l'a noté l'autre évaluateur, tel des récits exemplaires. Le va et vient entre l'individu et la collectivité est alors constant. Sur le rôle de la responsabilité individuelle en matière de préservation du groupe (dans ses assises linguistiques et nationales) voir Arrighi et Violette, 2013. Dans le cas de figure envisagé dans la contribution de 2013, on voit aussi dépeintes des tranches de vie données comme exemplaires.

14. Notons que cette façon de dépeindre l'analphabétisme, comme un fléau à éradiquer ou une maladie dont les victimes infortunées peuvent être traitées et doivent guérir est dénoncé par certaines instances en charge de l'alphabétisation. Ainsi, un rapport de l'UNESCO souligne les « connotations très négatives de l'analphabétisme [qui] ont stigmatisé ceux qui avaient des compétences faibles en écriture et ont contribué à forger un concept dichotomique plutôt que continu de l'alphabétisme. » (UNESCO, 2006 : 173). 
Indiquons que les thèmes de la maladie, la peur et la lutte sont ceux-là mêmes qui caractérisent de façon plus générale bien des discours sur la qualité de la langue, notamment celui concernant les anglicismes (Bérubé, 2010). Il faut que tout le monde s'engage et lutte, car telle une maladie, l'anglicisme comme l'illettrisme font peur et sont à combattre. Le thème de la lutte est particulièrement développé : il faut se mobiliser, fourbir ses armes et frapper efficacement là où ça fait mal. En 2015, à peine élu, le nouveau gouvernement provincial met sur pied un comité de lutte contre l'analphabétisme nommé selon une rhétorique très en vogue « la Stratégie d'alphabétisation du NouveauBrunswick ». Le premier ministre d'alors, Brian Gallant en a fait l'annonce à l'Assemblée législative et L'Acadie Nouvelle relate la nouvelle:

«Les deux coprésidentes mèneront un processus d'engagement visant à consulter le public et les experts afin de trouver des solutions ingénieuses et transformationnelles pour relever nos défis en matière de littératie », a déclaré Brian Gallant. « Pour soutenir la création d’emplois, accroître la productivité et combattre la pauvreté, nous devons mettre l'accent surtout sur la littératie. » (AN, 11 mars 2015)

Au passage, notons ici la présence d'un thème issu de l'idéo logie néo-libérale voulant que la littératie soit un ingrédient de la réussite économique (des individus mais surtout des communautés). Ainsi, nous retrouvons dans le corpus un discours de l'alphabétisation bureaucratique (selon le mot de Budach, 2003 ${ }^{15}$ ), celui qui promeut l'alphabétisation comme moyen de répondre aux besoins des employeurs et vise l'adaptation de la main-d'œuvre aux nouvelles conditions économiques. Ce faisant, il est question de «niveaux de rendement en littératie » (AN, 21 octobre 2016), de bons ou de mauvais rendements, individus comme gouvernements sont invités à investir en alphabétisation et en littératie, etc.

Enfin, en parallèle à un traitement global et alarmiste de la question, celle-ci est aussi, en même temps, envisagée de façon plus personnelle et positive. Après avoir brossé un tableau désastreux, on travaille à souligner les bons coups, les réussites, on fait une belle part à ces héros du quotidien qui donnent sans compter pour une meilleure littératie en Acadie ou qui se sont dépassés pour sortir de cette condition.

\section{Portrait de l'analphabète}

Présenter la nouvelle par un traitement qui n'accable pas trop la communauté est un mandat implicite du journaliste en milieu minoritaire (Corriveau, 2006 ; Beauchamp et Watine, 2006). Une façon de présenter sous un jour favorable un sujet qui, par ailleurs, fait globalement l'objet d'un traitement négatif est de miser sur le singulier. Le cas personnel, relevant plus ou moins de l'exceptionnel, est

15. Plus qu'une manière d'en parler, ce que Budach (2003) nomme l'alphabétisation bureaucratique, c'est une façon de l'envisager propre au virage néo-libéral. Désormais, les investissements en la matière se doivent d'être rentables, les résultats sont donc évalués, les formateurs professionnalisés, les bénéficiaires rigoureusement sélectionnés selon leur potentiel d'employabilité, etc. 
alors là pour donner le bon exemple. Dans des travaux antérieurs sur les communautés francophones minoritaires en Amérique du Nord, j’avais déjà pu constater avec ma collègue Émilie Urbain qu'une présentation positive de membres de ces communautés voyait le jour dès lorsqu'il s'agissait de promouvoir des activités et initiatives individuelles ou communautaires (Arrighi et Urbain, 2016, 2016/2017). On loue d'autant plus l'agentivité individuelle ou l'efficacité communautaire que les ressources sont maigres, le contexte fortement minoritaire, etc. On propose alors des modèles à suivre sous forme de portrait où le dévouement des uns n'a d'égal que l'héroïsme des autres. Ces panégyriques de bons membres de la communauté sont légion. Ce qui m’a frappé en dépouillant le corpus, c'est le nombre d'articles qui rendent compte de médailles, prix, bourses pour les organismes, institutions, individus qui œuvrent dans le domaine de l'alphabétisation :

Un citoyen de Le Goulet, dans la Péninsule acadienne, fait partie des lauréats régionaux du prix en alphabétisation de l'Association canadienne d'éducation de langue française et de la Fédération canadienne pour l'alphabétisation en français. Donat Roussel recevra une bourse de 100 \$ et un certificat. Un jury composé de trois apprenants et de deux formateurs en alphabétisation a sélectionné les textes en fonction des défis que la personne a réussi à relever. Au total, 86 Canadiens ont participé au prix en alphabétisation. (AN, 26 mai 2004)

Au total, l'Association pour l'alphabétisation du Grand Moncton (Greater Moncton Literacy Advisory Board) a remis six prix à des apprenants adultes, trois dans la catégorie francophone et trois dans la catégorie anglophone. Chacune des auteures en herbe a relaté son parcours, parfois difficile et touchant. (AN, 27 avril 2009)

La représentation des analphabètes que nous offrent les médias est ainsi équivoque. D'une part, on dresse de l'analphabète générique un sombre portrait, d'autre part, on propose de l'analphabète spécifique un portrait plein d'espoir et de lumière. S'alphabétiser, c'est s'améliorer et surtout améliorer la société, comme dit une formatrice citée dans un article : «Il n’y a pas de honte à suivre des cours d'alphabétisation. Des gens éduqués permettent de former une société plus démocratique. L'alphabétisation est là pour répondre aux besoins actuels et futurs du marché du travail. » (AN, 6 mars 2001). Le « choix » de l'alphabétisation est présenté comme un engagement qui suppose un projet de transformation et de réappropriation de sa vie. L'ex-analphabète, celui qui n'a pas eu " honte à suivre des cours d'alphabétisation », est présenté dans le cadre d'une véritable histoire à succès, disant sa résilience et son empowerment. Pour construire un certain pathos, on appuie le côté histoire à succès en rappelant la vie difficile des portraiturés, reprenant à l'échelle individuelle 
les composantes du discours alarmiste mis au jour ci-haut. Nombre d'articles rendent compte de parcours individuels difficiles mais transcendés ${ }^{16}$ :

Mère de trois jeunes enfants, Mélanie Massé a trouvé le courage et la détermination nécessaires pour retourner aux études et obtenir son diplôme d'équivalence d'études secondaires. / Malgré un parcours difficile, elle a su surmonter les obstacles afin de réaliser son rêve, celui d'être acceptée au programme de Techniques d'intervention en délinquance du CCNB. / Mélanie Massé a indiqué vouloir se servir de son expérience de vie afin d’aider les jeunes à retourner sur le droit chemin et à réaliser leurs rêves. (AN, 9 septembre 2015)

"L'alphabétisation a été le commencement de ma vie », avoue Claudette Audet. /Orpheline de père, la jeune fille, huitième d'une famille de neuf enfants, doit à l'époque quitter l'école pour aider sa mère à subvenir aux besoins de la famille. / À l'âge adulte, avec une faible estime d'elle-même, Claudette Audet se replie sur elle-même et ne fréquente les magasins qu'en compagnie d'amis ou de proches et doit demander de l'aide de ses voisins pour les devoirs de ses enfants. / Inscrite à des ateliers d'alphabétisation, la mère de famille reprend peu à peu confiance et est aujourd'hui propriétaire d'un foyer pour soins spéciaux. Mme Audet œuvre également au sein de la Croix-Rouge et recevait, en avril dernier, le prix de l'Apprenante de l'année des mains du ministre de l'Éducation du Nouveau-Brunswick. (AN, 10 septembre 2001)

Claudette Audet, originaire de Val-d'Amour, a remporté le prix de la Francophonie en alphabétisation. Elle a reçu une bourse de 1000 \$ dans le cadre de la Journée internationale de la francophonie. / Mme Audet a mérité le prix pour avoir écrit un texte touchant sur les changements survenus dans sa vie lorsqu'elle a appris à lire, à écrire et à compter. / Le concours s'adressait à des adultes inscrits en alphabétisation. / « Je peux dire que l'alphabétisation a changé ma vie et a probablement sauvé ma vie, a écrit Mme Audet. Je suis plus sociale, je m'isole moins. Du fait que je m'affirme, je suis plus respectée, personne ne peut me dire que je suis une moins que rien, je suis capable de parler et je ne suis plus gênée. » (AN, 21 mars 2002)

Tel un publi-reportage, ce type de portrait, à la faveur de la Journée internationale de l'alphabétisation, se présente sous la forme d'un encadré.

16. Pour avoir fréquenté des organismes en charge de l'alphabétisation, je peux indiquer que l'exercice du portrait fait partie des activités proposées aux bénéficiaires notamment comme moyen de donner sens à sa trajectoire. C'est aussi un « exercice » demandé dans le cadre de certains événements et concours tels ceux mentionnés dans le corps du texte. Le meilleur récit de vie se voyant récompensé. La presse locale publie alors ces portraits comme à l'occasion de la Semaine de la fierté française, elle publie l'autoportrait de bons élèves engagés dans la cause du français (voir Arrighi et Violette, 2013). 


\section{Journée internationale de l'alphabétisation}

\section{Mission accomplie pour Genéva Léger}

Lorsque Genéva Léger de NotreDame-de-Kent a pris sa retraite, une amie lui a conseillé de suivre des cours en alphabétisation. Même si elle savait lire et écrire, Genéva voulait s'améliorer pour réaliser l'un de ses plus grands rêves : travailler sur une collection de photos de famille et raconter son histoire avec des faits vécus. Elle voulait faire ce projet sans faire de fautes d'orthographe.

Mme Léger a travaillé au cours de sa vie comme commis dans un magasin et comme concierge à l'Université de Moncton. Elle a dû faire preuve de persévérance car elle manQuait de confiance lorsou'il était question

d'entreprendre des travaux d'écriture.

* Je riavais pas ma $12^{*}$ année, mais je me suis toujours débrouillée Quand même! l'ai persisté dans mes emplois parce Qu'ils étaient permanents et bien rémunérés.

"Avec la formation en alphabétisation que j'ai reçue, je me vois plutôt comme recherchiste en

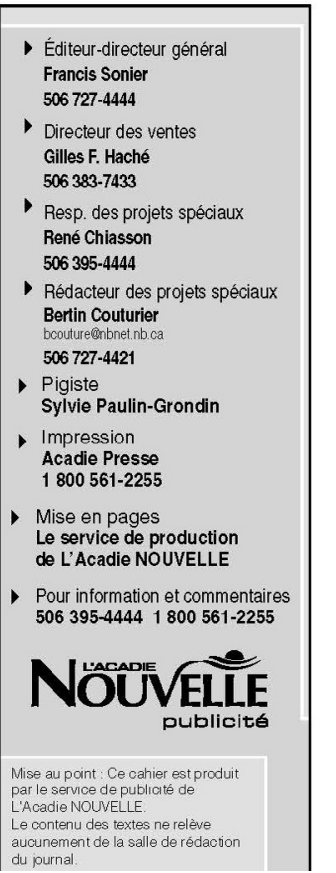

\author{
généalogie. C'est \\ une passion que j'ai \\ découverte lorsque \\ jai suivi mes classes \\ en alphabétisation, 》
}

Mme Léger, Qui a remporté le prix Northup Frye en avril dernier, avai soif de vouloir écrire dans un bon français. Elle est allée dans les classes d'alphabétisation à NotreDame et à Saint-Antoine.

Elle fait partie de la liste des finalistes nationaux dans la catégorie Accomplissement personnel, au
Prix communautaire de l'alphabétisation 2009 de Postes Canada.

Avec la formation en alphabétisation, j'ai plus de confiance en moimême. Par exemple, je suis actuel lement secrétaire du Club de l'âge d'or à Notre-Dame, Queloue chose Que je n'aurais jamais pensé pouvoir faire un jour. Je suis aussi présidente du comité familial du foyer à SainteAntoine. le fais également de la lecture à l'église. Avant, je n'aurais jamais osé lire devant le public. le me surprends à aimer ça et ce sont des qualités que je ne pensais pas Que j'avais. "

Mme Léger encourage fortement toute personne à poursuivre une formation en alphabétisation. Personnellement, un nouveau monde s'est ouvert à moi. Je n'ai

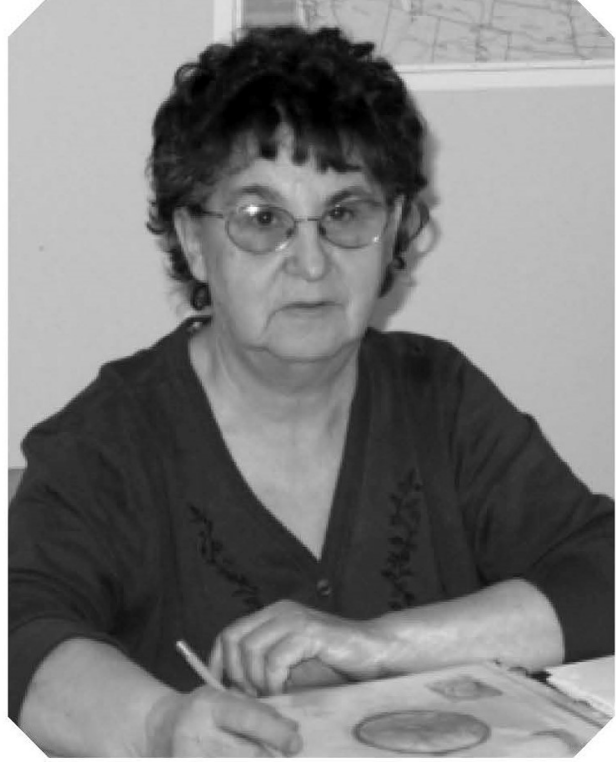

Genéva Léger peut être fière d'elle. Son parcours en alphabétisation lui proarre de belles expériences. pas de mots pour exprimer tout ce oue je ressens. Auparavant, jétais toujours négative et les autres étaient toujours meilleurs
Que moi. Maintenant, je me compte chanceuse : je réalise ou'il y a des gens qui ont vécu des expériences plus pénibles que moi. *
Le conseil d'administration, la directrice générale et les employés de la

Fédération d'alphabétisation du Nouveau-Brunswick profitent de la Journée internationale de l'alphabétisation pour souligner le courage et la

persévérance des apprenants en alphabétisation. Ils tiennent aussi à remercier les personnes qui oeuvrent à l'avancement de l'alphabétisation en français au Nouveau-Brunswick.

Bonne Journée internationale de l'alphabétisation!

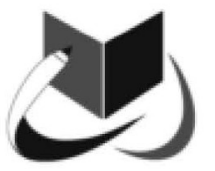

\section{Agir pour garantir l'avenir!}

Fédération d'alphabétisation du Nouveau-Brunswick

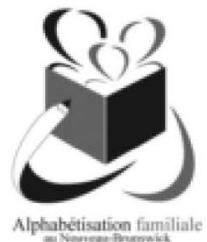
219, rue Main, bureau 8

Bathurst (Nouveau-Brunswick) E2A 1A9

Téléphone : 1866 473-4404 Télécopieur : (506) 548-5564

Courriel : fanb@nbnet.nb.ca $\quad$ Site Web : www.fanb.ca.

IMAge 1 : Portrait de GEnÉva LÉGER PubliÉ dANS L'ACAdIE Nouvelle (8 SEPTEMBRE 2009)

Alphabétisation en milieu de travail Coordonnateur : Reno Michel Haché, M.Éd.

Téléphone : (506) 548-1943
Alphabétisation familiale Coordonnatrice : Réjeanne Cormier Téléphone : (506) 548-1942 
Ce qui ressort c'est un discours qui célèbre la résilience individuelle, met de l'avant le cas particulier pris comme modèle afin de montrer qu'en matière de compétences linguistiques, c'est possible pour tous de s'améliorer avec un peu de bonne volonté. Chacun doit faire sa part pour le plus grand bien de la communauté est un leitmotiv au sein du corpus. On rejoint là le motif de la responsabilité des citoyens en matière de préservation linguistique (Klinkenberg, 2015), discours particulièrement saillant en milieu minoritaire (Arrighi et Violette, 2013). Les compétences linguistiques sont ainsi associées à des attributs personnels (travail, effort, bonne volonté) plutôt qu'à des conditions sociologiques dans la mesure où l'on montre des individus qui ont su dépasser leurs défis de vie. Selon une idéologie forte voulant que l'amélioration des compétences linguistiques soit un processus accessible à tous moyennant un effort personnel (Cameron, 1995 ; Heller, 2007), ces portraits nous montrent comment le perfectionnement individuel est proposé comme clé pour s'en sortir et dépasser des compétences linguistiques jugées déficientes. Pour témoigner de cela, on fait large recours à la parole même de l'analphabète, ce qui est destiné à assoir le crédit du discours proposé.

\section{Pour conclure}

Je voudrais conclure cette contribution sur trois plans différents. En premier lieu, je rappelle que si le traitement médiatique de la question de l'alphabétisation en Acadie (et les idéologies qui soustendent parfois un tel traitement) me parait interrogeable, la pertinence des efforts entrepris par les agents, agentes et bénéficiaires des services dédiés me parait indéniable. S'engager dans un processus d'alphabétisation, c'est s'orienter vers une démarche de sécurisation sociale et langagière. Lise Savoie, chercheuse en travail social, a mené en Acadie un travail auprès de femmes ayant suivi cette voie (2011). Beaucoup de participantes rapportent avoirvécu, lors des sessions d'alphabétisation, des expériences qui ont transformé leur rapport à elles-mêmes et aux autres. Sans avoir nécessairement amélioré leur compétence lettrée, elles disent désormais saisir la possibilité de pouvoir prendre la parole (comme dans les portraits présentés ci-dessus). Cette prise de parole leur permet de développer une nouvelle forme de pouvoir d'agir. Un pouvoir d'agir qui débute avec la prise de conscience du fait qu'elles peuvent redéfinir une image d'elles-mêmes de manière positive. Les participantes racontent qu'elles deviennent des femmes plus autonomes qu'avant et cela se manifeste dans leurs prises de décisions, leur engagement communautaire, la création d'un nouveau sens à leur vie. On est ainsi amené à se demander si l'insécurité ressentie par ces femmes avant leur participation à des sessions d'alphabétisation était le fruit d'un manque de compétences, qui n'a pas toujours été amélioré ou d'un manque de confiance qui lui l'a été. On peut penser notamment que lors de ces sessions, elles ont rencontré un discours alternatif sur l'alphabétisation et la littératie. Ce faisant, non dans l'action en faveur de l'alphabétisation, mais dans les discours qui la promeut, il convient de souligner une certaine prépondérance de propos convenus, des motifs discursifs incontournables et une unanimité d'opinion dont on doit questionner les causes et les enjeux. Ainsi, en second lieu, je voudrais proposer une piste explicative à la prégnance de ce discours posant un déficit linguistique majeur des membres de la communauté acadienne. Au-delà du fait que la déploration du niveau de littératie semble être un sujet largement propagé médiatiquement (Lahire, 1999), pourquoi ce dis- 
cours trouve-t-il en Acadie un si bon écho ? J'ai indiqué dès l'introduction l'ampleur des discours sur les questions linguistiques en Acadie. Plus encore que le statut politique du français comme langue minoritaire, c'est la forme de la langue, sa maitrise par la population, qui est le plus souvent objet de discours et débats. Au Canada français, la question de la langue, de sa qualité, de sa transmission, est éminemment liée à la reproduction et à la pérennité du groupe, à sa survie. C'est une conception à la base du discours national et des revendications de droits des minorités (Heller, 2007), ainsi le discours sur sa qualité ne peut dès lors qu'être très chargé politiquement et émotionnellement. La crainte de disparaitre, où idéologies de la langue et de la nation se mêlent, nous ramène au lien établi entre la langue et le devoir citoyen. Enfin, prompte à accepter qu'elle est en déficit au niveau linguistique, la communauté acadienne semble accepter le diagnostic sur son niveau de littératie telle une donnée irréfutable et non telle une opération d'évaluation, comme un mécanisme au moins en partie subjectif. Il convient donc de se rappeler que les pratiques de littératie sont, comme toutes pratiques et performances socioculturelles, interdépendantes des ordres sociaux et des rapports de pouvoir particuliers où elles apparaissent. À ce sujet, et ce sera mon dernier point, j’ai avancé dès l'introduction que ce discours se comprenait dans une lecture qui, à la suite de Street (1984) notamment, pose l'alphabétisation comme une notion chargée idéologiquement. Reste en partie en suspens le fait de savoir de quelle idéologie relève-t-elle.

Si plusieurs recherches ont mis de l'avant le fait que les attentes en termes de scolarisation et plus particulièrement en termes d'alphabétisation sont modelées par les idéologies linguistiques à l'œuvre au sein d'une société et de ses aspirations en termes politiques, culturels, sociétaux et économiques ${ }^{17}$, il n'en demeure pas moins, qu'en dépit de ces nombreuses recherches, il n'est pas évident de poser quelle grande idéologie reconnue (celle du standard? du monolinguisme ?) sert la notion de littératie.

Étant donné que les discours évaluatifs sur le niveau d'alphabétisation de tel ou tel groupe peuvent servir des intérêts nettement divergents, je propose que ces discours peuvent se mettre au service d'idéologies différentes et même que ces discours permettent de voir poindre des idéologies non encore travaillées par les sociolinguistes.

L’idéologie du standard est assurément concernée dans la mesure où toute valorisation des compétences lettrées est à la fois un ingrédient et un moteur de cette idéologie. Également, comme signalé dans le texte, en faisant de la présence de l'anglais l'une des causes du problème, c'est l'idéologie du monolinguisme qui est servie.

17. Les traditions d'alphabétisation pensées et conduites par l'élite dirigeante sont étroitement liées au contrôle social dans la plupart des sociétés. Pour le passé, on peut mentionner le cas de la mise en place de la scolarisation obligatoire en France où l'apprentissage de la lecture a servi de pierre angulaire à une volonté politique d'unification linguistique (voir Boutet et Fiala, 1978). On peut citer aussi les pratiques coloniales où l'alphabétisation a soutenu les politiques d'acculturation et où le niveau de littératie des peuples colonisés a été instrumentalisé dans un but d'exclusion civique voire civile et de privation du contrôle politique, économique voire parental (voir Woolard et Schieffelin, 1994). 
Quelle (autre) ou quelles (autres) idéologies servent ces discours dans la situation particulière envisagée, et plus largement dans les sociétés occidentales au XXIe siècle ? II n'est pas aisé de répondre définitivement à cette question. En l'état de ma recherche et de ma réflexion, je propose d'y voir à la fois une idéologie (que je nommerai faute de mieux) de la compétence linguistique qui non seulement présuppose que nous disposons des outils pour évaluer ces compétences, que nous pouvons les évaluer sans a priori et que les besoins en la matière seraient déterminés de façon neutre et objective. Cette même idéologie autorise la discrimination sur base linguistique. Par ailleurs, nous avons affaire à une idéologie (que je désignerai toujours faute de mieux) de la bonne langue et des bonnes pratiques linguistiques ${ }^{18}$ qui manifeste une domination culturelle en ce sens que l'alphabétisation dont il est le plus souvent question dans mon corpus renvoie en fait à la maitrise d'une certaine culture lettrée (je rappelle l'absence d'illettré et d'illettrisme comme termes mais non comme référents dans mon corpus). Cette idéologie suppose aussi un niveau optimum ou du moins seuil de compétence en deçà duquel l'individu ne peut être reconnu fonctionnel. Ceci étant si l'idéologie, ou les idéologies, que sert les discours que je viens de présenter est ardue à définir.C'est aussi parce que, pour la ou les déterminer scrupuleusement, il faut tenir compte plus minutieusement que dans la présente contribution, de la figurevoire de la personnalité des discoureurs, de leur occupation, de leur engagement, du moment lors duquel ils prennent la parole, etc. Tous ces paramètres sont encore à creuser dans une exploitation plus en finesse du corpus envisagé. II reste surtout à entreprendre une sociographie auprès des acteurs et actrices de l'alphabétisation en français au Nouveau-Brunswick.

18. On pourrait envisager que cette vision d'un locuteur-scripteur idéal renvoie à l'un des ingrédients de l'idéologie du monolinguisme or, comme le note Ellis (2006), il s'agit d'une idéologie que l'on discute peu notamment en termes de compétences individuelles. En revanche, l'idéologie du bilinguisme qui implique, dans son versant individuel (Heller, 2000), une compétence optimale dans les deux langues comporte cette dimension d'un locuteur scripteur idéal type dont on a montré le caractère illusoire et idéologiquement chargé. 


\section{Références}

\section{Sources primaires}

Brock, Anthony (1971), "Où en est l'alphabétisation dans le monde ? », L'Évangéline, 30 septembre 1971, p. 4.

Dauphin, Damien (2014), « Les élèves encouragés à découvrir la lecture », L’Acadie Nouvelle, 28 janvier 2014, p. 7.

Dupuis, Justin (2008), «L'alphabétisation, un élément important du mieux-être », L’Acadie Nouvelle, 8 septembre 2008, p. 8.

Dyer, Gwynne (2010), « Les objectifs du millénaire », L’Acadie Nouvelle, 22 septembre 2010, p. 19.

Hubert, Jean (1962), « La lutte à l'analphabétisme », L'Évangéline, 16 mai 1962, p. 4.

Lang, Mathieu (2016), "L'alphabétisation doit être au centre de notre projet de société », L’Acadie Nouvelle, 22 septembre 2016, p. 10.

Lyons, Beth (2016), «Services de garde : le soutien essentiel du Gouvernement », L'Acadie Nouvelle, 21 octobre 2016, p. 14.

Marks, Raissa (2014), «En finir avec la pensée conventionnelle », L'Acadie Nouvelle, 10 septembre 2014, p. 14.

Martin, André (2000), «Robert Melanson, le libraire nomade », L’Acadie Nouvelle, 12 mai 2000, p. 6.

Mousseau, Sylvie [SM] (2009), « Brunch littéraire émouvant », L’Acadie Nouvelle, 27 avril 2009, p. 16.

Mousseau, Sylvie (2014), « Le projet Lire et faire lire Acadie célèbre ses cinq ans », L'Acadie Nouvelle, 25 octobre 2014, p. 35.

Roy-Comeau, Mathieu (2015), « Nouveau leadership à l'alphabétisation », L'Acadie Nouvelle, 11 mars 2015, p. 6.

s.a. (1977), « Savent-ils encore lire et écrire? », L'Évangéline, 27 juillet 1977, p. 6.

s.a. (1977), « Un diplômé analphabète », L'Évangéline, 23 septembre 1977, p. 11.

s.a. (1988), «Une association provinciale d'alphabétisation voit le jour », L’Acadie Nouvelle, 3 août 1988, p. 6.

s.a. (2002), « Claudette Audet remporte le prix de la Francophonie en alphabétisation », L’Acadie Nouvelle, 21 mars 2002, p. 5.

s.a. (2004), « Un citoyen de Le Goulet lauréat d'un prix en alphabétisation », L'Acadie Nouvelle, 26 mai 2004, p. 5. 
s.a. (2006), « Dimanche dans le Grand Moncton : courir pour la littératie », L'Acadie Nouvelle, 3 novembre 2006, p. 45.

s.a. (2009), «Trois coopératives du N.-B. mises en évidence», L’Acadie Nouvelle, 15 octobre 2009, p. 15.

s.a. (2009), «Prix Dr Marilyn Trenholme Counssell », L’Acadie Nouvelle, 31 octobre 2009, p. 31.

s.a. (2011), « Clinique pour clients sans médecin de famille », L'Acadie Nouvelle, 25 janvier 2011, p. 23.

s.a. (2011), « La Fédération d’alphabétisation comble un besoin important dans notre société », L'Acadie Nouvelle, 8 septembre 2011, p. 22.

s.a. (2015), « Mission accomplie pour Genéva Léger », L’Acadie Nouvelle, 8 septembre 2015 p. 15.

Shippley, Cyrille (2004), « Un mal social », L’Acadie Nouvelle, 18 décembre 2004, p. 12.

SL (2015), «Deux Néo-Brunswickoises lauréates des Prix de l'Alphabétisation », L’Acadie Nouvelle, 9 septembre 2015, p. 13.

Snow, Claude (Comité des 12) (2015), « Adapter les programmes pour analphabètes à leurs besoins », L'Acadie Nouvelle, 7 août 2015, p. 14.

\section{Sources citées}

Achard, Pierre (1986), « Analyse du discours et sociologie du langage », Langage et société, n 37, p. 5-60.

Arrighi, Laurence et Annette Boudreau (2013), «La construction discursive de l'identité francophone en Acadie ou "comment être francophone à partir des marges" ? ", Minorités linguistiques et société, n³ (La francophonie canadienne en mouvement: continuité ou rupture?, sous la dir. de Pierre Foucher), p. 80-92.

Arrighi, Laurence et Annette Boudreau (2016), « La construction discursive du locuteur francophone : mise en perspective. L'exemple acadien », dans Laurence Arrighi et Annette Boudreau (dir.) Langue et légitimation: la construction discursive du locuteur francophone, Québec, Presses de l’Université Laval, p. 1-18.

Arrighi, Laurence et Émilie Urbain (2016/2017), "Wake up Québec” : du recours aux communautés francophones minoritaires dans le discours visant l'émancipation nationale du Québec », Francophonies d'Amérique, nos 42/43 (Les idéologies linguistiques dans la presse francophone nord-américaine : approches critiques, sous la dir. de Wim Remysen), p. 107-126.

Arrighi, Laurence et Émilie Urbain (2019), «Les “mauvais exemples” de la francophonie nord-américaine : intérêt des acteurs, construction des images, instrumentalisation des groupes », dans Sandrine Hallion et Nicole Rosen (dir.), Les français d'ici : des discours et des usages, Québec, Presses de l'Université Laval, p. 11-32.

Arrighi, Laurence et Isabelle Violette (2013), « De la préservation linguistique et nationale : la qualité de la langue de la jeunesse acadienne, un débat linguistique idéologique », Revue de l'Univer- 
sité de Moncton, vol. 44, nº 2 (Usages, discours et idéologies linguistiques dans la francophonie canadienne : perspectives sociolinguistiques, sous la dir. de Catherine Léger, Matthieu LeBlanc, Laurence Arrighi et Isabelle Violette.), p. 67-101.

Barton, David, Mary Hamilton et Roz Ivanić (dir.) (2000), Situated literacies : reading and writing in context, Londres/New York, Routledge.

Beauchamp, Michel et Thierry Watine (dir.) (2006), Médias et milieux francophones, Québec, Presses de l'Université Laval.

Beaulieu, Gérard (1993), «Les médias en Acadie », dans Jean Daigle (dir.), L'Acadie des maritimes: études thématiques des débuts à nos jours, Moncton, Chaire d'études acadiennes, Université de Moncton, p. 505-542.

Beaulieu, Gérard (dir.) (1997), L'Évangéline 1887-1982 : entre l'élite et le peuple, Moncton, Éditions d'Acadie/Chaire d'études acadiennes.

Bérubé, Julie (2010), Discours et idéologies linguistiques en Acadie du Nouveau-Brunswick: l'exemple de la presse et du milieu scolaire, thèse de doctorat, Université de Moncton.

Boudreau, Annette (2009), «La construction des représentations linguistiques : le cas de l'Acadie », Revue canadienne de linguistique, vol. 54, n³, p. 439-459.

Boudreau, Annette (2011), «La nomination du français en Acadie : parcours et enjeux », dans James de Finney, Hélène Destrempes et Jean Morency (dir.), L'Acadie des origines : mythes et figurations d'un parcours littéraire et historique, Sudbury, Éditions Prise de parole, p. 71-94.

Boudreau, Annette (2012), « Discours, nomination des langues et idéologies linguistiques », dans Davy Bigot, Michael Friesner et Mireille Tremblay (dir.), Les français d'ici : description, représentation et théorisation, Sainte-Foy, Presses de l'Université Laval, p. 89-109.

Boudreau, Annette (2014), « Des voix qui se répondent : analyse discursive et historique des idéologies linguistiques en Acadie : l'exemple de Moncton. », Minorités linguistiques et société, nº 4 (Le français en milieu minoritaire : défis et enjeux. La situation du français en Acadie du NouveauBrunswick, sous la dir. d'Annette Boudreau), p. 175-199.

Boudreau, Annette (2016), Àl'ombre de la langue légitime: l'Acadie dans la francophonie, Paris, Garnier.

Boudreau, Annette et Émilie Urbain (2013), « La presse comme tribune d'un discours d’autorité sur la langue : représentations et idéologies linguistiques dans la presse acadienne, de la fondation du Moniteur Acadien aux Conventions nationales », Francophonies d'Amérique, n 35 (Les journaux des communautés francophones minoritaires en Amérique du Nord, sous la dir. de Dominique Laporte), p. 23-46.

Boutet Josiane et Pierre Fiala (1978), «À propos de ... et il fallut apprendre à écrire à tous les petits français (histoire de la grammaire scolaire) d’A. Chervel », Langage \& société, n³, p. 93-102.

Boutet, Josiane (2001), « La part langagière du travail : bilan et évolution », Langage \& société, n 98, p. 17-42. 
Boutet, Josiane (2007), " La part langagière du travail : théories et analyses », Annuaire de l'EHESS, disponible sur http://journals.openedition.org/annuaire-ehess/18452. [Page consultée le 26 avril 2019.]

Budach, Gabriele (2003), «L'alphabétisation d'adultes en Ontario : la valeur du français entre identité culturelle et ressource économique », dans Monica Heller et Normand Labrie (dir.), Discours et identités : la francité canadienne entre modernité et mondialisation, Louvain-la-Neuve, EME éditions, p. 333-363.

Cameron, Deborah (2007), «Language Endangerment and verbal Hygiene: history, morality and politics », dans Alexandre Duchêne et Monica Heller (dir.), Discourses of endangerment: ideology and interest in the defense of languages, Londres, Continuum, p. 268-285.

Canut, Cécile et Alexandre Duchêne (2011), «Introduction. Instrumentalisations politiques et économiques des langues : le plurilinguisme en question », Langage \& société, nº 136, p. 5-12.

Clerc, Stéphanie et Mireille Rispail (2008), « Former aux langues et aux cultures des autres, une gageure? », Ela : études de linguistique appliquée, vol. 151, n³, p. 277-292.

Collins, James et Richard Blot (2003), Literacy and literacies : text, power and identity, Cambridge, Cambridge University Press.

Corriveau, Claire (2006), «Informer ou défendre la cause : le dilemme de la presse franco-manitobaine », dans Michel Beauchamp et Thierry Watine (dir.), Médias et milieux francophones, Québec, Presses de l'Université Laval, p. 47-64.

Eddie, Marie Hélène (2011), Médias en milieu minoritaires : les attentes et perceptions des publics de l'Acadie du Nouveau-Brunswick envers leur quotidien L'Acadie Nouvelle, thèse de maitrise, Ottawa, Université d'Ottawa.

Eddie, Marie Hélène (2015), «La fermeture du quotidien L'Évangéline en 1982 et la place occupée par le journal dans la mémoire collective acadienne aujourd'hui : entre fatalité, résistance et optimisme », dans Michelle Landry, Martin Pâquet et Anne Gilbert (dir.), Mémoire et mobilisations, Québec, Presses de l'Université Laval, p. 103-124.

Ellis, Elizabeth (2006), «Monolingualism : the unmarked case », Estudios de Sociolingüística, vol. 2, n० 7, p. 173-196.

Espérandieu, Véronique et Jean Vogler (2000), L'illettrisme, Paris, Flammarion.

Fairclough, Norman (1995), Critical Discourse Analysis, Londres, Longman.

Flubacher, Mi-Cha et Alfonso Del Percio (2017), Language, education and neoliberalism : critical studies in sociolinguistics, Londres, Multilingual Matters.

Foucault, Michel (1971), L'ordre du discours, Paris, Gallimard.

Gusfield, Joseph (1981), The culture of public problems : drinking-driving and the symbolic order, Chicago, University of Chicago Press. 
Hambye, Philippe et Anne-Sophie Romainville (2013), "L'appropriation du français : cause ou conséquence d'une intégration réussie », communication présentée à la journée de réflexion L'appropriation du français par les pratiques culturelles, organisée par le Ministère de la Culture, de l'Audiovisuel, de la Santé et de l'Égalité des chances, Molenbeek-Saint-Jean, 20 mars.

Haroche, Claudine, Paul Henry et Michel Pêcheux (1971), "La sémantique et la coupure saussurienne : langue, langage, discours », Langages, n²4, p. 93-106.

Heller, Monica (2000), "Bilingualism and identity in the post-modern world », Estudios de Sociolingüística, vol. 2, nº 1, p. 9-24.

Heller, Monica (2007), "Langue", "communauté" et "identité" : le discours expert et la question du français au Canada », Anthropologie et sociétés, vol. 1, n³1, p. 39-54.

Johnson, Sally et Astrid Esslin (2007), Language in the media : representations, identities, ideologies, Londres/New York, Bloomsbury.

Johnson, Sally et Tomasso Milani (dir.) (2010), Language ideologies and media discourse : texts, practices, politics, Londres, Continuum.

Klinkenberg, Jean-Marie (2015), La langue dans la cité : vivre et penser l'équité culturelle, Bruxelles, Les impressions nouvelles.

Lahire, Bernard (1999), L'invention de l'«illettrisme », Paris, La découverte.

Lahire, Bernard (1992), «Discours sur l'illettrisme et cultures écrites : remarques sociologiques sur un problème social » dans Jean-Marie Besse, Marie-Madeleine De Gaulmyn, Dominique Ginet et Bernard Lahire (dir.), L'«illettrisme» en questions, Lyon, Presses universitaires de Lyon, p. 60-75.

LeBlanc, Mélanie et Annette Boudreau (2016), "Discourses, legitimization, and the construction of Acadianité », Signs and Society, vol. 1, n 4, p. 80-108.

McLaughlin, Mireille (2014), " "I say they don't have education" : industrialisation, mobilité sociale et militantisme linguistique au Canada, 1914-1952 », Langage \& société, n 149, p. 127-142.

Neumann-Holzschuh, Ingrid et Julia Mitko (2018), Grammaire comparée des français d'Acadie et de Louisiane avec un aperçu sur Terre-Neuve, Berlin/Boston, De Gruyter.

OCDE [Organisation de coopération et des développement économiques] (2013), Perspectives de l'OCDE sur les compétences 2013 : premiers résultats de l'évaluation des compétences des adultes, Éditions OCDE, disponible en ligne http://dx.doi.org/10.1787/9789264204096-fr.

Savoie, Lise (2011), Comprendre les trajectoires scolaires de femmes francophones du NouveauBrunswick ayant participé à un processus d'alphabétisation : une perspective féministe, thèse de doctorat, Moncton, Université de Moncton.

Street, Brian (1984), Literacy in theory and practice, Cambridge, Cambridge University Press.

Street, Brian (1995) Social Literacies : critical approaches to literacy development, ethnography and education, Londres, Longman. 
Street, Brian (1996), « Preface », dans Mastin Prinsloo et Mignonne Breir (dir.), The social uses of literacy: theory and practice in contemporary South Africa, Amsterdam, Benjamins, p. 1-10.

Street, Brian (2005), "At last : recent applications of new literacy studies in educational contexts », Research in the teaching of English, vol. 39, n 4, p. 417-423.

Street, Brian (2006), «Autonomous and ideological models of literacy : approaches from new literacy studies », Media Anthropology Network, disponible sur http://www.media-anthropology.net/ street_newliteracy.pdf. [Page consultée le 26 avril 2019.]

UNESCO (2006), «Les défis de l'alphabétisme : un état des lieux », dans Rapport mondial du suivi sur l'éducation pour tous, Paris, Éditions UNESCO, p. 170-199.

Watine, Thierry (1992), «Pratiques journalistiques en milieu acadien : une tradition militante... », dans Fernand Harvey (dir.), Médias francophones hors Québec et identité : analyses, essais et témoignages, Québec, Institut québécois de recherche sur la culture, p. 75-82.

Watine, Thierry (1993), Pratiques journalistiques en milieu minoritaire : la sélection et la mise en valeur des nouvelles en Acadie, thèse de doctorat, Université de Lille III.

Woolard, Kathryn A.et Bambi B. Schieffelin (1994), "Language ideology », Annual Review of Anthropology, vol. 1, n² 23 , p. 55-82. 


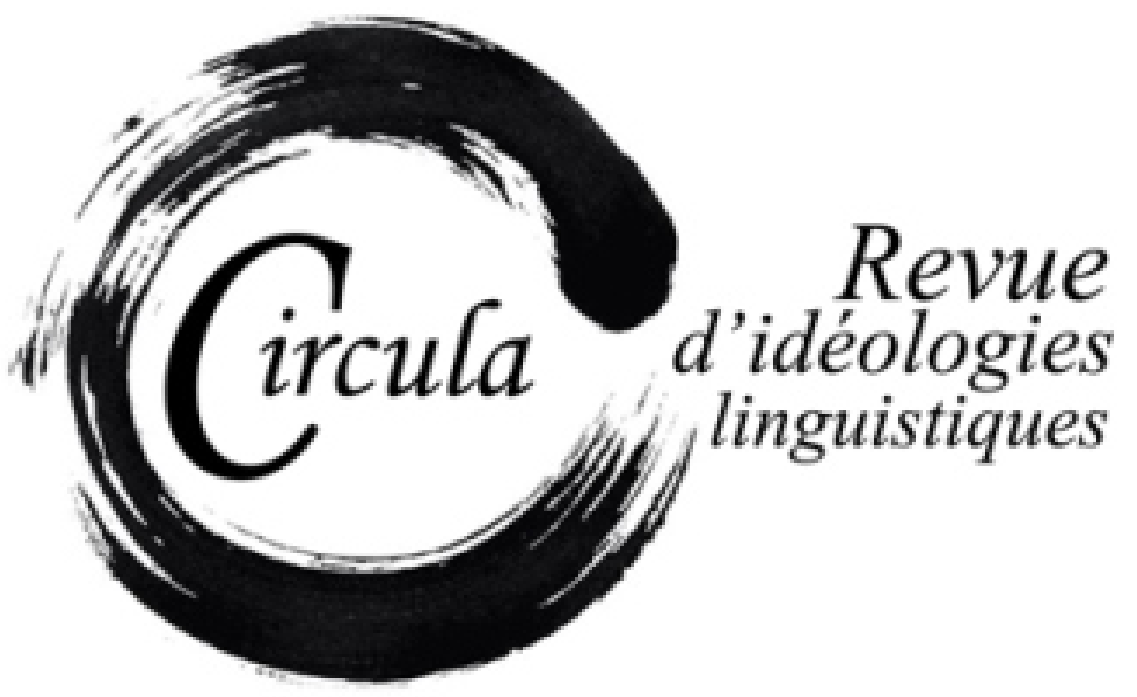

Titre: Narvaja de Arnoux, Elvira y Bein, Roberto (edS.) (2019). Ideologías lingǘ́sticas. Legislación, universidad, medios, Buenos Aires, EditORIAL BIBLOS, COL. CienCIAS DEL LENGUJe, 246 P. [ISBN: 978-987691-719-3]

Auteure: Victoria Scotto, Universidad Nacional de La Plata/CONICET

Revue: CirCula, NUMÉRO 10

PAGES: $91-97$

ISSN: 2369-6761

URI: HTTP://HDL.HANDLE.NET/11143/16775 


\section{Narvaja de Arnoux, Elvira y Bein, Roberto (eds.) (2019). Ideologías lingüísticas. Legislación, universidad, medios, Buenos Aires, Editorial Biblos, col. Ciencias del Lenguje, 246 p. [ISBN: 978-987-691-719-3]}

Victoria Scotto, Universidad Nacional de La Plata/CONICET scottovictoria @gmail.com

El volumen que aquí se reseña está compuesto por una presentación a cargo de los editores y siete artículos centrados en el problema de las ideologías lingüísticas en corpus vinculados a las políticas públicas de gobiernos peronistas en Argentina. A partir de múltiples análisis que se componen de diversos corpus, se estudian en el libro algunas de las causas o consecuencias de la toma de posición lingüística en el estudio de medios de comunicación, legislaciones y discursos políticos y académicos que conformaron las políticas lingüísticas durante los peronismos. Publicado en 2019, este libro representa un aporte para entender en múltiples dimensiones una realidad política y lingüística en constante transformación; tanto las referencias a los "70 años de peronismo" construidas durante los últimos años de administración de Mauricio Macri como las intervenciones sobre qué es y cómo "debe ser" la lengua en Argentina por parte del poder político en el Congreso de la Lengua realizado en la ciudad argentina de Córdoba en marzo de 2019 resultan un contexto sumamente propicio para la publicación de un volumen construido por expertos que apuntalan problemas actuales y necesarios.

El volumen es producto del extendido trabajo realizado a partir de proyectos de investigación de financiación diversa radicados en la UBA y centrados en las intervenciones institucionales, discursos y artículos de prensa sobre la lengua, instrumentos lingüísticos y problemas sobre el derecho a la palabra durante los peronismos en Argentina. El financiamiento de los proyectos posibilitó la realización de un libro que expresa, "en su variedad temática, una muestra representativa de cómo abrarcar y analizar diversas maneras en que la política opera sobre el lenguaje y de aquellas instancias en que el propio lenguaje asume un carácter político, aun cuando no hable directamente de política." (Narvaja de Arnoux y Bein, 2019: 16). El enfoque glotopolítico del volumen se advierte en el modo de abordar el comportamiento lingüístico de una población, entendiendo que este responde tanto a una tradición heredada como a diferencias sociales, intervenciones de la institución escolar, de los medios de comunicación e incluso de esfuerzos organizados para la defensa de las lenguas originarias; y el estudio de estos factores, además, no escapa a las tensiones impuestas por la inte- 
racción dialéctica entre el comportamiento lingüístico espontáneo de los hablantes y el control de las lenguas por parte de autoridades gubernativas. El reconocimiento de estas tensiones organiza un volumen que, a partir de múltiples y diversos recortes de corpus, aporta un panorama de la relación entre proyectos políticos e ideologías lingüísticas en Argentina.

El primer capítulo del libro, "Intervenciones institucionales y discursos oficiales sobre la lengua en la Argentina kirchnerista 2003-2015): medios de comunicación, ciencia, educación superior y turismo idiomático", está a cargo de Daniela Lauría. En él, la autora analiza diversos aspectos en los cuales considera que el kirchnerismo formuló, promovió o implementó discursos y políticas sobre la lengua que "estuvieron atravesados tanto por gestos de regulación (y de resistencia) soberana como también por demandas y requerimientos de los fenómenos de transnacionalización e integración regional, propios del escenario global contemporáneo" (Lauría, 2019: 17). El corpus sobre el que Lauría realiza esta investigación se compone de un conjunto de legislaciones (leyes, decretos y resoluciones) y por documentos oficiales heterogéneos (disposiciones, recomendaciones y textos de presentación de programas) generados por organismos públicos. Lauría desarrolla su artículo en principio epxoniendo algunos lineamientos generales del kirchnerismo, en términos políticos, económicos y de integración regional. Luego, introduce el problema de la política lingüística en el nuevo orden mundial propuesto por la globalización, para adentrarse directamente en las representaciones de la lengua en el discurso oficial del kirchnerismo. A partir de allí, Lauría estudia estas representaciones en el perfil del Museo del Libro y de la Lengua, en los programas científicos estatales, en el discurso sobre y de los medios audiovisuales de gestión estatal, y en la caracterización del "turismo idiomático" como actividad alentada desde el Estado. El análisis de Lauría concluye en que, entre 2003 y 2015, el Estado manifestó un notorio interés por intervenir en el espacio público del lenguaje, evidenciado en las diversas posiciones en torno a la proyección de determinada imagen de la lengua.

El segundo artículo se titula "El español neutro: análisis de la normativa argentina sobre doblajes en medios audiovisuales" y su autora es Natalia Inés Bengochea. En este artículo, con un enfoque similar al anterior, se trabaja sobre la Ley de Doblaje: el recorrido de esta legislación establecido por la autora conduce a un análisis tanto de los momentos políticos en los que se redactaron legislaciones con respecto a los doblajes en medios audiovisuales, como de las categorías utilizadas para establecer la "lengua oficial" en la que estos doblajes deberían realizarse. El artículo, entonces, está organizado en función de dos ejes: el primero es el estudio de la ley 23.316 de 1986 reglamentada en 1988 por el decreto 1091, y modificada según el espíritu de la Ley de Servicios de Comunicación Audiovisual por el decreto 933 de 2013; el segundo eje debate en torno a la política lingüística asociada a esta ley y sus respectivos decretos de implementación, sobre todo a partir del problema de la lengua oficial y de la categoría que se utiliza para nombrarla, el "español neutro". Más allá del análisis de la legislación, el artículo resulta un aporte interesante para estudiar la inserción de una categoría atravesada por la ideología lingüística como la de "español neutro": ¿cómo se determina la neutralidad? ¿Qué esfuerzos por establecerla se analiza en una lengua marcada por la diversidad 
de una gran extensión como es la del territorio argentino? ¿Cómo se vincula una legislación que establece la oficialidad de una lengua "neutra" con el reconocimiento de las lenguas originarias que habitan el territorio? ¿Cuál es la relación que guarda este "español neutro" argentino con los doblajes mexicanos que buscan reducir la ideología de la autenticidad para reforzar la de la neutralidad? Estas son algunas de las preguntas exploradas en este artículo por Bengochea.

El capítulo de Diego Bentivegna, el tercero del libro, se denomina "Más allá del hispanismo: lingüistas y filólogos extranjeros en la Argentina peronista (1946-1955)". Aquí se analizan los casos de filólogos y lingüistas específicos de procedencia no hispánica, que emigraron a la Argentina provenientes de países europeos derrotados en la Segunda Guerra Mundial. De sus intervenciones en la academia argentina se desprenden, según Bentivegna, "un conjunto de gestos que, de manera amplia, podemos pensar como glotopolíticos” (Bentivegna, 2019: 85). Este artículo expone algunos de los debates en torno a las posiciones hispanistas o de soberanía idiomática que tensaban la academia argentina durante el peronismo, los cuales "dan cuenta de un panorama cultural complejo, en el que la persistencia de las diferentes lenguas de inmigración se perciben como parte de un entramado lingüístico no uniforme" (87) en el que las disputas políticas acompañan ideologías lingüísticas que ordenan este campo. Bentivegna se ocupa de estos filólogos precisamente porque considera que las que elaboran "son intervenciones que sostienen la pertenencia de la cultura argentina a una matriz más amplia de la que ofrecían los diferentes hispanismos que operaban en la Argentina" (ibid.). Bentivegna aquí analiza el rol académico de Fritz Krüger y Alfred Dornheim y la influencia de las categorías de análisis de la escuela de las Palabras y las Cosas en los debates entre lengua y pueblo desde la Universidad Nacional de Cuyo; indaga en la importancia de la filiación con el archivo románico a partir de las figuras de Demetrio Gazdaru y Benvenuto Terracini; finalmente, cierra el artículo con el estudio de las intervenciones de José Imbelloni y Gerhard Moldenhauer, centrados en la relación entre nación y lengua, entendiendo que este binomio se ve atravesado por la cuestión de las lenguas originarias, tanto en el territorio argentino como en los limítrofes. Para finalizar, Bentivegna aclara que las intervenciones analizadas "no enfatizan la especificidad latinoamericana de los estudios lingüísticos en Argentina” (Bentivegna, 2019: 122), sino que los piensan en una serie académica, en permanente interrelación con la política peronista del esos años.

En cuarto lugar aparece un análisis de "La revista Logos y la producción académica de la Facultad de Filosofía y Letras (1941-1954): los paratextos normativos”, a cargo de María Eugenia Gattari. Como el artículo anterior, el recorte temporal corresponde a los primeros peronismos, aunque esta vez involucra también un período previo, entre 1941 y 1946, en el cual Gattari recupera los primeros años de la revista y un discurso programático inicial que marcó los años siguientes de Logos. A partir de este primer período, al cual lo considera en armonía con la perspectiva hispanizante de Amado Alonso y el Instituto de Filología de la Universidad de Buenos Aires, se dispara la producción de un volumen doble de la revista en 1951, que Gattari considera el segundo período, una vez que la intervención estatal iniciada en 1946 finalizó tres años después. Sin embargo, tensiones con respecto a cómo se concebía el análisis del espacio lingüístico-filosófico de vinculación entre la lengua y los 
estudios universitarios rápidamente decantan en el tercer y último período de la revista, entre 1952 y 1954, donde se inicia una reestructuración a partir del ingreso de una respuesta orgánica al Segundo Plan Quinquenal, que transforma la disposición de secciones y el contenido. El valor agregado del artículo de Gattari es que no sólo organiza un recorrido que reseña la situación política entre las fechas señaladas de la Facultad de Filosofía y Letras, una caracterización de Logos y un análisis período por período, sino que radica un análisis glotopolítico en cada apartado a partir del estudio de los elementos paratextuales de la revista (organización de secciones, disposición de los apartados, distribución del contenido, entre otros). Específicamente, Gattari estudia las "Notas liminares" que, firmadas por la dirección de la revista, buscaban explicitar las intervenciones que, a juicio de la autora, "pueden ser interpretadas como intervenciones de carácter glotopolítico porque están destinadas a homogeneizar el espacio lingüístico y a disciplinar las prácticas discursivas dentro de la universidad" (Gattari, 2019: 146). Se incluyen en forma de anexo, al final del artículo, las "Notas" de 1941, 1952 y 1954 como un claro aporte para el estudio de la relación entre la Facultad de Filsofía y Letras y las políticas lingüísticas preperonistas y peronistas y al análisis de las ideologías lingüísticas del período.

El quinto capítulo está a cargo de una de los editores del volumen, Elvira Narvaja de Arnoux, y se titula "En torno a las ideologías lingüísticas: un modelo de comunicación política en editoriales de prensa (las notas de Juan Domingo Perón en Democracia, 1951-1952)". Narvaja de Arnoux abre su artículo con un análisis sobre el estudio de las ideologías lingüísticas y cómo abordarlo: mientras que es posible partir de apreciaciones explícitas (o fácilmente reconstruibles) sobre objetos lingüísticos, también puede realizarse en torno a relevamientos de usos y prácticas, de regularidades de las que se infieren representaciones sociolingüísticas integradas en sistemas sociológicos. Ubicándose dentro del segundo modo de análisis, el trabajo de Narvaja de Arnoux considera "las representaciones respecto de la comunicación política mediada por la prensa en una serie de notas editoriales que aparecieron en la primera plana del diario oficial argentino Democracia, firmadas con el pseudónimo de Descartes" (Narvaja de Arnoux 2019: 155), nombre tras el cual se escondía en este diario el presidente del período, Juan Domingo Perón. Se estudian aquí tres notas que se publicaron en 1951, 1952 y 1953 bajo el título "Política y estrategia". Las notas abarcan temas de política internacional y su incidencia en Argentina, pero el análisis glotopolítico que realiza sobre ellas Narvaja de Arnoux permite hacer una lectura de la construcción del armado ideológico peronista a partir de la construcción de sintagmas, deíxis textuales, el registro discursivo y la construcción de universos de sentido en torno a ciertos conceptos. El foco del artículo está en la idea de que ciertas regularidades discursivas en esta serie de notas editoriales en las que no se tematiza el lenguaje ponen de relieve no obstante "una política del lenguaje que propone un modelo de comunicación política en el que los requerimientos de un género propio de la prensa gráfica que se adecuan a la lucha ideológica y a la formación de militantes y cuadros" (Narvaja de Arnoux, 2019: 186), en consonancia con el poryecto peronista de modelar las subjetividades necesarias a partir de instalar un discurso en torno a la "crítica" propuesto para la homogeneidad del campo nacional. 
El sexto artículo, "El discurso de los derechos humanos en la sociedad argentina tras la última dictadura", a cargo de Roberto Bein, representa un cambio en el recorte temporal que marcaron en los artículos anteriores los otros autores. En este caso, Bein se dedica a analizar el discurso en torno al derecho en tres períodos democráticos que siguieron a 1983: 1983-1989 (recuperación democrática), 1989-2003 (neoliberalismo y crisis político-económica) y 2003-2015 (kirchnerismo). Para esto, Bein parte de la hipótesis de que "derechos humanos", con posterioridad a la última dictadura, funcionó como un ideologema, una condensación de sentidos en torno, sobre todo, a aquellos derechos que habían sido violados durante la dictadura, construyendo una reivindicación de la libertad de los derechos políticos y sindicales, la recuperación de la identidad robada a hijos de activistas asesinados, la averiguación del paradero de personas desaparecidas y el rechazo a las torturas y fusilamientos. En este sentido, Bein desarrolla un análisis de la construcción discursiva de este ideologema en la historia reciente, para luego adentrarse en un recorrido histórico de largo plazo en torno al discurso de los derechos humanos, desde sus primeras apariciones en el siglo XVI con la Escuela de Salamanca, pasando por el derecho norteamericano y La cuestión judía de Karl Marx. Pero para regresar al tema que origina el artículo, Bein recupera la forma que los discursos sobre los derechos humanos tomaron y toman en la Argentina actual: recupera entonces escenas de noviembre de 2015 y las vinculaciones político-partidarias de los discursos de los derechos humanos y aquellos sectores que buscan combatirlos desde el poder económico, político o mediático. A partir de estas escenas propone analizar cómo, en qué momentos y a partir de qué procesos políticos el discurso de los derechos humanos cobró fuerza y legitimidad en la sociedad argentina en los tres períodos mencionados anterioremente.

El último capítulo del volumen recupera el momento histórico con el que Bein cierra su artículo, y se ocupa de la última etapa del kirchnerismo. El trabajo de Mariana di Stefano y María Cecilia Pereira, denominado "De buitres, holdouts y acreedores: selección léxica e ideología lingüística en el diario La Nación en el tratamiento del conflicto por el pago de la deuda externa argentina", estudia algunas de las consecuencias del reparto ideológico-político de la construcción discursiva en torno a problemas políticos y las tensiones construidas entre cierta prensa y el Estado. Puntualmente se encargan del análisis de las ideologías lingüísticas en el uso de dos "unidades léxicas", "holdouts" y "fondos buitres", en los artículos del diario La Nación entre el 15 de julio y el 15 de agosto de 2014. Las autoras hacen en principio una introducción al problema político-económico desencadenado por el juicio que ciertos tenedores de títulos de deuda pública hicieron al Estado Argentino para cobrar la totalidad del valor de los bonos que habían adquirido antes de la reestructuración de la deuda de 2003. Di Stéfano y Pereira señalan en principio la transformación en función de la situación política de los significados asociados a los holdouts y "fondos buitre" y cómo estos sentidos, de 2001 a 2015, pasaron de representar dos referentes distintos a referenciar a un tipo de tenedor de deuda único, que, en función del posicionamiento ideológico detentado por quien enuncia, se lo nombra con una u otra unidad léxica. En este sentido, las autoras analizan la distancia ideológica que consituye el uso de uno u otro término para construir posicionamienos periodísicos tanto en artículos como en algunos "diccionarios" o "glosarios" ofrecidos por La Nación para determinar lecturas de la eco- 
nomía kirchnerista y del litigio con los mencionados fondos. Las autoras muestran eficazmente en este artículo cómo la intervención glotopolítica realizada a nivel léxico por La Nación representó una operación ideológica que implicó un posicionamiento político-económico por parte del diario con respecto a las decisiones tomadas por el gobierno de Cristina Fernández.

El volumen que aquí se reseña constituye un aporte sumamente interesante a la construcción discursiva de ideologías políticas en la historia reciente de Argentina. El enfoque que los autores de los artículos imprimen a sus trabajos es el glotopolítico, que asume el carácer intrínsecamente político del lenguaje, y que entiende que "el conjunto de representaciones lingüísticas, al que le damos el nombre de ideologías lingüísticas para acentuar su condición de sociohistóricamente situadas y su vínculo con los sistemas ideológicos más amplios" (Narvaja de Arnoux, 2019: 156) orienta las prácticas discursivas y se manifiesta en valorizaciones que redundan en intervenciones políticas. Estas intervenciones pueden racionalizar, justificar o naturalizar, como dice Narvaja de Arnoux, la conexión entre el lenguaje y cierto orden social: con el objeto de desnaturalizar estas prácticas y estudiarlas, este volumen se abre frente a sus lectores como una oportunidad de pensar de una manera diferente el rol del lenguaje en la sociedad. 